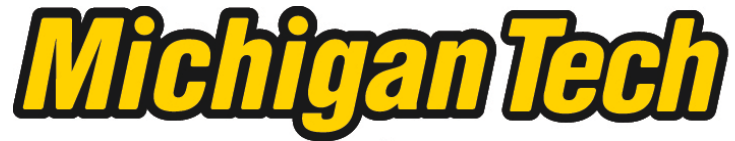 \\ Michigan Technological University Create the Future Digital Commons @ Michigan Tech
}

Dissertations, Master's Theses and Master's Reports - Open

Dissertations, Master's Theses and Master's

Reports

2012

\section{Microwave-assisted wet chemical (MAWC) synthesis of lithium iron phosphate}

Shangzhao Shi

Michigan Technological University

Follow this and additional works at: https://digitalcommons.mtu.edu/etds

Part of the Engineering Science and Materials Commons

Copyright 2012 Shangzhao Shi

\section{Recommended Citation}

Shi, Shangzhao, "Microwave-assisted wet chemical (MAWC) synthesis of lithium iron phosphate", Dissertation, Michigan Technological University, 2012.

https://doi.org/10.37099/mtu.dc.etds/20

Follow this and additional works at: https://digitalcommons.mtu.edu/etds

Part of the Engineering Science and Materials Commons 


\title{
MICROWAVE-ASSISTED WET CHEMICAL (MAWC) SYNTHESIS OF LITHIUM IRON PHOSPHATE
}

\author{
By \\ Shangzhao Shi \\ A DISSERTATION \\ Submitted in partial fulfillment of the requirements for the degree of \\ DOCTOR OF PHILOSOPHY
}

In Materials Science and Engineering

MICHIGAN TECHNOLOGICAL UNIVERSITY

2012

(C) 2012 Shangzhao Shi 
This dissertation has been approved in partial fulfillment of the requirements for the Degree of DOCTOR OF PHILOSOPHY in Materials Science and Engineering.

Department of Materials Science and Engineering

Dissertation Advisor: Jiann-Yang Hwang

Committee Member: Steven A. Hackney

Committee Member: Xiaodi Huang

Committee Member: Shiyue Fang

Department Chair: Stephen L. Kampe 


\section{Table of Contents}

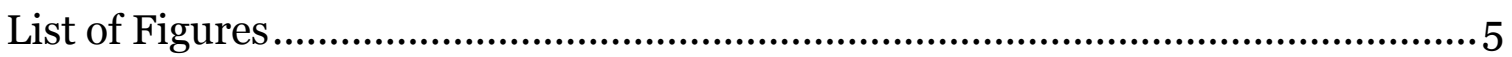

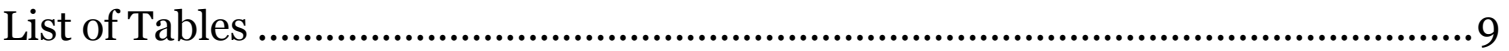

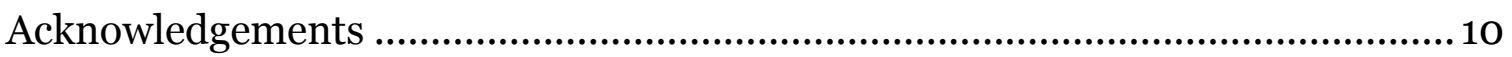

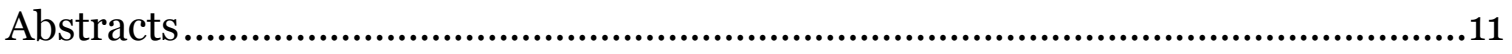

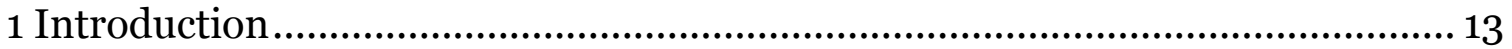

1.1 Significance of $\mathrm{LiFePO}_{4}$ material................................................................. 13

1.1.1 Electric Vehicles ....................................................................................... 13

1.1.2 Lithium ion batteries......................................................................... 14

1.1.3 $\mathrm{LiFePO}_{4}$-based cathode material......................................................... 15

1.2 Methods for synthesis of $\mathrm{LiFePO}_{4}$ and the technical barriers...................... 16

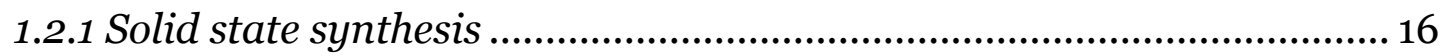

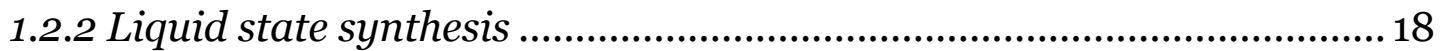

1.2.3 Microwave-assisted solid state synthesis ..................................................20

1.2.4 Microwave-assisted liquid state synthesis ............................................24

1.3 Evaluation of the state-of-art synthesis approaches...................................... 27

2 Goals and hypotheses.....................................................................................29

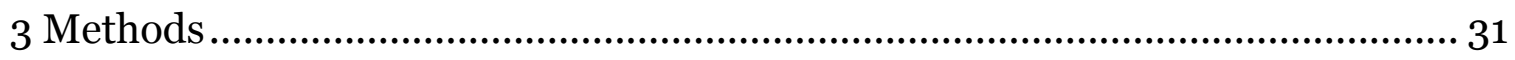

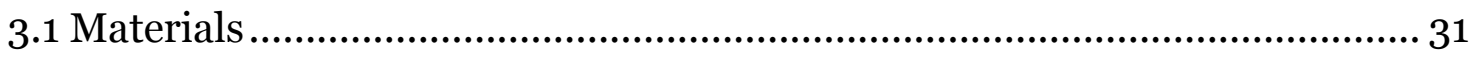

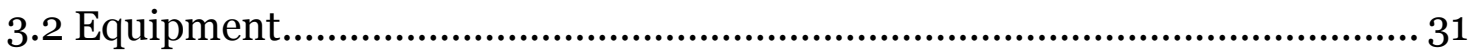

3.3 Synthesis …........................................................................................ 31

3.4 Characterization.................................................................................32

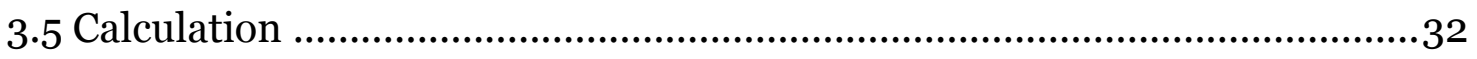

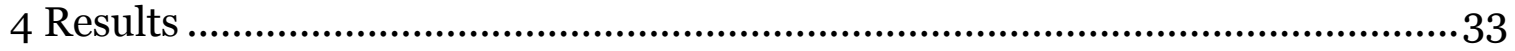

4.1 Precipitation of Precursors......................................................................... 33

4.1.1 Visual observation ..................................................................................3

4.1.2 XRD and SEM characterization .............................................................34

4.2. Phases evolved in MAWC synthesis .............................................................34

4. 3 Microstructure development of $\mathrm{LiFePO}_{4}$ in MAWC synthesis.................... 35

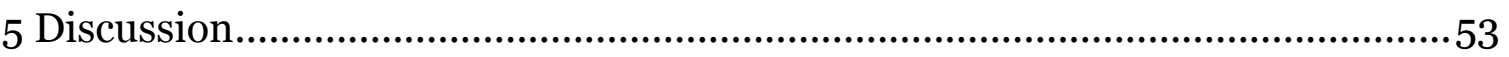




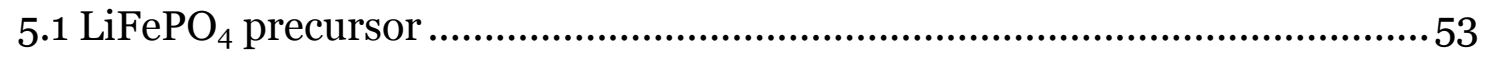

5.2 Development of crystalline phases ................................................... 57

5.3 Development of the crystalline microstructures ...................................60

5.3.1 Nucleation and growth in amorphous precursor .............................60

5.3.2 Preferable periphery crystallization ..............................................65

5.3.3 Oriented Attachment .................................................................68

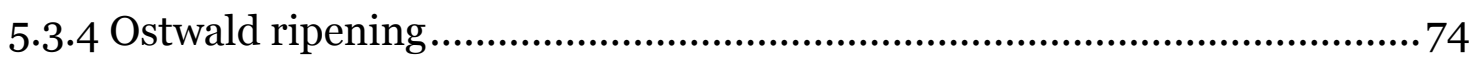

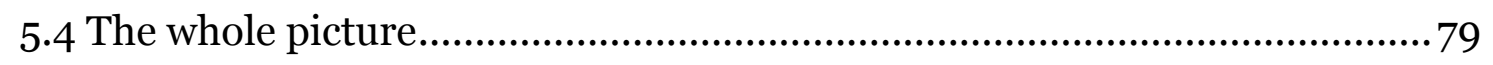

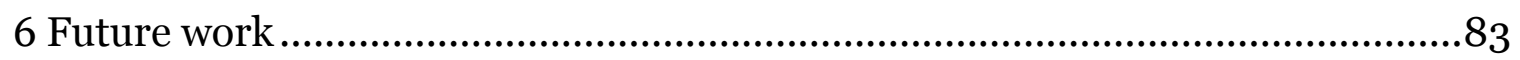

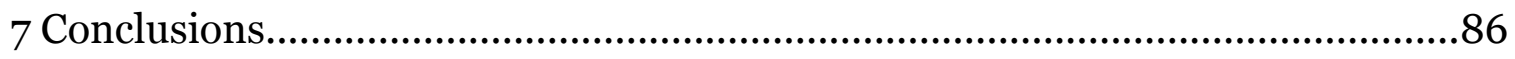

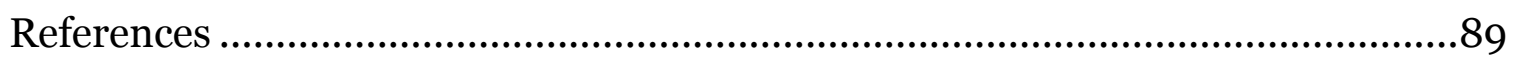

Appendix: Theoretical Analysis of $\mathrm{LiFePO}_{4}$ precursors .................................101 


\section{List of Figures}

Figure 1, XRD spectra of $\mathrm{LiFePO}_{4}$ precursor precipitated from mixed

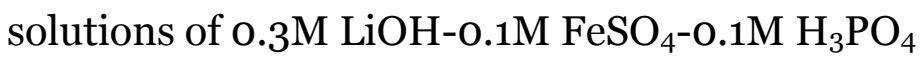

Figure 2, SEM photograph of the $\mathrm{LiFePO}_{4}$ precursor precipitated from mixed solution of $0.3 \mathrm{M}$ LiOH-o.1M $\mathrm{FeSO}_{4}-\mathrm{O} .1 \mathrm{M} \quad \mathrm{H}_{3} \mathrm{PO}_{4}, \times 8.1 \mathrm{k}$ magnification

Figure 3, SEM photograph of the $\mathrm{LiFePO}_{4}$ precursor precipitated from

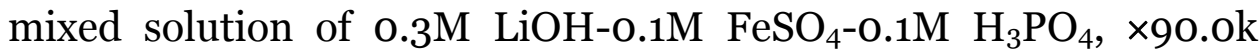
magnification

Figure 4, XRD spectra of $\mathrm{LiFePO}_{4}$ precursors treated by different microwave hydrothermal conditions

Figure 5, Temperature profiles corresponding to microwave hydrothermal conditions shown in Figure 4

Figure 6, XRD spectra of $\mathrm{LiFePO}_{4}$ precursors treated by different microwave hydrothermal conditions.

Figure 7, Temperature profiles corresponding to microwave hydrothermal conditions shown in Figure 6

Figure 8, XRD spectra of $\mathrm{LiFePO}_{4}$ precursors treated by different microwave hydrothermal conditions

Figure 9, Temperature profiles corresponding to microwave hydrothermal conditions shown in Figure 8

Figure 10, SEM micrograph of the sample obtained from microwave hydrothermal treatment of $\mathrm{LiFePO}_{4}$ precursor at $100^{\circ} \mathrm{C}$ for $1 \mathrm{~min}$. $\times 3.50 \mathrm{k}$ magnification

Figure 11, SEM micrograph of a magnified view of a micron sized particle shown in Figure 4.6a. ×90.ok magnification

Figure 12, SEM micrograph of a magnified view of a micron sized particle shown in Figure 4.6a. ×90.ok magnification

Figure 13, SEM photograph of the sample obtained from microwave 
hydrothermal treatment of $\mathrm{LiFePO}_{4}$ precursor at $130^{\circ} \mathrm{C}$ for $1 \mathrm{~min}$. $\times 4.54 \mathrm{k}$ magnification

Figure 14, SEM micrograph of a magnified view of a micron sized particle shown in Figure 4.7a. ×90.ok magnification

Figure 15, SEM micrograph of a magnified view of a micron sized particle shown in Figure 13. ×90.ok magnification

Figure 16, SEM photograph of the sample obtained from microwave hydrothermal treatment of $\mathrm{LiFePO}_{4}$ precursor at $170^{\circ} \mathrm{C}$ for $1 \mathrm{~min}$. $\times 4.54 \mathrm{k}$ magnification

Figure 17, SEM micrograph of a magnified view of a micron sized particle shown in Figure 16. ×90.ok magnification

Figure 18, SEM micrograph of a magnified view of a micron sized particle shown in Figure 16. ×90.ok magnification

Figure 19, SEM photograph of the sample obtained from microwave hydrothermal treatment of $\mathrm{LiFePO}_{4}$ precursor at $200^{\circ} \mathrm{C}$ for $1 \mathrm{~min}$. $\times 13.0 k$ magnification

Figure 20, SEM photograph of the sample obtained from microwave hydrothermal treatment of $\mathrm{LiFePO}_{4}$ precursor at $200^{\circ} \mathrm{C}$ for $1 \mathrm{~min}$. $\times 40.0 k$ magnification

Figure 21, SEM photograph of the sample obtained from microwave hydrothermal treatment of $\mathrm{LiFePO}_{4}$ precursor at $200^{\circ} \mathrm{C}$ for $1 \mathrm{~min}$. $\times 60.0 \mathrm{k}$ magnification

Figure 22, SEM photograph of the sample obtained from microwave hydrothermal treatment of $\mathrm{LiFePO}_{4}$ precursor at $200^{\circ} \mathrm{C}$ for $15 \mathrm{~min}$. $\times 5$.ok magnification

Figure 23, SEM photograph of the sample obtained from microwave hydrothermal treatment of $\mathrm{LiFePO}_{4}$ precursor at $200^{\circ} \mathrm{C}$ for $15 \mathrm{~min}$. $\times 80.0$ k magnification.

Figure 24, SEM photograph of the sample obtained from microwave 
hydrothermal treatment of $\mathrm{LiFePO}_{4}$ precursor at $200^{\circ} \mathrm{C}$ for $15 \mathrm{~min}$. $\times 80$. ok magnification

Figure 25, SEM photograph of the sample obtained from microwave hydrothermal treatment of $\mathrm{LiFePO}_{4}$ precursor at $200^{\circ} \mathrm{C}$ for $30 \mathrm{~min}$. $\times 3.02 \mathrm{k}$ magnification .50

Figure 26, SEM photograph of the sample obtained from microwave hydrothermal treatment of $\mathrm{LiFePO}_{4}$ precursor at $200^{\circ} \mathrm{C}$ for $30 \mathrm{~min}$. $\times 60.0 k$ magnification .50

Figure 27, SEM photograph of the sample obtained from microwave hydrothermal treatment of $\mathrm{LiFePO}_{4}$ precursor at $200^{\circ} \mathrm{C}$ for $30 \mathrm{~min}$. $\times 60.0 k$ magnification

Figure 28, SEM photograph of the sample obtained from microwave hydrothermal treatment of $\mathrm{LiFePO}_{4}$ precursor at $200^{\circ} \mathrm{C}$ for $45 \mathrm{~min}$. $\times 60.0 k$ magnification 51

Figure 29, SEM photograph of the sample obtained from microwave hydrothermal treatment of $\mathrm{LiFePO}_{4}$ precursor at $200^{\circ} \mathrm{C}$ for $45 \mathrm{~min}$. $\times 60.0 \mathrm{k}$ magnification 52

Figure 30, SEM photograph of the sample obtained from microwave hydrothermal treatment of $\mathrm{LiFePO}_{4}$ precursor at $200^{\circ} \mathrm{C}$ for $45 \mathrm{~min}$. $\times 60.0 k$ magnification 52

Figure 31, Multistep crystallization mechanism .................................................. 61

Figure 32, Crystallization by nucleation and growth of multiple subcrystalline nuclei inside an amorphous droplet..

Figure 33, Crystallization takes place preferably at the periphery of an amorphous droplet. .66

Figure 34, Oriented attachment by collision between two crystallites in same crystallographic orientation.

Figure 35, Oriented attachment by collision between two crystallites in mismatched crystallographic orientations. 70 
Figure 36, Final particle shapes resulted from oriented attachment.....................71

Figure 37, Growth of crystalline particles by Ostwald ripening. ........................... 75 


\section{List of Tables}

Table A1 Values of the dissociation constants of $\mathrm{H}_{3} \mathrm{PO}_{4}$ in aqueous solution .... 104

Table A2 Concentrations of chemical species in $\mathrm{H}_{3} \mathrm{PO}_{4}$ aqueous solutions

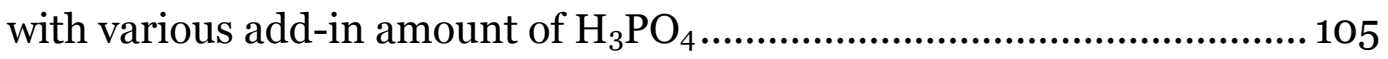

Table A3 Gibbs free energy of species in $\mathrm{FeSO}_{4}$ aqueous solution....................... 108

Table A4 Concentrations of chemical species in $\mathrm{FeSO}_{4}$ aqueous solutions ......... 108

Table A5 Initial dilution of chemical species when the $0.2 \mathrm{M} \mathrm{FeSO}_{4}$ solution

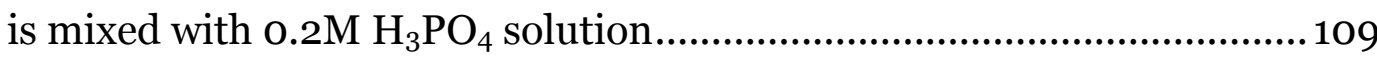

Table A6 Concentration of chemical species in $\mathrm{FeSO}_{4}-\mathrm{H}_{3} \mathrm{PO}_{4}$ solutions ..............114

Table A7 Concentration of chemical species in $\mathrm{LiOH}-\mathrm{H}_{3} \mathrm{PO}_{4}$ solution without $\mathrm{Li}_{3} \mathrm{PO}_{4}$ precipitation $\left(m_{1}=0.1 \mathrm{M}, m_{3}=0.003 \mathrm{M}\right)$.........................117

Table A8 Concentration of chemical species in $\mathrm{LiOH}-\mathrm{H}_{3} \mathrm{PO}_{4}$ solution after

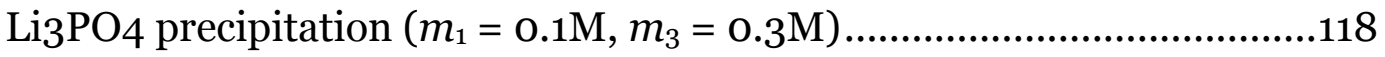

Table A9 Concentration of chemical species in $\mathrm{LiOH}-\mathrm{H}_{3} \mathrm{PO}_{4}$ at critical amount of add-in $\mathrm{LiOH}\left(m_{1}=0.1 \mathrm{M}\right)$

Table A10 Concentration of chemical species in $\mathrm{LiOH}-\mathrm{H}_{3} \mathrm{PO}_{4}$ solution below and above critical amount of add-in $\mathrm{LiOH}\left(m_{1}=0.1 \mathrm{M}\right)$.

Table A11 Concentration of species in $\mathrm{LiOH}-\mathrm{FeSO}_{4}-\mathrm{H}_{3} \mathrm{PO}_{4}$ solution at the point when $\mathrm{Fe}_{3}\left(\mathrm{PO}_{4}\right)_{2}$ precipitation begins $\left(m_{1}=m_{2}=0.1 \mathrm{M}\right)$

Table A12 Concentration of chemical species in $\mathrm{LiOH}-\mathrm{FeSO}_{4}-\mathrm{H}_{3} \mathrm{PO}_{4}$ solution with selected amount of add-in $\mathrm{LiOH}\left(m_{1}=m_{2}=0.1 \mathrm{M}\right)$ 128 


\section{Acknowledgements}

I would like to express my appreciations to a number of people who helped me in my research. I am particularly grateful to Dr. Jiann-Yang Hwang as my advisor for his guidance and support throughout this research. I am also grateful for Dr. Steven A. Hackney, Dr. Xiaodi Huang and Dr. Shiyue Fang as my advisory committee member.

I want to thank Mr. Owen P Mills, Mr. Edward A Laitila, Mrs Ruth I. Kramer, Mr. Stephen F. Forsell, and Mr. Patrick Quimby for their lab support.

I would like to express my gratitude to the following people who provided me with various support and help during my research: Dr. Bowen Li, Dr. Zhiwei Pen, Dr. Zheng Zhang, Dr. Xiang Sun, Mrs. Allison M. Hein, Mrs. Margaret P Rothenberger, and Mrs. Beth R Sickler.

Finally, I am thankful to my family for continuing support and love! 


\section{Abstracts}

$\mathrm{LiFePO}_{4}$ is a Co-free battery material. Its advantages of low cost, non-toxic and flat discharge plateau show promising for vehicle propulsion applications. A major problem associated with this material is its low electrical conductivity. Use of nanosized $\mathrm{LiFePO}_{4}$ coated with carbon is considered a solution because the nanosized particles have much shorter path for $\mathrm{L}^{+}$ions to travel from the $\mathrm{LiFePO}_{4}$ crystal lattice to electrolytes. As other nano material powders, however, nano $\mathrm{LiFePO}_{4}$ could have processing and health issues.

In order to achieve high electrical conductivity while maintaining a satisfactory manufacturability, the particles should possess both of the nano- and the microcharacteristics correspondingly. These two contradictory requirements could only be fulfilled if the $\mathrm{LiFePO}_{4}$ powders have a hierarchical structure: micron-sized parent particles assembled by nanosized crystallites with appropriate electrolyte communication channels.

This study addressed the issue by study of the formation and development mechanisms of the $\mathrm{LiFePO}_{4}$ crystallites and their microstructures. Microwaveassisted wet chemical (MAWC) synthesis approach was employed in order to facilitate the evolvement of the nanostructures. The results reveal that the $\mathrm{LiFePO}_{4}$ crystallites were directly nucleated from amorphous precursors by competition against other low temperature phases, $\mathrm{Li}_{3} \mathrm{PO}_{4}$ and $\mathrm{Fe}_{3}\left(\mathrm{PO}_{4}\right)_{2} \cdot 8 \mathrm{H}_{2} \mathrm{O}$. Growth of the crystalline $\mathrm{LiFePO}_{4}$ particles went through oriented attachment first, followed by revised Ostwald ripening and then recrystallization. While recrystallization played the role in growth of well crystallized particles, oriented attachment and revised Ostwald ripening were responsible for formation of the straight edge and plate-like shaped $\mathrm{LiFePO}_{4}$ particles comprised of nanoscale substructure. Oriented attachment and revised Ostwald ripening seemed to be 
also responsible for clustering the plate-like $\mathrm{LiFePO}_{4}$ particles into a high-level aggregated structure.

The finding from this study indicates a hope for obtaining the hierarchical structure of $\mathrm{LiFePO}_{4}$ particles that could exhibit the both micro- and nano- scale characteristics. Future study is proposed to further advance the understanding of the structural development mechanisms, so that they can be manipulated for new $\mathrm{LiFePO}_{4}$ structures ideal for battery application.

Keywords: Lithium iron phosphate, battery materials, microwave hydrothermal, hierarchical structure, oriented attachment, revised Ostwald ripening 


\section{Introduction}

\subsection{Significance of $\mathrm{LiFePO}_{4}$ material}

\subsubsection{Electric Vehicles}

Electric and electric hybrid vehicles are placed in a hot area of research and development. It is expected that these new kinds of vehicles would be able to relieve the nation from oil dependency and significantly reduce the $\mathrm{CO}_{2}$ emission. According to a report made by International Energy Agency (1), the EV industry "had $\$ 31.1$ billion sales globally in 2005 at ex factory prices excluding electric toys. It is growing strongly and, by 2015, the $\mathrm{EV}$ market will have grown to 7.3 times its value in 2005." It is estimated that the plug-in hybrid and electric vehicles will make up nearly $20 \%$ of the global vehicle market by 2030 .

In 2009, the US Department of Energy (2) projected to commercialize 1,000,000 electrical and electrical hybrid vehicles in the coming five years. These vehicles will serve as demonstrative models that would lead to vast number of replacement of the fossil fuel powered vehicles by electricity powered vehicles within 20 years. This will have an immense impact on the automobile industry, since the United States have the largest population of car consumers. According to Gomes (3), there were 255,917,664 vehicles on the highways just in the year 2008.

China is a fast-growing market. According to Bradsher (4), the current automobile market size in China already reached the second-biggest in the world and the growth rate is about $12 \%$ a year. The total number of vehicles is predicted to be over 280 million by 2030. In order to avoid the potential environmental issues induced by the large number of automobile fleet, China has to invest new vehicle technologies that are more energy-efficient and friendly to environment. All-electric and electric-hybrid vehicles are the first choice. The present Chinese annual production capacity for electric vehicles is about 500,000. An expansion of several folds in the coming two decades could be anticipated. 
Europe is a region with highly urbanized countries where the emphasis on reducing tailpipe emissions have been drawing attentions on low \& zero emission vehicles. The effort on development of the new vehicles could lead to increased use of electric motors to replace the internal combustion engines. According to Kumar (5), "the markets for motors in Europe and North America together are expected to scale up to 4.8 million units by 2017."

\subsubsection{Lithium ion batteries}

Batteries are the key devices for the vehicles powered by electricity. For the vehicle propulsion batteries, high energy density, fast charging rate and low cost are desired. In fact, there were various kinds of batteries had already been developed and demonstrated even before 1980s (6). However, many of them have been abandoned because of such problems as low energy density, unsatisfactory charging rate, or and structural instability. Among a few survived batteries (lead acid batteries, $\mathrm{Ni} / \mathrm{MH}$ batteries and Li-ion batteries, etc.), the Li-ion batteries are most promising because of their high energy density and good electrochemical performance compared to other kinds of batteries.

At present, the technologically mature lithium ion batteries are those using $\mathrm{LiCoO}_{3}$ as cathode materials (7). This kind of batteries is widely employed in various portable electronic devices and could be used for vehicle propulsion in the near future (8). However, since $\mathrm{Co}$ is expensive and toxic, use of $\mathrm{LiCoO}_{3^{-}}$ based batteries for vehicle propulsion is not a viable technology. Much effort was made in the past years in order to reduce its high cost by replacing the expensive cobalt with other cheaper chemical constituents and appreciable progress has been made (9). At present a number of battery formula have been identified that could use low-Co or Co-free materials for the battery cathode. The low-Co materials are typically $\mathrm{Li}-\left(\mathrm{Ni}_{1 / 2} \mathrm{Mn}_{1 / 2}\right) \mathrm{O}_{2}, \quad \mathrm{Li}\left(\mathrm{Mn}_{1 / 3} \mathrm{Co}_{1 / 3} \mathrm{Ni}_{1 / 3}\right) \mathrm{O}_{2}, \quad$ and $\mathrm{Li}\left[\mathrm{Ni}_{1 / 2} \mathrm{Mn}_{3 / 2}\right] \mathrm{O}_{4}[10]$. The Co-free materials could be $\mathrm{LiMn}_{2} \mathrm{O}_{4}, \mathrm{LiMnNiO}_{4}$, etc (11). The energy storage capacity and the charge rate could be made fairly well by 
preparing these materials in the form of nanoparticles, in which the area for electrolyte-to-electrode contact is larger and the length for $\mathrm{Li}^{+}$diffusion is shorter (12). The methods for producing nano particles include mechanical grinding, solution based synthesis or sol-gel approaches. However, these materials are vulnerable to oxidation that causes electrolyte decomposition and form a nonactive solid layer at the interface between the electrolyte and the $\mathrm{LiFePO}_{4}$ particles, resulting in degradation of charge capacity $(12,13)$.

\subsection{3 $\mathrm{LiFePO}_{4}$-based cathode material}

$\mathrm{LiFePO}_{4}$ is another Co-free material for the cathode of lithium ion batteries. According to Shukla et al (14), the discharge potential of this material is $3.4 \mathrm{~V}$ and its discharge plateau is exceptionally flat. The energy storage capacity is about $150-160 \mathrm{mAh} / \mathrm{g}$. It is non-toxic, low capacity fade and also much safer compared to $\mathrm{LiCoO}_{2}$. The lower charging voltage $(<4 \mathrm{~V})$ of the $\mathrm{LiFePO}_{4}$ battery makes the material less reactive with electrolyte.

The most appropriateness of this material is that the constituent elements ( $\mathrm{Li}, \mathrm{Fe}$ and $\mathrm{P}$ ) in $\mathrm{LiFePO}_{4}$ are cheap and abundant in natural resources. Because of this, the use of $\mathrm{LiFePO}_{4}$-based battery for vehicle propulsion is viewed as the most viable technology. Furthermore, the $\mathrm{LiFePO}_{4}$-based battery is anticipated to take over many of other applications that are currently dominated by the expensive $\mathrm{LiCoO}_{3}$-based batteries, due to its cheapness.

A problem associated with the $\mathrm{LiFePO}_{4}$ material is its low electrical conductivity at room temperature, only of the order of $10^{-9} \mathrm{~S} / \mathrm{cm}$. Shukla described two approaches to circumvent this problem (14): "one is the reduction of the grain size of the cathode particle, which would lead to a diminution of the diffusion lengths both for electrons and ions, and the other is the use of nanocomposites of $\mathrm{LiFePO}_{4}$ with a conductive matrix such as carbon." 
Another problem is the sensitivity of $\mathrm{Fe}^{2+}$ ions in the $\mathrm{LiFePO}_{4}$ to preparation environment $(15,16)$. Improper preparation may lead to oxidation of $\mathrm{Fe}^{2+}$ to $\mathrm{Fe}^{3+}$, which is detrimental to battery applications. Although the presence of sufficient amount of carbon is able to suppress the oxidation, the excessive carbon may reduce $\mathrm{Fe}^{2+}$ to $\mathrm{Fe}$, which must be also avoided.

At present time, there is no big difference between the prices of $\mathrm{LiFePO}_{4}$ and $\mathrm{LiCoO}_{2}$. However, because the high cost of $\mathrm{LiFePO}_{4}$ comes from processing rather than from natural resources, it can be dramatically reduced by development of appropriate synthesis and processing technology.

1.2 Methods for synthesis of $\mathrm{LiFePO}_{4}$ and the technical barriers

There are a large number of publications reporting the synthesis of $\mathrm{LiFePO}_{4}$. For an overview, the article authored by Jugovic et al (17) may be referred. Here in the following context, I would like to address the technical barriers inherent in several important approaches.

\subsubsection{Solid state synthesis}

Mixing-and-firing is a traditional approach for synthesis of ceramic powders. It is currently the major approach in industrial production of $\mathrm{LiFePO}_{4}$. In the synthesis, the first step is to decompose the $\mathrm{Li}, \mathrm{Fe}$ and $\mathrm{P}$ salts into oxides. The product phase, $\mathrm{LiFeO}_{4}$, then nucleates from these oxides and, as the synthesis proceeds, growth of the $\mathrm{LiFeO}_{4}$ takes place accompanied by diffusion of the metals from the oxides to the product particles.

The approach involves a 3-member solid state reaction. Formation of the $\mathrm{LiFePO}_{4}$ phase goes through the diffusion of the metal ions in solids. Since diffusion through solid phases is slow, it requires the grinding and firing repeat several times in order to minimize the diffusion paths. It is a lengthy procedure 
and also consumes large amounts of energy. What is more is that the oxidation state of $\mathrm{Fe}$ is sensitive to firing conditions. $\mathrm{Fe}^{2+}$ is desired in the $\mathrm{LiFePO}_{4}$ structure, but some of them may be oxidized to $\mathrm{Fe}^{3+}$ if in ambient synthesis atmosphere. If using reducing atmosphere, $\mathrm{Fe}^{\mathrm{o}}$ is likely to be resulted in. Control of the processing conditions, such as atmosphere, firing temperature and time, is difficult $(18,19)$. In addition, the mixing-and-firing method is hard to control the particle size and to achieve the desired compositional homogeneity (20-22). These disadvantages limit the performance of the synthesized material.

In order to improve the milling efficiency of the mixing-and-firing approach, mechanochemical activation is introduced. Use of the high energy mill to pulverize the solid powders is able to comminute the material powders into very small sizes. Accordingly, the large specific surface area associated with the small particle size could improve the electronic conductivity (23). The small particles could also improve the compositional homogeneity. However, the mechanochemical process alone is not able to produce single-phase lithium iron phosphate, repeated firing is still needed. The process may still suffer from Fe valence deviation.

Another attempt to improve the mixing-and-firing process is the introduction of electric discharge into the mechanical milling. According to Needham et al (24), two electrodes were introduced into the mill. One electrode metallic chamber and the other is a vibratory rod. Milling of the powder was implemented by vibration of the rod inside the chamber. In the meantime, a high frequency AC power was applied to the electrodes which caused an electric discharge between the stainless steel rod and the chamber wall. The electrical discharge resulted in rapid temperature increase inside the precursor powders and thus caused solid state synthesis of $\mathrm{LiFePO}_{4}$ occur. The concurrent milling instantly removed the product layers from the surfaces of the reacting particles and exposed the fresh precursors for further reaction. This is a quite new idea and the reduction of synthesis time 
was demonstrated. However, the discharge capacity of the synthesized material is only one half of that of the materials synthesized by other approaches. The poor electrochemical properties may be due to the unstable synthesis conditions.

\subsubsection{Liquid state synthesis}

Use of molten salt approach changed the synthesis from solid state reaction to liquid state reaction. Since the ionic diffusion in liquid phase is much faster than in solid phases, this approach has the capability of enhancing the synthesis kinetics. In an experiment made by Anderson et al (25), the total time for producing the $\mathrm{LiFePO}_{4}$ was reported to be 8 hours. However, it requires an additional step for removal of the flux $(\mathrm{KCl})$. Equipment corrosion and the contamination of the product wherefrom would turn out to be problems.

The liquid state synthesis can be more efficient by using spray pyrolysis (26-29). In this process, the reactants were made into aqueous solutions that were mixed with appropriate carrier gases and sprayed into a reactor at temperatures that are able to evaporate the solvents and decompose the precursors. Spray pyrolysis has the advantages of rapid kinetics and producing spherical fine particles. However, the as-sprayed fine powders have low crystallinity, so it needs to be annealed at high temperatures in non-oxidizing atmospheres. Another disadvantage may be that this process consumes large amount of energy for evaporation of water, which may render it an incompetent process compared to other approaches.

Sol-gel approach (30) has a potential to produce materials of higher purity and high homogeneity. It is also a facile method to prevent the material structure from growing beyond nano scales at the very beginning of the synthesis. In addition, the processing temperatures of sol-gel approach are generally lower than that of traditional powder processing methods. However, the use of large amount of organic solvent is not only a matter of cost, but also an environmental issue. 
Emulsion-drying approach was attempted for synthesis of $\mathrm{LiFePO}_{4}$ by Sastry (31) and $\mathrm{Yu}(32)$ with their corresponding co-workers. According to their approach, the first step was to make oil-in-water emulsion containing stoichimetric $\mathrm{Li}, \mathrm{Fe}$ and $\mathrm{P}$ salts. The emulsion was then dropped hot kerosene by which powdery precursor was obtained. The third step was to dry the powdery precursor at 300$400^{\circ} \mathrm{C}$ in order to remove the oil and the emulsifying agents. Finally high temperature calcination $\left(750^{\circ} \mathrm{C}\right)$ was employed to obtain the target crystalline phase of $\mathrm{LiFePO}_{4}$. With this synthesis route, high level mixing of the reactants can be achieved and coalescence of the $\mathrm{LiFePO}_{4}$ grains can be effectively inhibited. Its disadvantages are high cost, environmental pollution as well as hazardous processing conditions.

Hydrothermal synthesis involves dissolution of the reagents in water, precipitation of precursors and conversion of the precursor to target material phase. The whole process is carried out in aqueous solutions. Early attempts made by Goodenough et al (33) for hydrothermal synthesis of $\mathrm{LiFePO}_{4}$ used $\mathrm{FeSO}_{4}, \mathrm{H}_{3} \mathrm{PO}_{4}$ and $\mathrm{LiOH}$ as starting materials. In order to avoid the potential $\mathrm{Fe}(\mathrm{OH})_{2}$ and $\mathrm{FeO}(\mathrm{OH})$ impurities, they mixed the $\mathrm{FeSO}_{4}$ and $\mathrm{H}_{3} \mathrm{PO}_{4}$ solution first, followed by addition of $\mathrm{LiOH}$ solution. The obtained cream-like precursor was then processed under hydrothermal conditions at different temperatures for up to $5 \mathrm{~h}$. When the hydrothermal temperature is at about $150^{\circ} \mathrm{C}$, the charge capacity of the synthesized $\mathrm{LiFePO}_{4}$ powders was not as high as expected. The low charge capacity was attributed to some degree of lattice disorder between lithium and iron atoms. Although post-hydrothermal treatment of the synthesis material at elevated temperature with reducing agents could resolve the disorder issue (34), it appears more convenient to resolve it by raising the hydrothermal temperature $(35,36)$ and using more efficient reducing agent in situ in the hydrothermal process. It was found that the iron disorder could be eliminated and the material with correct lattice parameters and volume could be obtained when the synthesis temperature exceeded $175^{\circ} \mathrm{C}$ in presence of appropriate reducing agents. 
In some cases, $\mathrm{Li}_{3} \mathrm{PO}_{4}$ impurity was seen from the hydrothermal products (37, 38). The impurity could be removed by washing because $\mathrm{Li}_{3} \mathrm{PO}_{4}$ is soluble. However the dissolution of $\mathrm{Li}_{3} \mathrm{PO}_{4}$ in water could substantial increase the $\mathrm{pH}$ of the solution, which could result in dissolution of $\mathrm{LiFePO}_{4}$. In order to protect the $\mathrm{LiFePO}_{4}$ from dissolution, neutral buffer solution with a $\mathrm{pH}$ between 5.9 and 6.9 has to be employed.

\subsubsection{Microwave-assisted solid state synthesis}

Microwave-assisted solid synthesis of $\mathrm{LiFePO}_{4}$ has been explored by a number of researchers. Higuchi et al (39) reported the use of this approach to prepare $\mathrm{LiFePO}_{4}$ as early as in 2003. In their experiment, the precursors were prepared by mixing the corresponding $\mathrm{Li}, \mathrm{Fe}$ and $\mathrm{P}$ salts and microwaving the solid mixture in inert atmosphere. The lithium and phosphorus sources were lithium carbonate and ammonium phosphate, respectively. One of the iron sources was iron lactate. They expected that the iron source would act acts as a microwave absorber. However, the synthesis was not successful although prolonged microwaving was attempted. The reaction was improved by doping of metallic iron metal into the starting mixture (40). It was shown latterly that addition of activated carbon was even better. Carbon is a good microwave susceptor and also consumes oxygen at elevated temperatures. Use of carbon is able to heat the mixture rapidly and avoid oxidation of the iron(II) ions, that enables the processing in ambient atmosphere.

Different precursors were attempted for microwave synthesis. Li et al (41) employed $\mathrm{Li}_{3} \mathrm{PO}_{4}$ and $\mathrm{Fe}_{3}\left(\mathrm{PO}_{4}\right)_{2} \cdot 8 \mathrm{H}_{2} \mathrm{O}$, which were mixed and milled in a vibratory mill in argon for $30 \mathrm{~min}$. The microwave radiation only took $2 \mathrm{~min}$. the synthesized material exhibited a discharge capacity of $160 \mathrm{mAh} / \mathrm{g}$ at $\mathrm{C} / 10$. The precursors used by Wang et al (42) were $\mathrm{NH}_{4} \mathrm{H}_{2} \mathrm{PO}_{4}, \mathrm{CH}_{3} \mathrm{COOLi}$ and $\mathrm{FeC}_{2} \mathrm{O}_{4} \cdot 2 \mathrm{H}_{2} \mathrm{O}$. Stoichiometric $\mathrm{NH}_{4} \mathrm{H}_{2} \mathrm{PO}_{4}$ and $\mathrm{CH}_{3} \mathrm{COOLi}$ were mixed and ground at first and then added the $\mathrm{FeC}_{2} \mathrm{O}_{4} \cdot 2 \mathrm{H}_{2} \mathrm{O}$ and some amount of citric acid. The 
mixture was ground for another $10 \mathrm{~min}$ in order to obtain higher homogeneity. The time for microwave radiation was a matter of a few minutes. The obtained material consists of 40-50 $\mathrm{nm}$ crystalline phase and the electrochemical capacity retained $123 \mathrm{mAh} / \mathrm{g}$ at the 50 th cycle.

Beninati et al (43) combined microwave processing and sol-gel synthesis. The precursors were laboratory-made $\mathrm{C}_{6} \mathrm{H}_{5} \mathrm{FeO}_{7}$ and commercial $\mathrm{H}_{3} \mathrm{PO}_{4}$ and $\mathrm{Li}_{3} \mathrm{PO}_{4}$. By use of microwave processing, they were able to complete the gel formation step in 12 minutes that would otherwise be several hours if in a conventional solgel process. The dry gel was then calcined in furnace under $5 \% \mathrm{H}_{2}$-argon atmosphere at $700^{\circ} \mathrm{C}$ for 1 hour, that produced the final product with a chargedischarge capacity up to $150 \mathrm{mAh} / \mathrm{g}$ at C-rate $0.1 \mathrm{C}$ and a stability up to 600 deep charge-discharge cycles at $1 \mathrm{C}$.

Li et al (44) used a similar approach but the Fe-P precursor they prepared was $\mathrm{NH}_{4} \mathrm{Fe} \mathrm{PO}_{4} \cdot \mathrm{H}_{2} \mathrm{O}$ instead of $\mathrm{Fe}_{3}\left(\mathrm{PO}_{4}\right)_{2} \cdot 8 \mathrm{H}_{2} \mathrm{O}$. The preparation was made by mixing solutions of $\mathrm{FeSO}_{4}, \mathrm{H}_{3} \mathrm{PO}_{4}$ and $\mathrm{NH}_{3} \cdot \mathrm{H}_{2} \mathrm{O}$ in presence of reducing and chelating agent. This precursor was mixed with $\mathrm{Li}_{2} \mathrm{CO}_{3}$ and ball milled for 24 hours at 250rpm. Their best synthesis result was obtained by heating the ballmilled mixture in a domestic microwave oven at $320 \mathrm{~W}$ for $15 \mathrm{~min}$, of which the sample exhibited an initial discharge capacity of $156 \mathrm{mAh} / \mathrm{g}$ at o.05C. The $\mathrm{LiFePO}_{4}$ particles are flakelike in shape, which was the morphology of the precursor. The particles are conglomerated.

Zou et al's approach (45) used $\mathrm{FePO}_{4} \cdot 4 \mathrm{H}_{2} \mathrm{O}$ as the iron and phosphor precursor and the $\mathrm{Li}$ source was $\mathrm{Li}_{2} \mathrm{CO}_{3}$ or $\mathrm{LiOH} \cdot \mathrm{H}_{2} \mathrm{O}$ or $\mathrm{CH}_{3} \mathrm{COOLi} \cdot 2 \mathrm{H}_{2} \mathrm{O}$. The Fe-P precursor and the Li chemicals were stoichiometrically mixed with glucose and ball milled for 5 hours at 400 rpm. The microwave heating was done in a $1000 \mathrm{~W}$ domestic microwave oven. Different from others, their microwave heating was a kind of intermittent mode, namely 20 seconds power on followed by 10 seconds 
power off. With four on/off circles, the total microwave irradiation time was 80 seconds. With this heating method, pure olivine structure was obtained from all of the samples using either $\mathrm{Li}_{2} \mathrm{CO}_{3}$ or $\mathrm{LiOH} \cdot \mathrm{H}_{2} \mathrm{O}$ or $\mathrm{CH}_{3} \mathrm{COOLi} \cdot 2 \mathrm{H}_{2} \mathrm{O}$ as the $\mathrm{Li}$ source, respectively. The sample prepared from $\mathrm{Li}_{2} \mathrm{CO}_{3}$ exhibited the highest initial discharge capacity, $162 \mathrm{mAh} / \mathrm{g}$ at $0.1 \mathrm{C}$ charging rate, whereas the capacities of the samples prepared from $\mathrm{LiOH} \cdot \mathrm{H}_{2} \mathrm{O}$ and $\mathrm{CH}_{3} \mathrm{COOLi} \cdot 2 \mathrm{H}_{2} \mathrm{O}$ were measured as $156.7 \mathrm{mAh} / \mathrm{g}$ and $157.5 \mathrm{mAh} / \mathrm{g}$, respectively. The sample prepared from $\mathrm{Li}_{2} \mathrm{CO}_{3}$ also exhibited satisfactory cycling stability at discharge rates ranging from $1 \mathrm{C}$ to $10 \mathrm{C}$, no observable decrease of the discharge capacities after 50 circles. The particles of this sample show a spherical morphology with an average particle size ranging from 50 to $100 \mathrm{~nm}$.

Song et al (46) used $\mathrm{Li}_{3} \mathrm{PO}_{4}$ and $\mathrm{Fe}_{3}\left(\mathrm{PO}_{4}\right)_{2} \cdot 8 \mathrm{H}_{2} \mathrm{O}$ as the precursor materials for microwave synthesis of $\mathrm{LiFePO}_{4}$. Stoichiometric amounts of $\mathrm{Li}_{3} \mathrm{PO}_{4}$ and $\mathrm{Fe}_{3}\left(\mathrm{PO}_{4}\right)_{2} \cdot 8 \mathrm{H}_{2} \mathrm{O}(1: 1$, molar ratio) were mixed with 5 wt.\% acetylene black in a vibrant type mill under argon atmosphere for $30 \mathrm{~min}$. The ball-milled mixture was pressed into a pellet and then heated in a $750 \mathrm{OW}$ domestic oven for 2-5 min. In order to assist the materials with microwave absorption and prevent the divalent iron from oxidation, the samples were embedded into active carbon during the microwave irradiation. Best result was obtained from the sample that was ball milled in a ball-to-powder weight ration of 8.1:1 combined with 2 min microwave irradiation. The initial discharge capacity was reported as $161 \mathrm{mAh} / \mathrm{g}$ at $0.1 \mathrm{C}$ rate and fairly no discharge capacity drops can be seen after 50 circles. One reason that may be attributed to this phenomenon was the ball milling in high ball-to-powder ratio, which resulted small particle size and large contact area between the precursor mixture and the carbon that produced strong reducing atmosphere and enhanced microwave heating efficiency. Another reason seemed to be the presence of $\mathrm{Fe}_{2} \mathrm{P}$ phase, which was observed in this study and was supposed to increase the electrical conductivity of the $\mathrm{LiFePO}_{4} / \mathrm{C}$ conductivity (47). Their later investigation revealed that there was a critical 
concentration of $\mathrm{Fe}_{2} \mathrm{P}$ (48). Below the critical concentration, $\mathrm{Fe}_{2} \mathrm{P}$ enhanced the discharge capacity but above that, $\mathrm{Fe}_{2} \mathrm{P}$ deteriorated the capacity. They believe the negative effect of the higher concentration $\mathrm{Fe}_{2} \mathrm{P}$ came from the blockage of the one-dimensional $\mathrm{Li}^{+}$pathways in $\mathrm{LiFePO}_{4}$ that hindered the $\mathrm{Li}^{+}$movement in $\mathrm{LiFePO}_{4}$. Their study indicates that the amount of $\mathrm{Fe}_{2} \mathrm{P}$ contained in the synthesized $\mathrm{LiFePO}_{4}$ was related to the extensiveness of ball milling. Therefore control of the $\mathrm{Fe}_{2} \mathrm{P}$ concentration may be achieved by control of the milling time as well as the ball-to-powder ratio.

Co-precipitation is a kind of chemical mixing. Compared to ball milling, coprecipitation is soft and fast. It could achieve higher degree of homogeneity of mixture precursors. Furthermore, the solution process may have more freedom to mediate and to control the mixture morphology. Park et al (49) reported their work with the use of this approach. They mixed solutions of $(\mathrm{NH} 4)_{2} \mathrm{Fe}\left(\mathrm{SO}_{4}\right)_{2} \cdot 6 \mathrm{H}_{2} \mathrm{O}$ and $\mathrm{H}_{3} \mathrm{PO}_{4}$ at first and then added the mixture solution into a solution of $\mathrm{LiOH}$ in presence of blowing nitrogen. Co-precipitation was completed within $10 \mathrm{~min}$. The co-precipitate was separated, washed and dried in vacuum. Carbon black was added into the dried powder by homogeneous mixing. The mixture was pressed into small disks that were then put inside the beaker filled with granular activated carbon and heated in a $650 \mathrm{~W}$ domestic microwave oven for a few minutes. The shortest microwaving time for completion of $\mathrm{LiFePO}_{4}$ synthesis was $3 \mathrm{~min}$, although minor impurities of $\mathrm{Li}_{3} \mathrm{PO}_{4}$ and $\mathrm{Li}_{3} \mathrm{Fe}_{2} \mathrm{PO}_{4}$ could be detected. These impurities also exist in samples obtained from $4 \mathrm{~min}, 5 \mathrm{~min}$ and 6 min microwave heating. Their results showed that 4 min microwave heating was the best, from which the initial discharge capacity reached $151 \mathrm{mAh} / \mathrm{g}$ at $\mathrm{C} / 10$ rate. The initial discharge capacity at $\mathrm{C} / 1$ rate was $134 \mathrm{mAh} / \mathrm{g}$ and maintained at its $92 \%$ after 50 circles. The particles are irregular in shape with a wide range of particle size distribution.

Another report on $\mathrm{LiFePO}_{4}$ synthesis by microwave heating of co-precipitates was the work of Li et al (50). In addition to improved mixing homogeneity, they also 
attempted to increase the specific surface area of the synthesized material by means of bear yeast, a biotemplate. They prepared $\left(\mathrm{NH}_{4}\right) \cdot 2 \mathrm{HPO}_{4}-\mathrm{O} \cdot 5 \mathrm{M} \mathrm{FeSO}$ solution by dissolving $\left(\mathrm{NH}_{4}\right) \cdot 2 \mathrm{HPO}_{4}$ and $\mathrm{FeSO}_{4} \cdot 7 \mathrm{H}_{2} \mathrm{O}$ in distilled water in 1:1 molar ratio with concentrations of the both chemicals being $0.5 \mathrm{M}$. The solution was then added into the yeast-containing $\mathrm{Li}_{2} \mathrm{CO}_{3}$ solution with $0.3 \mathrm{M}$ of Li. Coprecipitation was also complete with $10 \mathrm{~min}$. The precipitates were vacuum dried, porphyrized, mixed with $5 \mathrm{wt} \%$ carbon black and then heated in a domestic oven at $300 \mathrm{~W}$ for $10 \mathrm{~min}$. The synthesized powder got a BET surface area of $77.5 \mathrm{~m}^{2} / \mathrm{g}$ compared to $66 . \mathrm{om}^{2} / \mathrm{g}$ of the samples without yeast. They further increased the BET surface area to $98.3 \mathrm{~m}^{2} / \mathrm{g}$ by varying the amount of the yeast (51). At $0.1 \mathrm{C}$ discharge rate, the initial discharge capacity of this sample is $147 \mathrm{mAh} / \mathrm{g}$, whereas that of without-yeast samples is $110 \mathrm{mAh} / \mathrm{g}$. After 20 circles, the discharge capacity of the former retained to about $97 \%$ of its initial capacity, whereas that of the later dropped to about $84 \%$ of the initial value.

\subsubsection{Microwave-assisted liquid state synthesis}

Microwave-assisted liquid state synthesis may use either water or organic solvents as the synthesis media. If water is used, the synthesis is referred to microwave hydrothermal synthesis. If organic solvent is used, the synthesis is termed as microwave solvothermal synthesis.

Sato et al (52) prepared $\mathrm{LiFePO}_{4}$ by microwave hydrothermal method. In their preparation, $\mathrm{LiOH}$ solution of $1 \mathrm{~mol} \mathrm{dm}{ }^{-1}$ was made by dissolving $\mathrm{LiOH} \cdot \mathrm{H}_{2} \mathrm{O}$ in distilled water, and then $\mathrm{H}_{3} \mathrm{PO}_{4}$ solution and $\mathrm{FeSO}_{4}$ powder were added in a molar ratio of $\mathrm{L}: \mathrm{Fe}: \mathrm{P}=3: 1: 1$. Olivine structure $\mathrm{LiFePO}_{4}$ was obtained by heating the mixed solution in a microwave digestion system at $150^{\circ} \mathrm{C}$ for $20 \mathrm{~min}$. The particle size ranged fro $200 \mathrm{~nm}$ to $300 \mathrm{~nm}$, whereas the particle size of their sample synthesized by conventional hydrothermal approach was in a range from $500 \mathrm{~nm}$ to $2 \mu \mathrm{m}$. The initial discharge capacity of the material is $113 \mathrm{mAh} / \mathrm{g}$ at $0.2 \mathrm{C}$ rate. This capacity is lower than that of a sample they prepared by conventional 
hydrothermal $(\mathrm{CH})$ synthesis at $150^{\circ} \mathrm{C}$ for $3 \mathrm{hr}$, which is $138 \mathrm{mAh} / \mathrm{g}$. However the $\mathrm{MH}$ sample exhibits higher cycling stability than the $\mathrm{CH}$ sample. The decrease of the discharge capacity of the $\mathrm{MH}$ sample after 10 circles was $8.1 \%$ but that of the $\mathrm{CH}$ sample is $14 \cdot 5 \%$.

A similar procedure was used by Yang et al (53). However, Yang's microwave heating was carried out at higher temperature but shorter time, $200^{\circ} \mathrm{C}$ for $5 \mathrm{~min}$. They obtained an average of $30 \mathrm{~nm}$ particle size, which incompactly agglomerated into homogenous aggregates in a size range of 1-3 $\mu \mathrm{m}$. The initial discharge capacity of the synthesized powder is $136 \mathrm{mAh} / \mathrm{g}$ at $0.1 \mathrm{C}$ rate. The capacity retains its $96.3 \%$ after 50 discharge circles. They further heat treated the synthesized powder at $400^{\circ} \mathrm{C}$ for $4 \mathrm{~h}$. However, such post-heat treatment did not improve the electrochemical property but lowered the discharge capacity instead. This negative effect was speculated to the larger particle size of the post-heat treated sample, which was about $80 \mathrm{~nm}$. The larger particles may have higher resistance against $\mathrm{Li}^{+}$diffusion.

Murugan et al (54) added carbon to their microwave hydrothermal synthesized $\mathrm{LiFePO}_{4}$ in order to improve the material's electrical conductivity. The carbon was added in the form of glucose at the time of mixing of $\mathrm{H}_{3} \mathrm{PO}_{4}$ and $\mathrm{LiOH}$ solutions, to which iron (ii) sulfate solution was added. The Li:Fe:P molar ratio in the mixed solution was 3:1:1 and the $\mathrm{Fe}^{2+}$ to glucose molar ratio was 2:1, which resulted in a carbon content of $5 \mathrm{wt} \%$ in the final product. Microwave heating was carried out in a commercial microwave oven at $230^{\circ} \mathrm{C}$ for $15 \mathrm{~min}$. The synthesized $\mathrm{LiFePO}_{4}$ has a nanorod-like morphology of 220-225nm in diameter, for which the authors attributes the morphology to their controlled $\mathrm{pH}$ value. The $\mathrm{LiFePO}_{4}$ particles were coated with carbon layer of 5-12 nm in thickness. The $\mathrm{LiFePO}_{4} / \mathrm{C}$ composite has an initial discharge capacity of $144 \mathrm{mAh} / \mathrm{g}$ at $0.1 \mathrm{C}$ rate and was able to retained $80 \%$ of the capacity after 25 circles. They further heat treated the material in inert atmosphere at $700^{\circ} \mathrm{C}$ for $1 \mathrm{~h}(55)$. They obtained a 
slightly higher initial discharge capacity, $146 \mathrm{mAh} / \mathrm{g}$ at $0.1 \mathrm{C}$ rate, but a larger improvement on cycling stability. The material was able to retained $98.6 \%$ of the capacity after 25 circles. Electron microscopy characterization revealed that the post heat treatment neither had a significant effect the size and morphology on $\mathrm{LiFePO}_{4}$ nor had an influence on the carbon coating thickness. The authors believed that the one hour treatment at $700^{\circ} \mathrm{C}$ significantly improved the order structure of the carbon coating, which lead to the improvement of the cycling stability.

BBilecka et al (56) reported their synthesis using organic solvent, i.e. microwave solvothermal synthesis. According to the authors, the advantage of microwave solvothermal synthesis over microwave hydrothermal synthesis is its ability to avoid high pressure, because solvothermal process may use solvents of higher boiling points. In their synthesis, the solvent was benzyl alcohol. Its boiling point is $205^{\circ} \mathrm{C}$. Their microwave solvothermal synthesis was carried at $180{ }^{\circ} \mathrm{C}$ for $3 \mathrm{~min}$. With $\mathrm{Fe}\left(\mathrm{C}_{2} \mathrm{H}_{3} \mathrm{O}_{2}\right)_{2}, \mathrm{LiCl}$ and $\mathrm{H}_{3} \mathrm{PO}_{4}$ (in 1:1:1 molar ratio) as the starting chemicals, they obtained a material with initial discharge capacity of $150 \mathrm{mAh} / \mathrm{g}$ at $2 \mathrm{C}$ rate and this capacity retained its $90-95 \%$ after 160 circles. The $\mathrm{LiFePO}_{4}$ particles are platelet-like and in micrometer size range. Inside the platelet-like particles, is a substructure composed of individual crystallographically aligned nanocrystallites of roughly $100 \mathrm{~nm}$. The authors believe that such mesocrystalline particle morphology is favorable with respect to the electrochemical performance.

Murugan et al (57) used tetraethyleneglycol (TEG) as the solvent. The boiling point of TEG ranges in $324-330^{\circ} \mathrm{C}$. Their microwave solvothermal synthesis was carried out at $300^{\circ} \mathrm{C}$ for $5 \mathrm{~min}$. As from their microwave hydrothermal synthesis (53), the $\mathrm{LiFePO}_{4}$ particles also showed nanorod morphology. The solvothermal synthesis, however, produced much smaller particle size and larger aspect ratio. The small nanorods have a width of $25 \pm 6 \mathrm{~nm}$ and a length up to $100 \mathrm{~nm}$. The large nanorods have a width of $40 \pm 6 \mathrm{~nm}$ and a length up to $1 \mu \mathrm{m}$. While they said the particle morphology of the microwave hydrothermal sample was controlled 
by the $\mathrm{pH}$ value of the solution, the particle morphology of the microwave solvothermal sample was said to be regulated by the reactant concentration. The pristine $\mathrm{LiFePO}_{4}$ had an initial discharge capacity of $146 \mathrm{mAh} / \mathrm{g}$ at $0.1 \mathrm{C}$ discharge rate and the capacity retained its $93.8 \%$ till 30 circles. The pristine powder was then mixed with mixed with 18 wt \% of sucrose powder and carbonized in a flowing $2 \% \mathrm{H} 2 / 98 \% \mathrm{Ar}$ at $700^{\circ} \mathrm{C}$ for $1 \mathrm{~h}$. The initial discharge capacity of the carbon coated $\mathrm{LiFePO}_{4}$ powder increased to $162 \mathrm{mAh} / \mathrm{g}$ and this value was retained in 30 circles. They also mixed the pristine $\mathrm{LiFePO}_{4}$ powder with multiwall carbon nanotube (MWCNT) and $p$-TSA doped poly $\left(3,4^{-}\right.$ ethylenedioxythiophene) (PEDOT) in 92:8 ratio, respectively (57). They were no further thermal treatment of these two mixtures except for being dried at $80^{\circ} \mathrm{C}$. The MWCNT-containing powder got an initial discharge capacity of $161 \mathrm{mAh} / \mathrm{g}$ at 0.1C rate, whereas the PEDOT-containing powder got an initial discharge capacity of $166 \mathrm{mAh} / \mathrm{g}$ at $0.1 \mathrm{C}$ rate.

\subsection{Evaluation of the state-of-art synthesis approaches}

Among the various synthesis approaches, hydrothermal appears much better than others. Hydrothermal synthesis is a soft process, of which the chemical composition of the reactant mixture is homogeneous in atomic level. The synthesis uses water as the reaction medium. It is therefore an environmentfriendly, clean process. Hydrothermal process is carried out in a closed reactor. It is much easier to control the Fe valence. The synthesis conditions are easier to control, from which higher reproducibility can be accomplished.

The hydrothermal synthesis also demonstrated an advantage of simplified procedure. All of other solution-based synthesis approaches need post-synthesis firing, in order to convert the amorphous material into crystalline product. Hydrothermal synthesis directly generates crystalline material. The potential to reduce the synthesis to one-step was demonstrated. 
Besides the hydrothermal approach, microwave method is most promising. Its ultrafast synthesis kinetics could significantly reduce the synthesis time, enhance the production capacity, save labor and energy, as well as facilitate the control of the product quality.

The most obvious advantage of the microwave approach is the speed. Through the solid state microwave synthesis approach, the synthesis time ranged from 2 $\min$ to $15 \mathrm{~min}$. By the liquid state microwave synthesis approach, the synthesis time ranged from $5 \mathrm{~min}$ to $20 \mathrm{~min}$. Compared to the conventional synthesis approaches, by which the solid state synthesis takes 10-24 hours (17) and the hydrothermal synthesis takes $5-12$ hours $(58,59)$, the one to two orders of increase in synthesis rate by microwave approach showed a great promise. It may lead to the miniaturization of the chemical plant. Consider that, when the job of a chemical plant can be done by a workshop, of which the size is just one hundredth of the plant, the savings in energy, labor, maintenance and the facility investment will be tremendous.

Fine grain size is the second advantage microwave approach brings to the $\mathrm{LiFePO}_{4}$ synthesis. While the particle sizes obtained from conventional carbothermal reduction method are in micrometer range (60), those obtained from microwave synthesis approaches can be reduced to less than $100 \mathrm{~nm}$. In liquid state synthesis, both the microwave and the conventional approaches are able to produced nanosized particles. However, the conventional liquid phase synthesis requires use of expensive precursors (sol-gel, for example) or toxic, flammable media (e.g. emulsion approach) in order to obtain fine and monodispersed particles. When using aqueous medium, the prolonged synthesis period usually lead to undesired grain growth. In contrast, microwave approach is able to produce well controlled particles in aqueous medium owing to its rapid synthesis capability. For example, Murugan's MH synthesises produced well dispersed $\mathrm{LiFePO}_{4}$ nanorods without agglomerations (55). 
2 Goals and hypotheses

The proposed research will carry out study on $\mathrm{LiFePO}_{4}$ synthesis via microwaveassisted wet chemical (MAWC) approach. The main focus of the research will address the development of the material structures and morphologies under microwave hydrothermal synthesis conditions.

As is reviewed in the last chapter, there are a number of approaches that are employed for synthesis of $\mathrm{LiFePO}_{4}$. However it cannot yet been seen a clear correlation between the synthesis approaches and electrochemical properties of the synthesized materials. The initial discharge capacities and the cycling stabilities of the materials synthesized by different groups appeared scattered. The difference of these properties between samples obtained in similar synthesis approaches is in the same amplitude as that between samples got from different preparation methods. The reason for the lack of the correlation is not understood.

Although in the past ten years, the efforts spending on development of $\mathrm{LiFePO}_{4}$ synthesis techniques were tremendous, the study on the structural evolvement in the material synthesis was lack. We believe it is worth to pursue, because the material properties are closely related to the microstructures, not only related to the particle sizes but may also to the morphology as well as to the aggregation manners.

$\mathrm{LiFePO}_{4}$ is known to be poor of electrical conductivity and there is a consent that reducing the particle size to nanoscale could greatly increase the charge/discharge capacity (61). However nanosized particles have problems in powder processing and battery assembling because of low tap density (62). There are also health issues in extended exposure to nanosized powders. It is found that nanoparticles may act like asbestos and silicone (63) that cause inflammation and release toxic molecules. These toxic molecules could attack DNA, proteins and 
cell membranes inducing dissimilar cell death and causing cancer (64).

The ideal structure of $\mathrm{LiFePO}_{4}$ powders for cathode application should have characteristics reflecting the both aspects of easy handling and nontoxic to human beings, and for high electrical conductivity. In order for easy handling and nontoxic, the $\mathrm{LiFePO}_{4}$ particles have to be in micron sizes. In order to achieve high electrical conductivity, the particles should be in nanoscale. These two contradictory requirements can only be fulfilled if the $\mathrm{LiFePO}_{4}$ powders have a hierarchical structure: micron-sized parent particles assembled by nanosized crystallites. In order for the electrolyte to effectively communicate with the nanocrystallites, there should be appropriate channels inside the particle extending to the particle surface

The state-of-art synthesis techniques have not yet accomplished on this ideal structure. Based on the current knowledge, what we can do at present is to control particle size and, to some extent, alter the particle shape (65-67). However, we are not able to manipulate the particles for building up such a kind of a hierarchical structure. Further research is needed in order for this accomplishment. Our knowledge on the microstructure development is primarily based on the classical theory of nucleation and growth, but this theory seems not lead to the hierarchical structure. We need to reinvestigate the mechanism by which how the $\mathrm{LiFePO}_{4}$ phase is produced, how its structural units are evolved and how these structural units are interacted. When our knowledge is advanced to this point, we would be able to manipulate the material into the desired structures. 


\section{Methods}

\subsection{Materials}

Lithium hydroxide $(\mathrm{LiOH})$, ferrous sulfate heptahydrate $\left(\mathrm{FeSO}_{4} \cdot 7 \mathrm{H}_{2} \mathrm{O}\right)$ and phosphoric acid $\left(\mathrm{H}_{3} \mathrm{PO}_{4}\right)$ of ACS reagent grade were used as the reactants. Organic antioxidant (ascorbic acid) was added for controlling the Fe ion valence. These reagents were purchased from Sigma-Aldrich for directly use without further purification. The chemicals were dissolved individually into distilled water and made into stocking solutions for future use. The water was bubbled with argon before use in order to purge out the oxygen.

\subsection{Equipment}

A microwave chemical reactor was used for the synthesis. The reactor could handle $10-100 \mathrm{ml}$ reactant solution, to which $1000 \mathrm{~W}$ microwave power could be delivered. Its working temperature ranges from room temperature to $200^{\circ} \mathrm{C}$ with control precision of $\pm 2^{\circ} \mathrm{C}$ and the heating rate can reach over $100^{\circ} \mathrm{C}$ per minute. Argon was sued as the exogenous pressure media. A T-type thermocouple was inserted inside the pressure chamber for accurate monitoring the temperature of the microwave hydrothermal process. Operation of the reactor was controlled by a computer program, so that the reproducible heating profile can be implemented.

\subsection{Synthesis}

The stocking solutions of $\mathrm{LiOH}, \mathrm{FeSO}_{4}$ and $\mathrm{H}_{3} \mathrm{PO}_{4}$ were mixed in 3:1:1 molar ratio. Such a ratio was used by considering that higher $\mathrm{Li}^{+}$concentration could prevent the $\mathrm{Fe}^{2+}$ from occupying the $\mathrm{Li}^{+}$sites in the $\mathrm{LiFePO}_{4}$ crystallographic structure (68). The mixing was carried out in a $50 \mathrm{ml}$ cone flask. Agitation was performed by a magnetic stirrer.

Precipitation occurred as $\mathrm{LiOH}$ was gradually added in and the solution turned into grayish slurry. After the LiOH addition was completed, the flask containing 
the slurry was moved into the microwave reactor. The reactor chamber was closed and argon was applied to pressurize the chamber to $275 \mathrm{psi}$.

The slurry was irradiated by the full power of the $1000 \mathrm{~W}$ microwave unit for fast ramp the slurry temperature to the designated temperature. When the slurry temperature reached the designated soaking temperature, the microwave power was automatically adjusted to keep soaking at the designated temperature for a period of designated soaking time. A series of soaking temperature and soaking time were designated in order to investigate the temperature-dependent and time-dependent development of the materials phases and microstructures.

\subsection{Characterization}

XRD was employed to identify the phases existing in the synthesized materials. The instrument was $\theta / \theta$ difractometer, CuKa radiation. SEM was used to examine the microstructures. The instrument was Hitachi S-4700 FE-SEM. In order for the SEM and XRD examination, the slurries treated under the designated microwave hydrothermal conditions were separated from their mother liquor by means of centrifuging. The collected solid samples were washed with de-ionized water and absolute alcohol and dried in vacuum at $60^{\circ} \mathrm{C}$ for 8 hours.

\subsection{Calculation}

Calculation was employed for prediction of the chemical species in the solutions of $\mathrm{LiOH}, \mathrm{FeSO}_{4}, \mathrm{H}_{3} \mathrm{PO}_{4}$ and their binary, ternary mixtures, and also in the precipitates from the mixed solutions. The calculation was performed by solving groups of equations that reflect the corresponding chemical equations, mass conservation and electrical neutrality. Because most of the equations are nonlinear, trial and error approach was used. The calculation is described in detail in the appendix. 
4 Results

4.1 Precipitation of Precursors

\subsubsection{Visual observation}

The $\mathrm{LiFePO}_{4}$ precursor was prepared by mixing solutions of $\mathrm{LiOH}, \mathrm{FeSO}_{4}$ and $\mathrm{H}_{3} \mathrm{PO}_{4}$ solution at concentration of 3:1:1 molar ratio. Two mixing orders were attempted:

1) Add $\mathrm{LiOH}$ into $\mathrm{H}_{3} \mathrm{PO}_{4}$ solution first and then add $\mathrm{FeSO}_{4}$ in to the $\mathrm{LiOH}-\mathrm{H}_{3} \mathrm{PO}_{4}$ solution mixture

2) Add $\mathrm{FeSO}_{4}$ in to $\mathrm{H}_{3} \mathrm{PO}_{4}$ solution first and then add $\mathrm{LiOH}$ in to the $\mathrm{FeSO}_{4}-\mathrm{H}_{3} \mathrm{PO}_{4}$ solution mixture

Via mixing order 1), a clear solution mixture of $\mathrm{LiOH}-\mathrm{H}_{3} \mathrm{PO}_{4}$ was seen when $\mathrm{LiOH}$ was added in small amount. However, as the addition of $\mathrm{LiOH}$ increased, the $\mathrm{LiOH}-\mathrm{H}_{3} \mathrm{PO}_{4}$ solution became turbidity and milky. The precipitates were white in color. Theoretical calculation indicates the white precipitates are $\mathrm{Li}_{3} \mathrm{PO}_{4}$.

Via mixing order 2), the $\mathrm{FeSO}_{4}-\mathrm{H}_{3} \mathrm{PO}_{4}$ solution mixture was remained clear when $0.1 \mathrm{M} \mathrm{FeSO}$ solution was added into the equal volume of $0.1 \mathrm{M} \mathrm{H}_{3} \mathrm{PO}_{4}$ solution. However, when the concentrations of the $\mathrm{FeSO}_{4}$ and $\mathrm{H}_{3} \mathrm{PO}_{4}$ were increased to 0.15M, cyan-colored precipitation was observed. Theoretical calculation indicates the cyan-colored precipitates are $\mathrm{Li}_{3} \mathrm{PO}_{4}$.

Addition of LiOH into $0.1 \mathrm{M} \quad \mathrm{FeSO}_{4}-\mathrm{O} .1 \mathrm{M} \quad \mathrm{H}_{3} \mathrm{PO}_{4}$ solution brought about immediate precipitation. The color of the initial precipitates appeared to be light blue. As the $\mathrm{LiOH}$ titration continued, the precipitates became grayish. Setting the slurry still (without agitation) for a while resulted in separation of the precipitates in two kinds. One looked white, the other looked blue. The blue and white precipitates were particulate in shape and uniformly distributed through 
each other. Theoretical calculation indicates that the precipitates are mixture of $\mathrm{Fe}_{3}\left(\mathrm{PO}_{4}\right)_{2}$ and $\mathrm{Li}_{3} \mathrm{PO}_{4}$.

\subsubsection{XRD and SEM characterization}

Figure 1 shows the XRD spectra of the as-precipitated precursor. It is the feature of amorphous, although theoretical calculation indicated that the precipitates are $\mathrm{Fe}_{3}\left(\mathrm{PO}_{4}\right)_{2}$ and $\mathrm{Li}_{3} \mathrm{PO}_{4}$. The amorphous nature is more evident when the XRD curve is put together with those from hydrothermal treated samples (Figure 4)

Figure 2 and Figure 3 show the precursor morphology at $\times 8.1 \mathrm{k}$ and $\times 90.0 \mathrm{k}$ magnification, respectively. The figures shows that the precursor is comprised of particles of less than 20 nanometers. These tiny particles are then clustered together and form clumps, of which the sizes range from 1 micron to 10 microns.

\subsection{Phases evolved in MAWC synthesis}

Figure 4 shows the XRD spectra of samples treated by microwave hydrothermal conditions at temperatures up to $170^{\circ} \mathrm{C}$. Figure 5 shows the corresponding microwave hydrothermal temperature profiles. From the figure, it can be seen that $100^{\circ} \mathrm{C} \times 1 \mathrm{~min}$ microwave hydrothermal treatment converted the amorphous precursor into two crystalline phases: $\mathrm{Fe}_{3}\left(\mathrm{PO}_{4}\right)_{2} \cdot 8 \mathrm{H}_{2} \mathrm{O}$ and $\mathrm{Li}_{3} \mathrm{PO}_{4}$. The phases remain same when under $130^{\circ} \mathrm{C} \times 1 \mathrm{~min}$ microwave hydrothermal treatment conditions. However, when the $\mathrm{MH}$ temperature increases to $170^{\circ} \mathrm{C}$, $\mathrm{Fe}_{3}\left(\mathrm{PO}_{4}\right)_{2} \cdot 8 \mathrm{H}_{2} \mathrm{O}$ disappeared. The two crystalline phases become $\mathrm{LiFePO}_{4}$ and $\mathrm{Li}_{3} \mathrm{PO}_{4}$

Figure 6 shows the XRD patterns of samples treated under microwave hydrothermal conditions of $170^{\circ} \mathrm{C}$ for $1 \mathrm{~min}, 200^{\circ} \mathrm{C}$ for $1 \mathrm{~min}$ and $200^{\circ} \mathrm{C}$ for $15 \mathrm{~min}$. Figure 8 shows the XRD patterns of samples treated under microwave hydrothermal conditions of $200^{\circ} \mathrm{C}$ for $15 \mathrm{~min}, 200^{\circ} \mathrm{C}$ for $30 \mathrm{~min}$ and $200^{\circ} \mathrm{C}$ for 45 min. Figure 7 and Figure 9 show the microwave hydrothermal treatment 
temperature profiles corresponding to the XRD patterns shown in Figure 6 and Figure 8, respectively.

From the figures, it can be seen that $\mathrm{Li}_{3} \mathrm{PO}_{4}$ diminishes as the microwave hydrothermal treatment temperature increased to $200^{\circ} \mathrm{C}$ and it completely disappeared when the $\mathrm{MH}$ treatment time elongated from $1 \mathrm{~min}$ to $15 \mathrm{~min}$. Longer $\mathrm{MH}$ treatment time does not have obvious effect on the $\mathrm{LiFePO}_{4}$ phase characteristics.

4. 3 Microstructure development of $\mathrm{LiFePO}_{4}$ in MAWC synthesis

Figure 10 shows the microstructure of samples obtained by microwave hydrothermal treatment of the $\mathrm{LiFePO}_{4}$ precursors at $100^{\circ} \mathrm{C}$ for 1 minute. It exhibits a different morphology from that of the as-precipitated precursor (as shown in Figure 2). While the micron sized particles sown in the as-precipitated precursor appear to be irregular and loose aggregates of nano sized particles, the microstructure shown in Figure 11 consists of micron sized particles that are straight edged and dense thin slabs. This morphology is the characteristics of crystalline structure, which is consistent with the XRD result shown in Figure 4.

Figure 11 shows a magnified view of a micron sized particle shown in Figure 10. The micrograph revealed that the micron sized particle has a substructure consisting of fragments of less than 20 nanometers.

Figure 13 shows the microstructure of samples obtained by microwave hydrothermal treatment of the $\mathrm{LiFePO}_{4}$ precursors at $130^{\circ} \mathrm{C}$ for 1 minute. Compared to the micrograph of the $\mathrm{MH}_{100}{ }^{\circ} \mathrm{C} \times 1 \mathrm{~min}$ sample, the straight-edged particles appeared to be fussy and smaller in size. Figure 14 shows a magnified view of a micron sized particle shown in Figure 13. Compared to the micrograph shown in Figure 11, the nano sized particles become more distinct and separated. 
Figure 16 shows the microstructure of samples obtained by microwave hydrothermal treatment of the $\mathrm{LiFePO}_{4}$ precursors at $170^{\circ} \mathrm{C}$ for 1 minute. Compared to those of samples obtained by lower temperature microwave hydrothermal treatments (Figure 11 and Figure 12), the $\mathrm{MH} 17 \mathrm{O}^{\circ} \mathrm{C} \times 1$ min treatment gives rise to well-crystallized clean microstructure. The particles are primarily square slabs and elongated rectangular strips. The sizes of the squares are in a range from 1 to 3 microns. The lengths of the strips are in the same range of the squares with their widths ranging from 0.5 to $1 \mu \mathrm{m}$. Figure 17 shows a magnified view of the rectangular strips shown in Figure 16. The figure reveals the thicknesses of these strips are mostly less than $50 \mathrm{~nm}$ with only a few seems thicker than $1 \mu \mathrm{m}$. A few flaws can also be seen on the surface of a few strips.

Figure 19 shows the microstructure of samples obtained by microwave hydrothermal treatment of the $\mathrm{LiFePO}_{4}$ precursors at $200^{\circ} \mathrm{C}$ for 1 minute. In this case, larger magnification $(\times 13.0 \mathrm{k}$ instead of $\times 3.0 \mathrm{k}$ as used in Figure 16$)$ was used because of the reduced particle size that could not be clearly seen with smaller magnifications. With the $\times 13.0 \mathrm{k}$ magnification, we can see that the powder is comprised of irregular aggregates of rectangles. The sizes of these rectangles range from less than $40 \mathrm{~nm}$ to about $400 \mathrm{~nm}$. Figure 20 shows a higher magnification view of the $\mathrm{MH} 200^{\circ} \mathrm{C} \times 1 \mathrm{~min}$ sample. The particles in the figure appear to be wedge-shaped. The sizes of the substructure particles inside the wedges are similar to those in rectangles as shown in Figure 17.

Figure 22 shows the microstructure of samples obtained by microwave hydrothermal treatment of the $\mathrm{LiFePO}_{4}$ precursors at $200^{\circ} \mathrm{C}$ for 15 minutes. It can be seen that the particle morphology is like that of the samples shown in Figure 16 and Figure 19, i.e., comprised of irregular aggregates of rectangles and squares. Substantial grain growth is seen when compared to the $\mathrm{MH} 200^{\circ} \mathrm{C} \times 1 \mathrm{~min}$ sample. The lengths of many rectangles become exceeding $1 \mu \mathrm{m}$ with some over 2 $\mu \mathrm{m}$. Figure 23 shows a higher magnification view of the $\mathrm{MH} 200^{\circ} \mathrm{C} \times 15 \mathrm{~min}$ 
sample. Compared to the substructure particles shown in Figure 20, the substructure particles shown in this micrograph appear to be somewhat fused.

Figure 25 shows the microstructure of samples obtained by microwave hydrothermal treatment of the $\mathrm{LiFePO}_{4}$ precursors at $200^{\circ} \mathrm{C}$ for 30 minutes. Further grain growth can be seen when compared to the $\mathrm{MH} 200^{\circ} \mathrm{C} \times 15 \mathrm{~min}$ sample (Figure 22). While the majority of rectangles shown in the $\mathrm{MH} 200^{\circ} \mathrm{C} \times 15$ min sample have lengths ranging within $2 \mu \mathrm{m}$, the length range of the platy particles shown in Figure 25 expanded to $10 \mu \mathrm{m}$. Figure 26 shows a higher magnification view of the $\mathrm{MH} 200^{\circ} \mathrm{C} \times 30$ min sample. Compared to the substructure particles shown in Figure 24, more of the substructure particles shown in this micrograph are fused.

Figure 28 shows the microstructure of samples obtained by microwave hydrothermal treatment of the $\mathrm{LiFePO}_{4}$ precursors at $200^{\circ} \mathrm{C}$ for 45 minutes. No further grain growth can be seen when compared to the $\mathrm{MH} 200^{\circ} \mathrm{C} \times 30$ min sample (Figure 25). The length of the platy particles shown in Figure 28 remains within the range of $10 \mu \mathrm{m}$. Figure 29 shows a higher magnification view of the $\mathrm{MH}_{200^{\circ}} \mathrm{C} \times 40 \mathrm{~min}$ sample. It can be seen from the figure that all of the substructure particles have disappeared. The surface of the rectangular particles becomes smooth.

Growth in thickness of the platy particles is also observed from the longer time microwave hydrothermal treatment at $200^{\circ} \mathrm{C}$. It can be seen in Figure 20 and Figure 23 that the thickness of the platy grains in the $\mathrm{MH} 200^{\circ} \mathrm{C} \times 1 \mathrm{~min}$ and

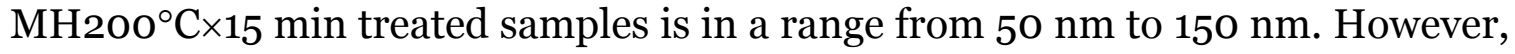
Figure 26 and Figure 29 show that the thickness of the platy grains in the $\mathrm{MH} 200^{\circ} \mathrm{C} \times 30$ min and $\mathrm{MH} 200^{\circ} \mathrm{C} \times 45$ min treated samples grew into a range from $200 \mathrm{~nm}$ to $250 \mathrm{~nm}$. 


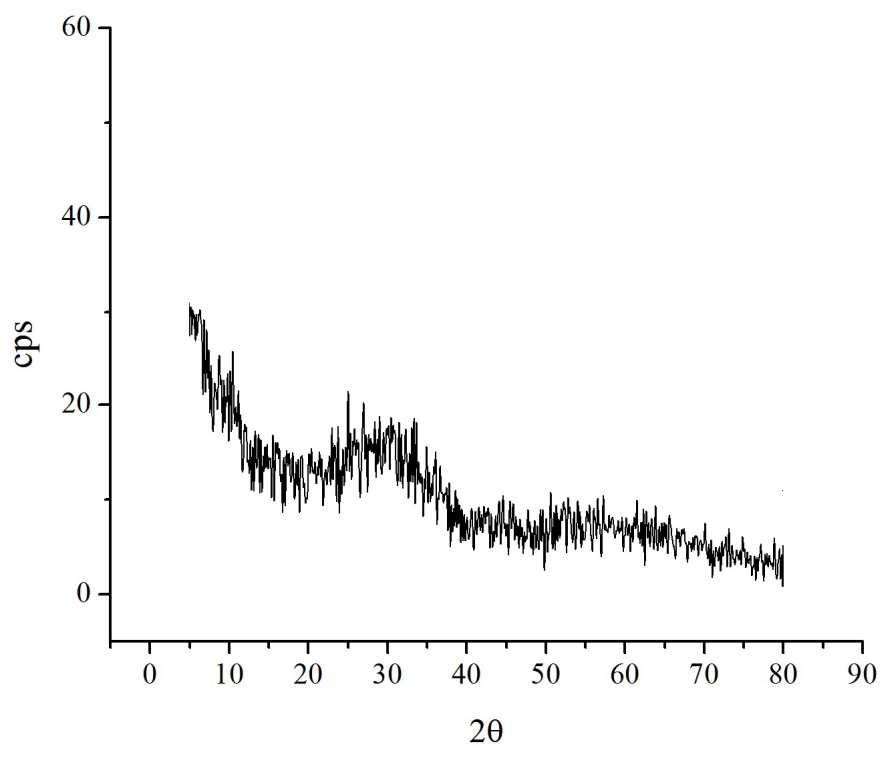

Figure 1, XRD spectra of $\mathrm{LiFePO}_{4}$ precursor precipitated from mixed solutions of $0.3 \mathrm{M}$ LiOH-0.1M FeSO ${ }_{4}-0.1 \mathrm{M} \mathrm{H}_{3} \mathrm{PO}_{4}$

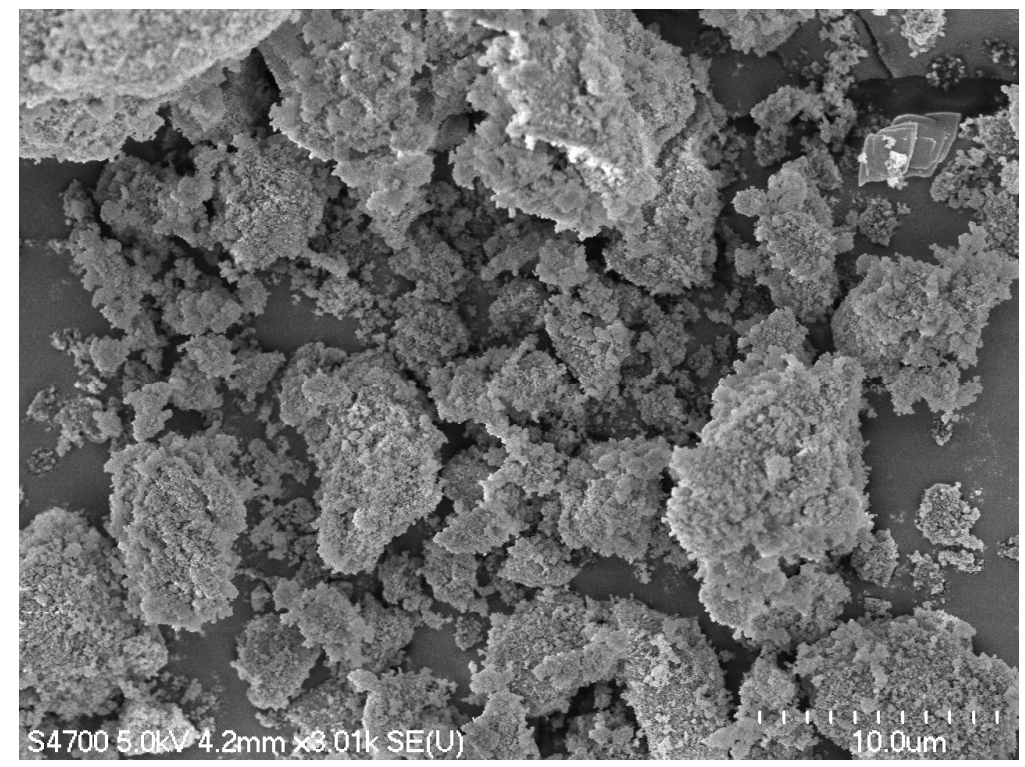

Figure 2, SEM photograph of the $\mathrm{LiFePO}_{4}$ precursor precipitated from mixed solution of $0.3 \mathrm{M} \mathrm{LiOH}-0.1 \mathrm{M} \mathrm{FeSO}_{4}-\mathrm{O} .1 \mathrm{M} \mathrm{H}_{3} \mathrm{PO}_{4}, \times 8.1 \mathrm{k}$ magnification 


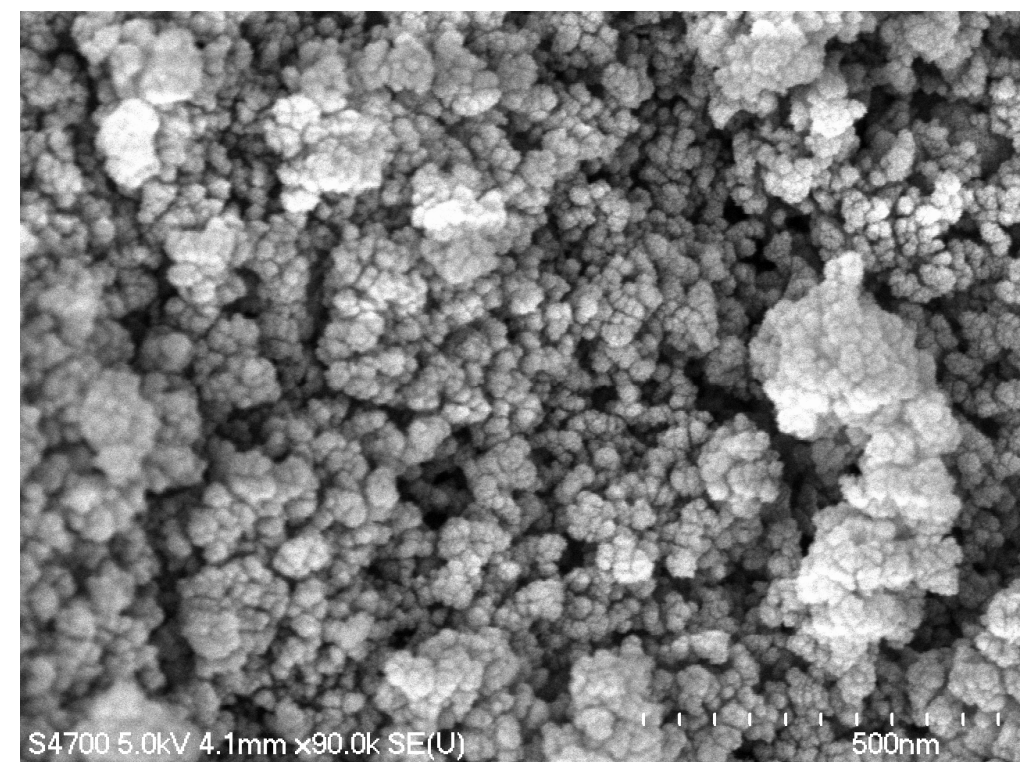

Figure 3, SEM photograph of the $\mathrm{LiFePO}_{4}$ precursor precipitated from mixed

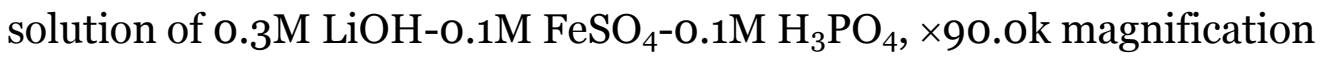
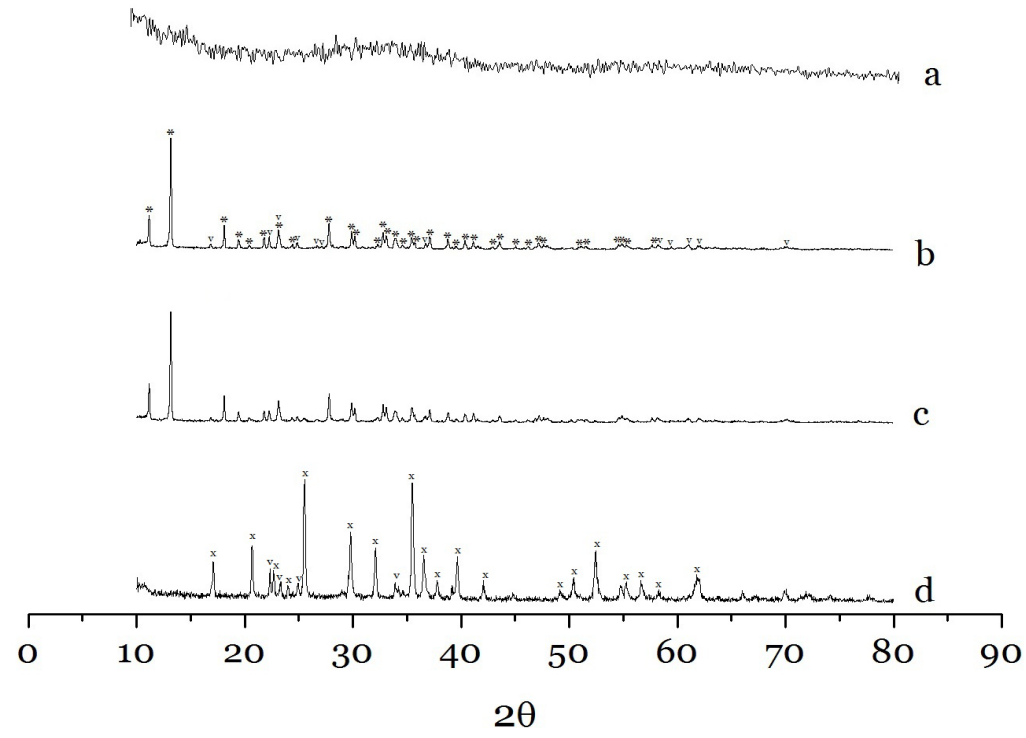

Figure 4, XRD spectra of $\mathrm{LiFePO}_{4}$ precursors treated by different microwave hydrothermal conditions. a), as precipitated; b), $\mathrm{MH}_{100^{\circ}} \mathrm{C} \times 1 \mathrm{~min}$; c), $\left.\mathrm{MH} 130^{\circ} \mathrm{C} \times 1 \mathrm{~min} ; \mathrm{d}\right), \mathrm{mw} 17 \mathrm{O}^{\circ} \mathrm{C} \times 1 \mathrm{~min} ;{ }^{*}-\mathrm{Fe}_{3}\left(\mathrm{PO}_{4}\right)_{2} \cdot 8 \mathrm{H}_{2} \mathrm{O} ; \mathrm{v}-\mathrm{Li}_{3} \mathrm{PO}_{4} ; \mathrm{x}-$ $\mathrm{LiFePO}_{4}$ 


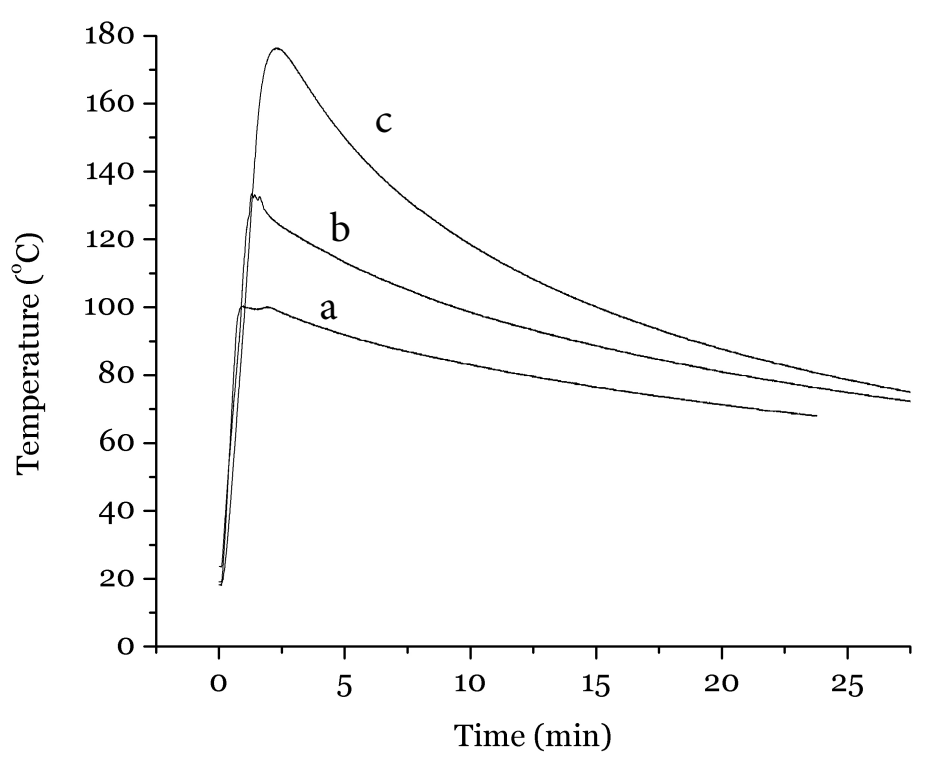

Figure 5, Temperature profiles corresponding to microwave hydrothermal

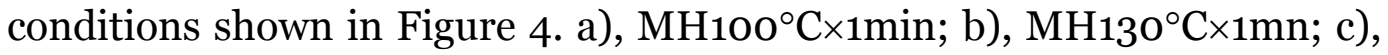
$\mathrm{MH} 170^{\circ} \mathrm{C} \times 1 \mathrm{mi}$

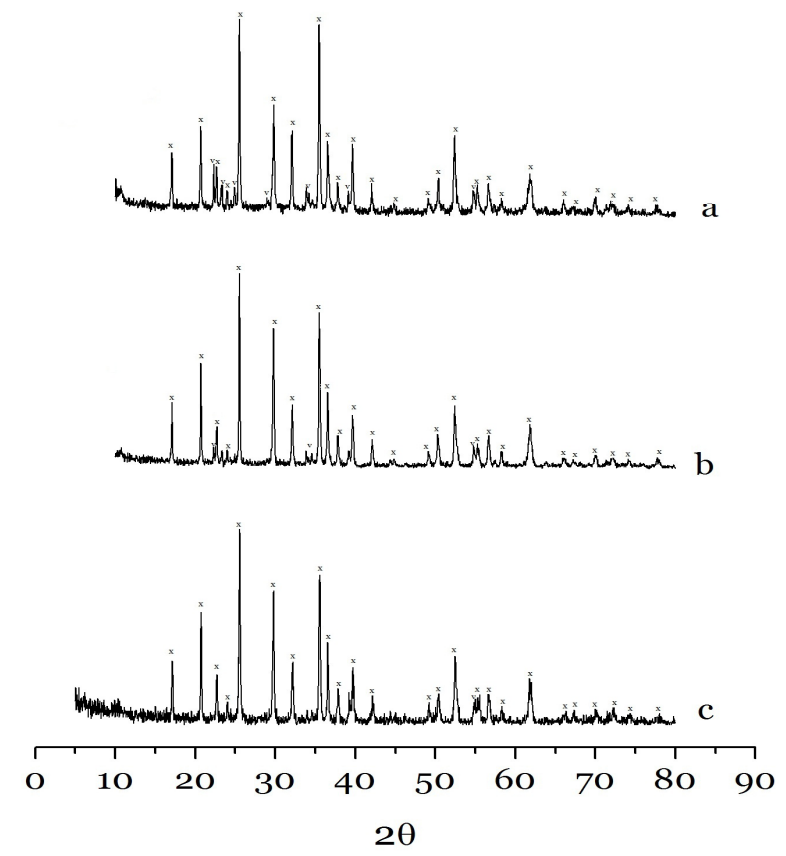

Figure 6, XRD spectra of $\mathrm{LiFePO}_{4}$ precursors treated by different microwave

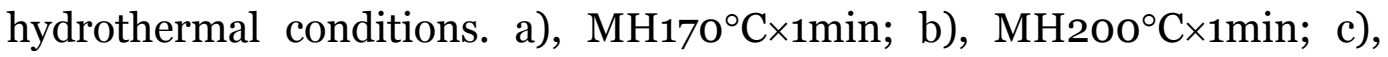
mw200 ${ }^{\circ} \times 15$ min; $v-\mathrm{Li}_{3} \mathrm{PO}_{4} ; \mathrm{x}-\mathrm{LiFePO}_{4}$ 


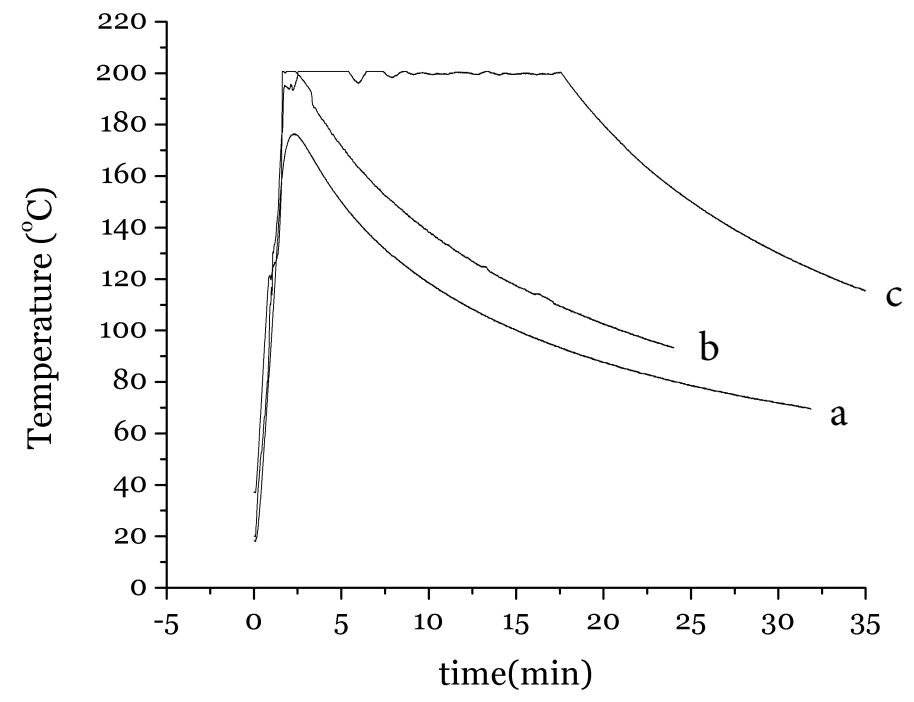

Figure 7, Temperature profiles corresponding to microwave hydrothermal

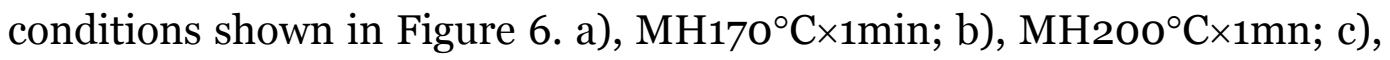
$\mathrm{MH}_{200^{\circ}} \mathrm{C} \times 15 \mathrm{~min}$.
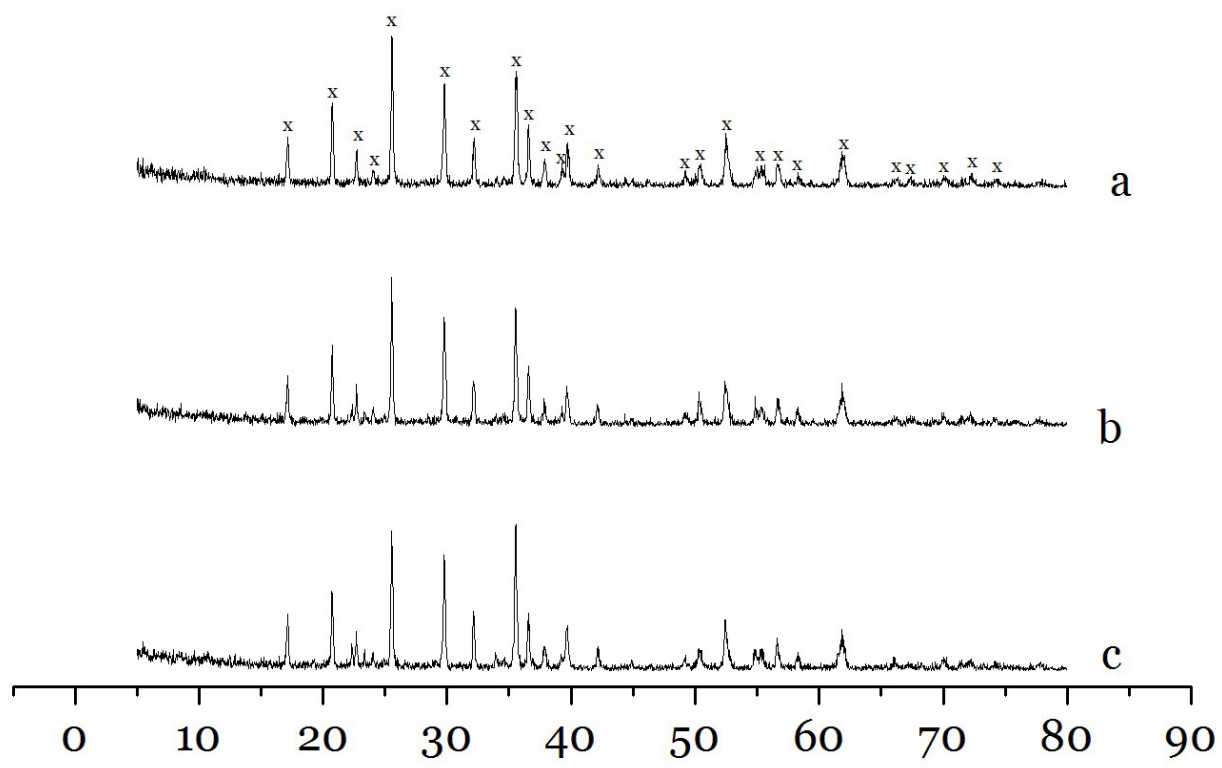

$2 \theta$

Figure 8, XRD spectra of $\mathrm{LiFePO}_{4}$ precursors treated by different microwave

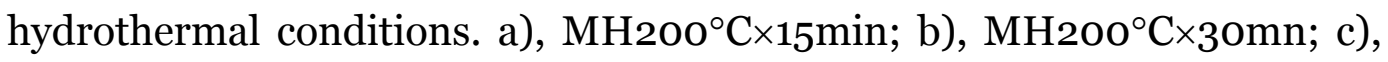
MH2OO ${ }^{\circ} \mathrm{C} \times 45$ min. $v-\mathrm{Li}_{3} \mathrm{PO}_{4} ; \mathrm{x}-\mathrm{LiFePO}_{4}$ 


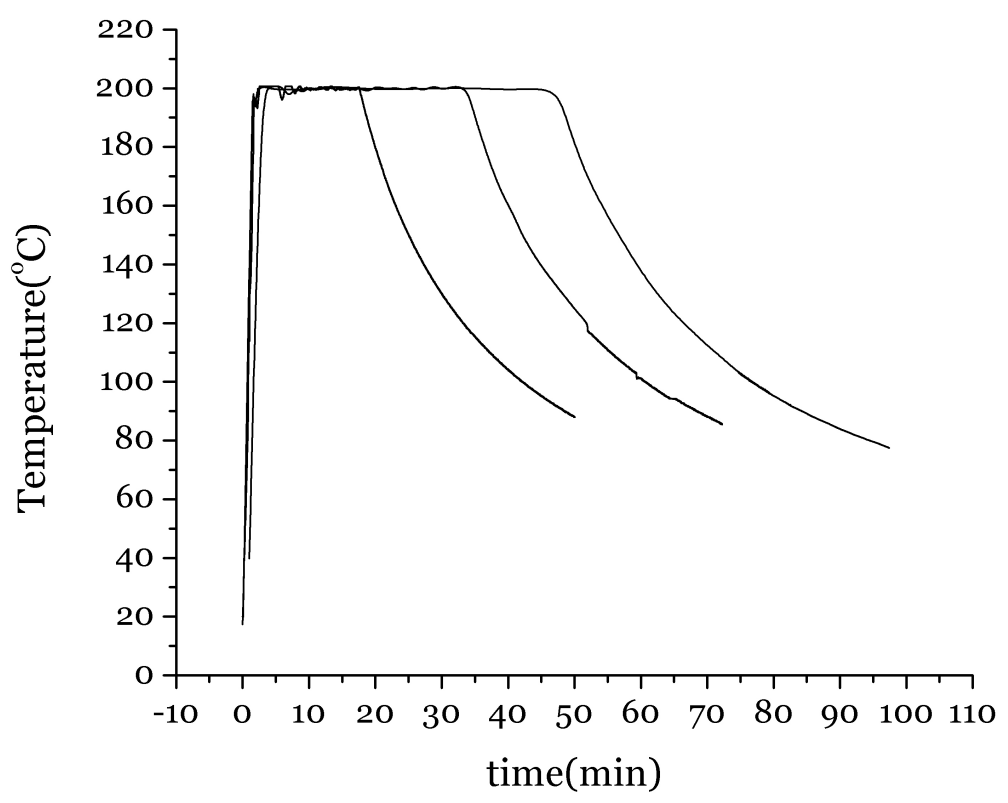

Figure 9, Temperature profiles corresponding to microwave hydrothermal conditions shown in Figure 8. a), $\mathrm{MH}_{200^{\circ}} \mathrm{C} \times 15 \mathrm{~min}$; b), $\mathrm{MH}_{200^{\circ}} \mathrm{C} \times 30 \mathrm{mn}$; c), $\mathrm{MH} 200^{\circ} \mathrm{C} \times 45 \mathrm{~min}$.

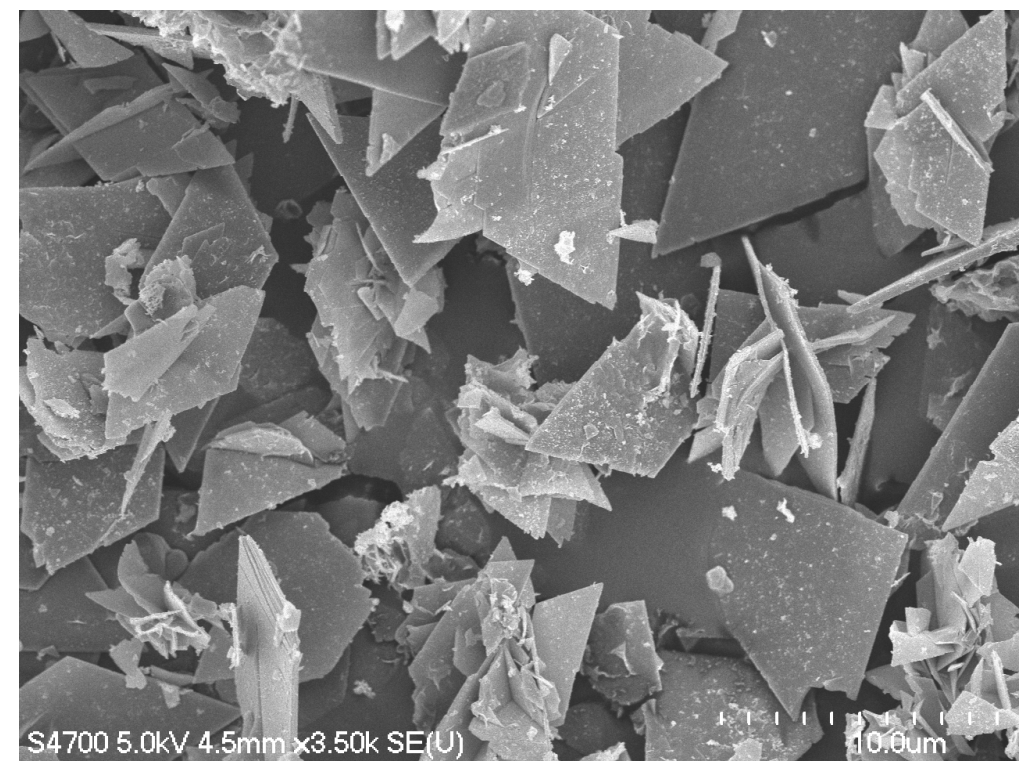

Figure 10, SEM micrograph of the sample obtained from microwave hydrothermal treatment of $\mathrm{LiFePO}_{4}$ precursor at $100^{\circ} \mathrm{C}$ for $1 \mathrm{~min} . \times 3.5 \mathrm{ok}$ magnification 


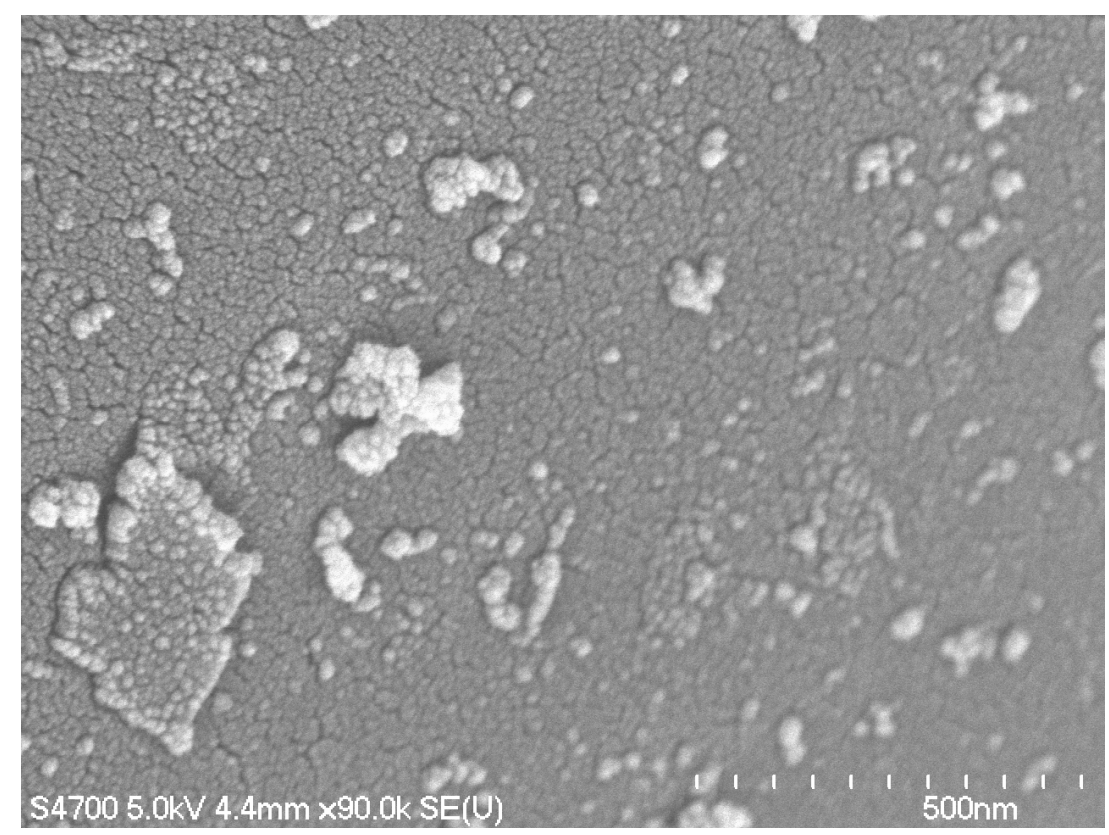

Figure 11, SEM micrograph of a magnified view of a micron sized particle shown in Figure 10. ×90.0k magnification

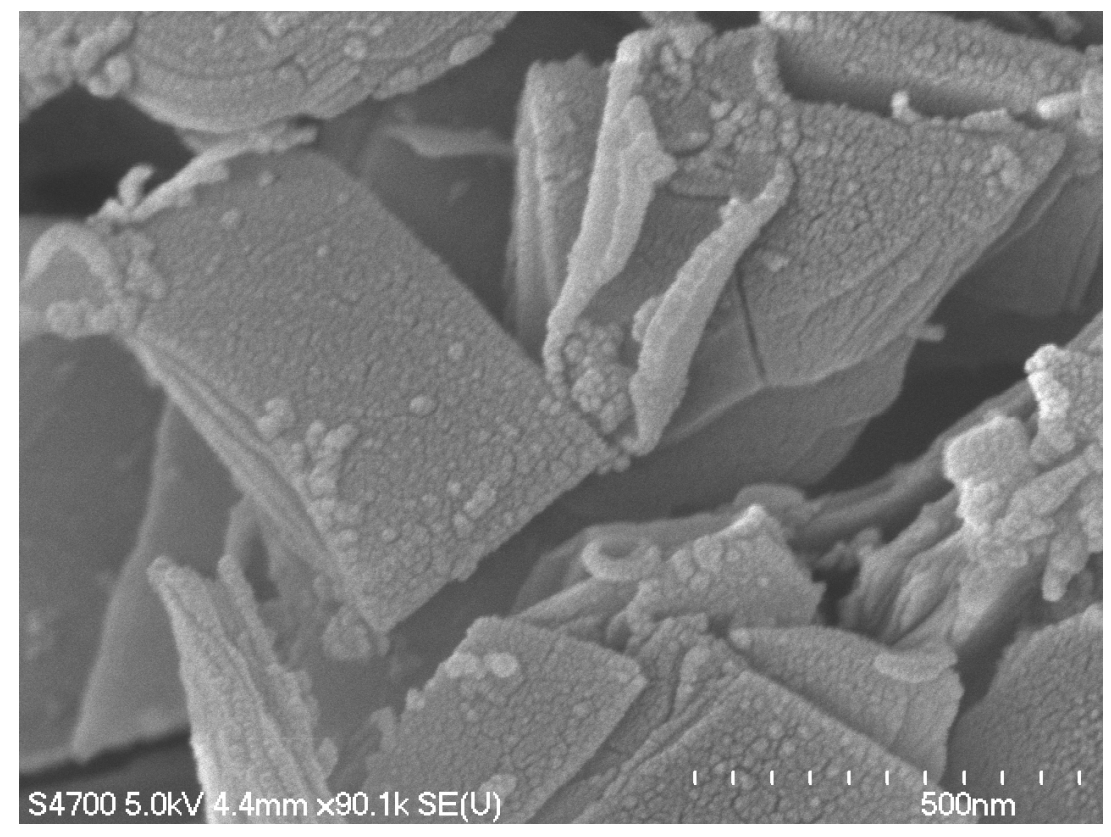

Figure 12, SEM micrograph of a magnified view of a micron sized particle shown in Figure 10. $\times 90.0 k$ magnification 


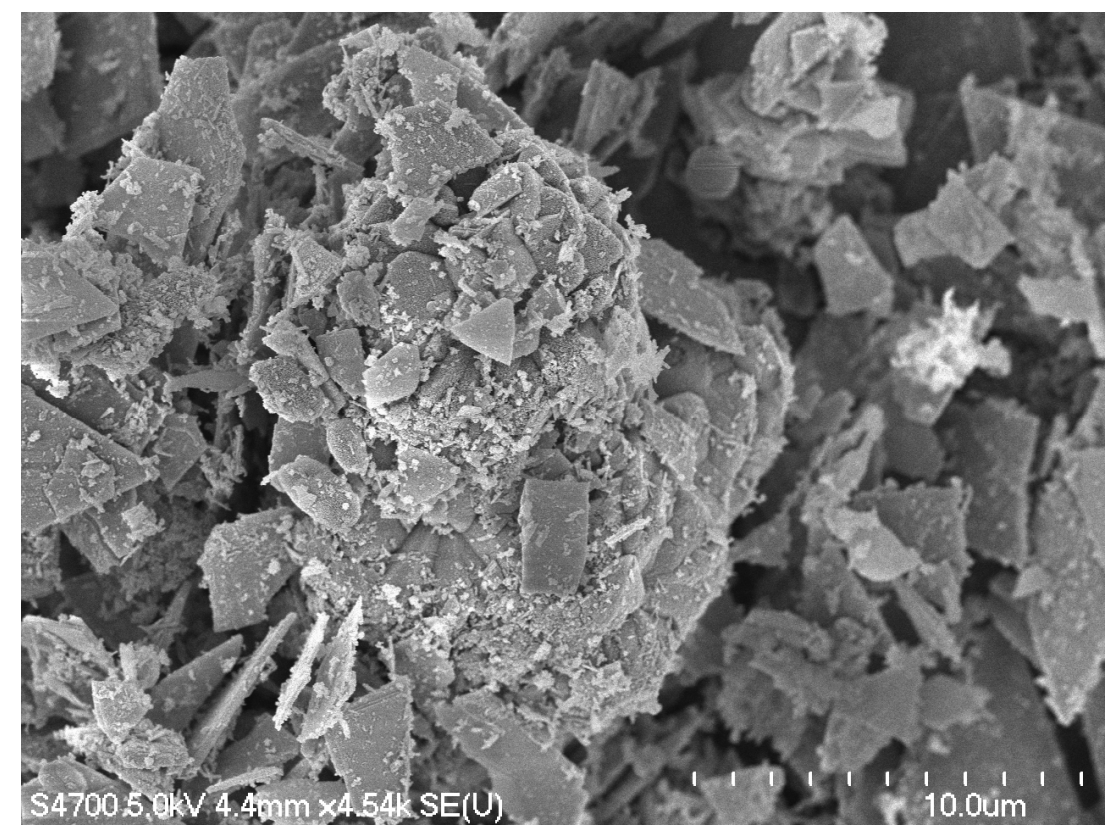

Figure 13, SEM photograph of the sample obtained from microwave hydrothermal treatment of $\mathrm{LiFePO}_{4}$ precursor at $130^{\circ} \mathrm{C}$ for $1 \mathrm{~min} . \times 4.54 \mathrm{k}$ magnification

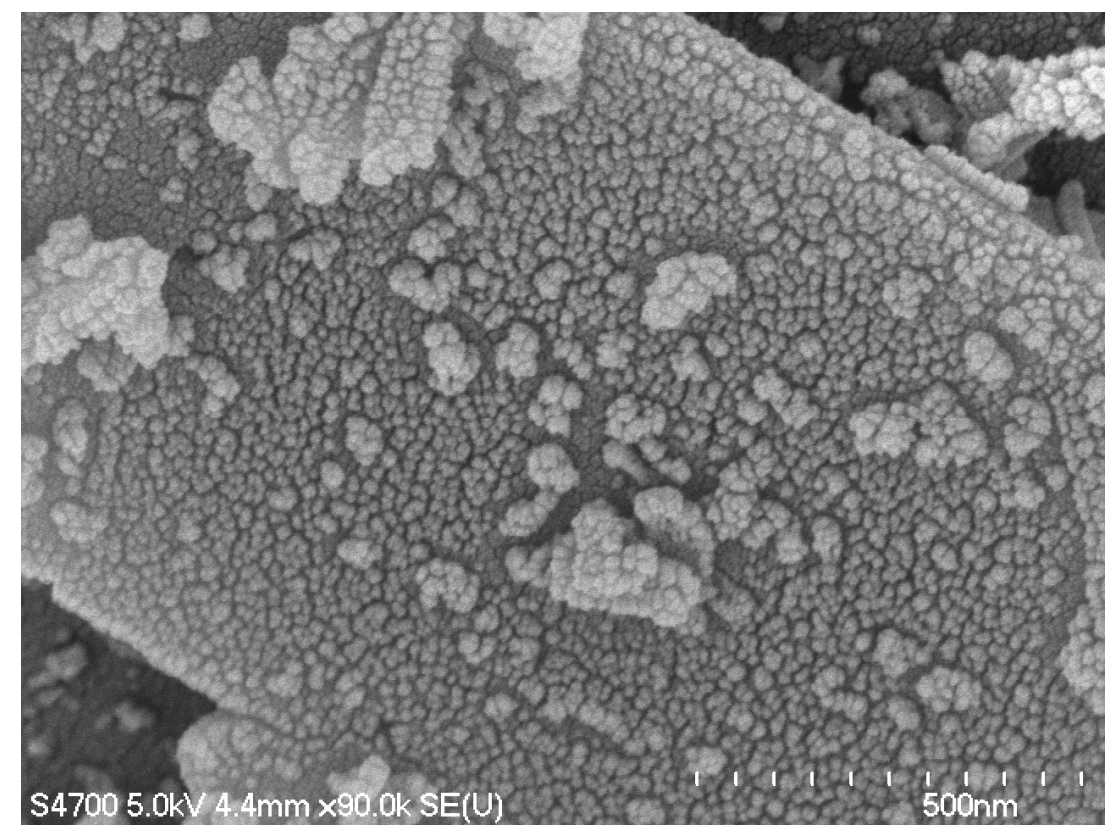

Figure 14, SEM micrograph of a magnified view of a micron sized particle shown in Figure 13. ×90.ok magnification 


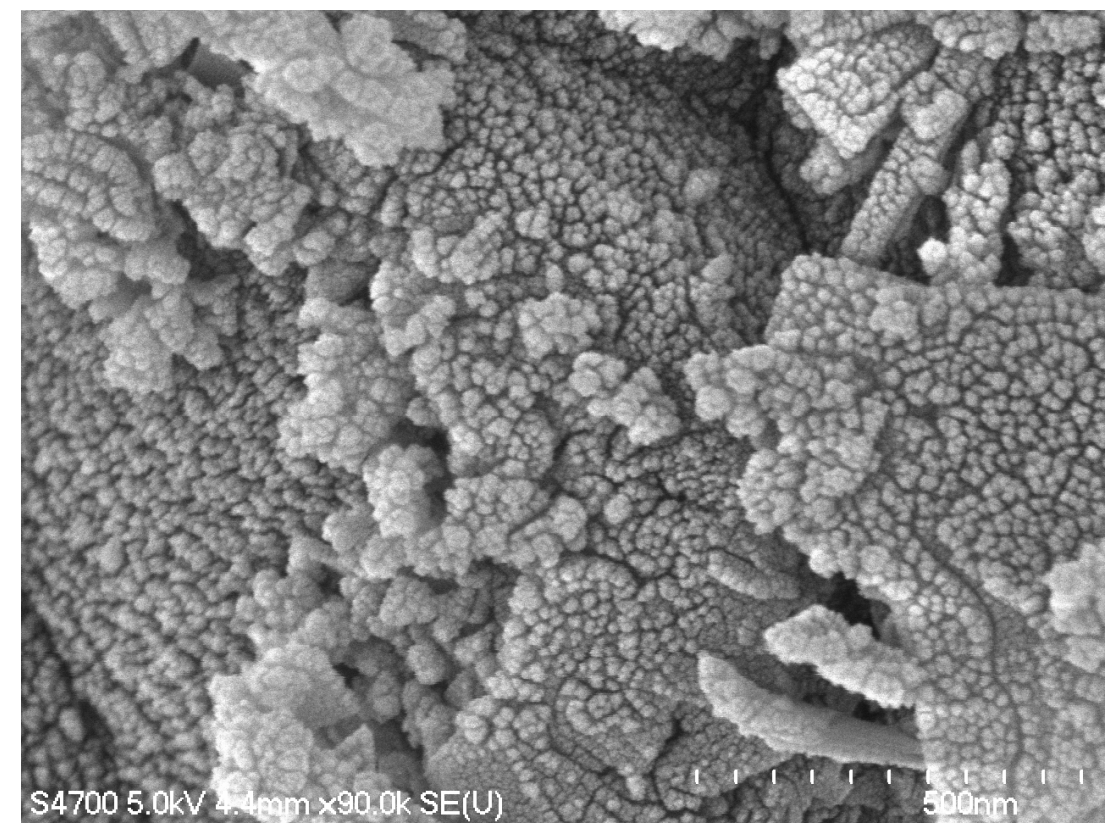

Figure 15, SEM micrograph of a magnified view of a micron sized particle shown in Figure 13. $\times 90.0 k$ magnification

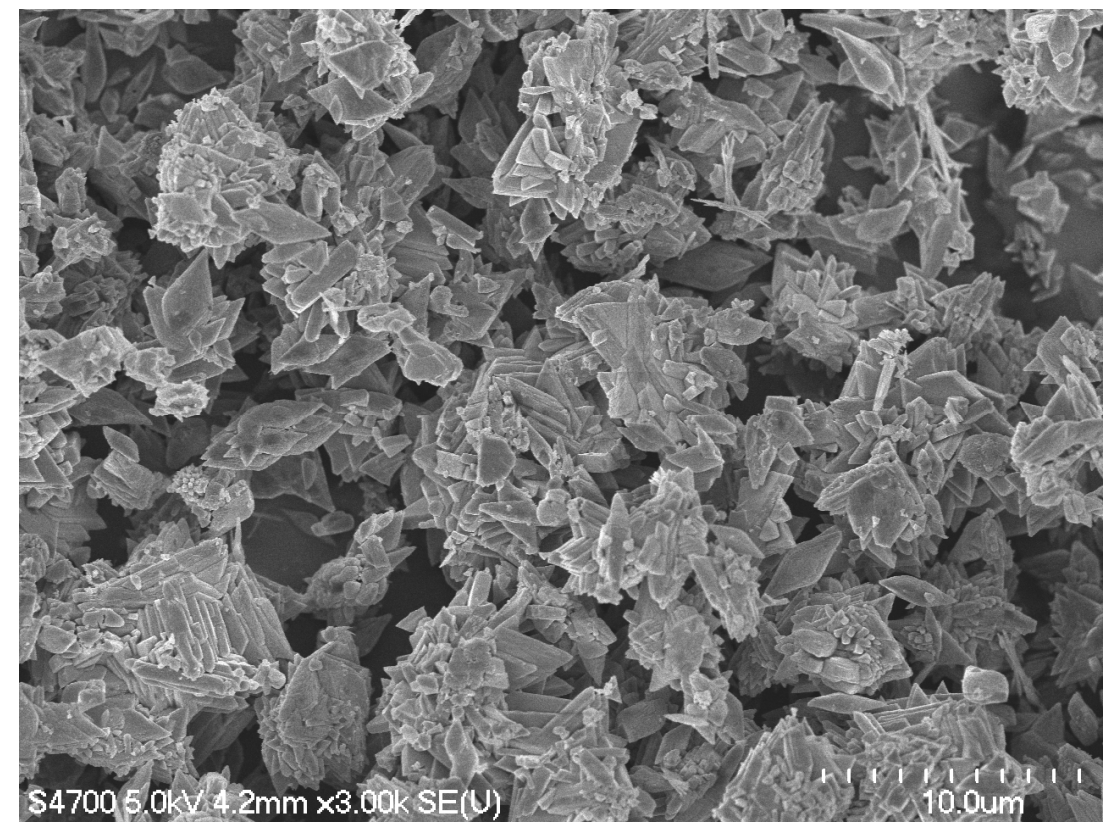

Figure 16, SEM photograph of the sample obtained from microwave hydrothermal treatment of $\mathrm{LiFePO}_{4}$ precursor at $170^{\circ} \mathrm{C}$ for $1 \mathrm{~min} . \times 4.54 \mathrm{k}$ magnification 


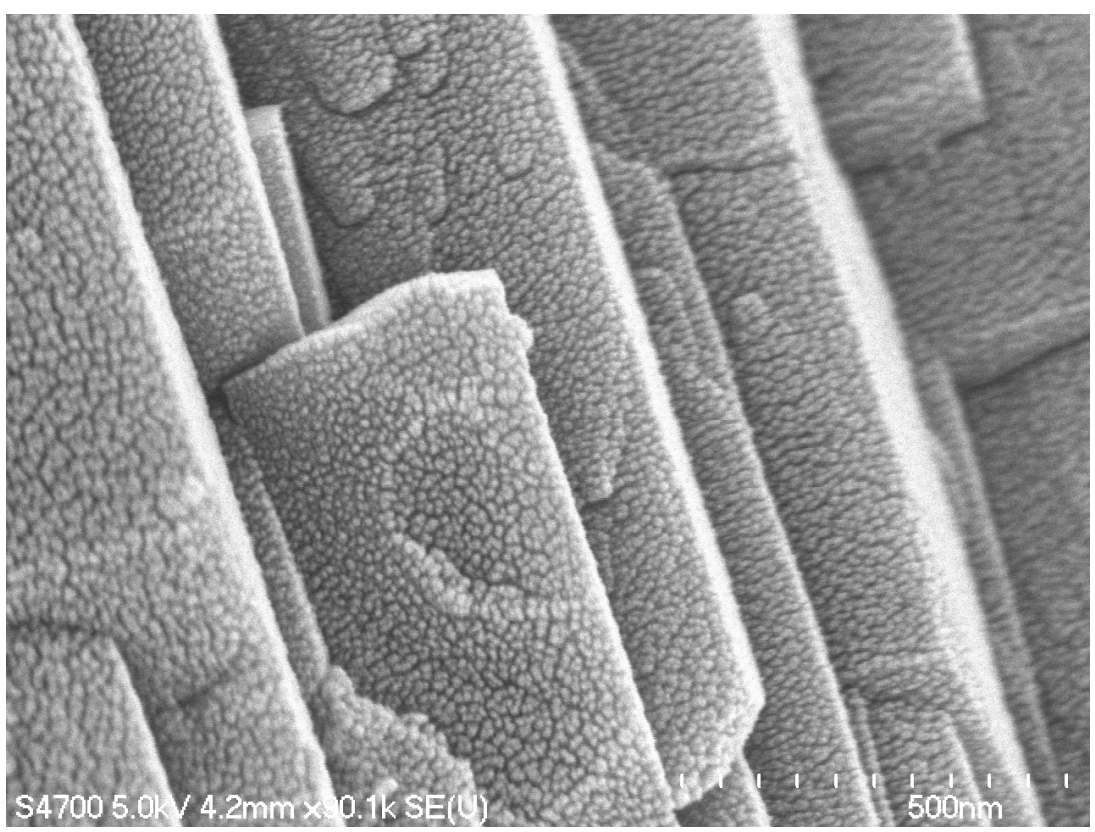

Figure 17, SEM micrograph of a magnified view of a micron sized particle shown in Figure 16. ×90.ok magnification

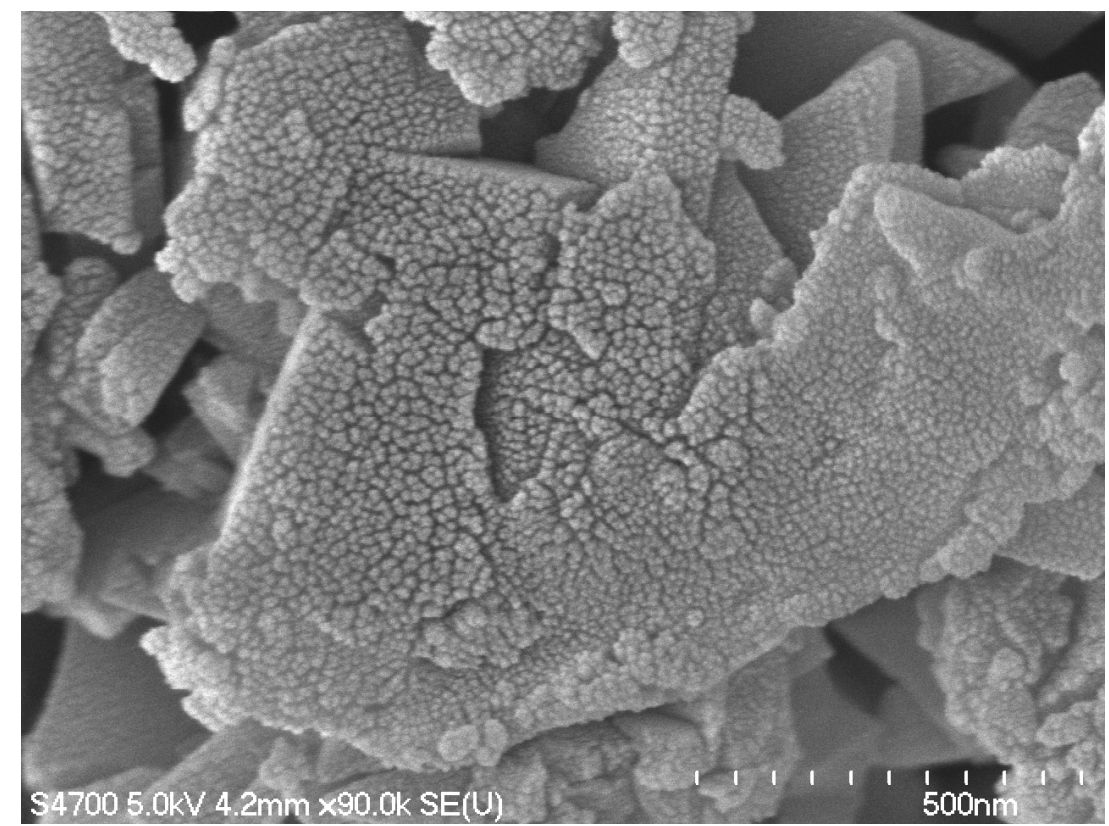

Figure 18, SEM micrograph of a magnified view of a micron sized particle shown in Figure 16. $\times 90.0 k$ magnification 


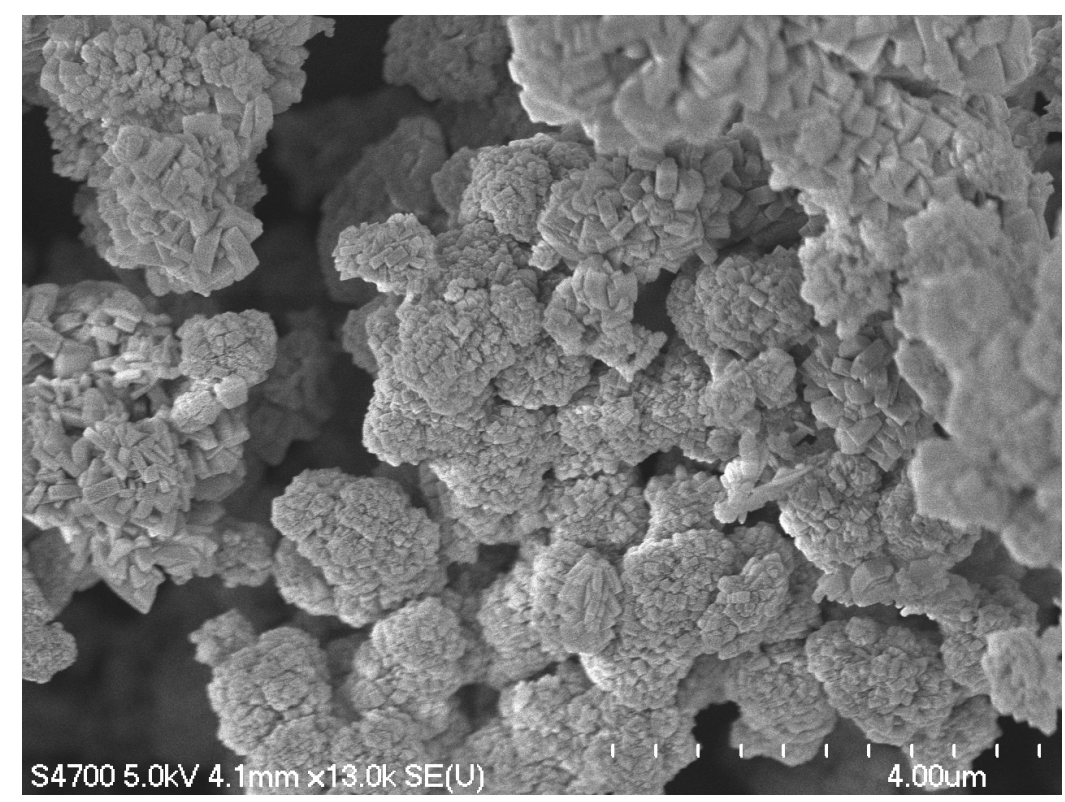

Figure 19, SEM photograph of the sample obtained from microwave hydrothermal treatment of $\mathrm{LiFePO}_{4}$ precursor at $200^{\circ} \mathrm{C}$ for $1 \mathrm{~min} . \times 13.0 \mathrm{k}$ magnification

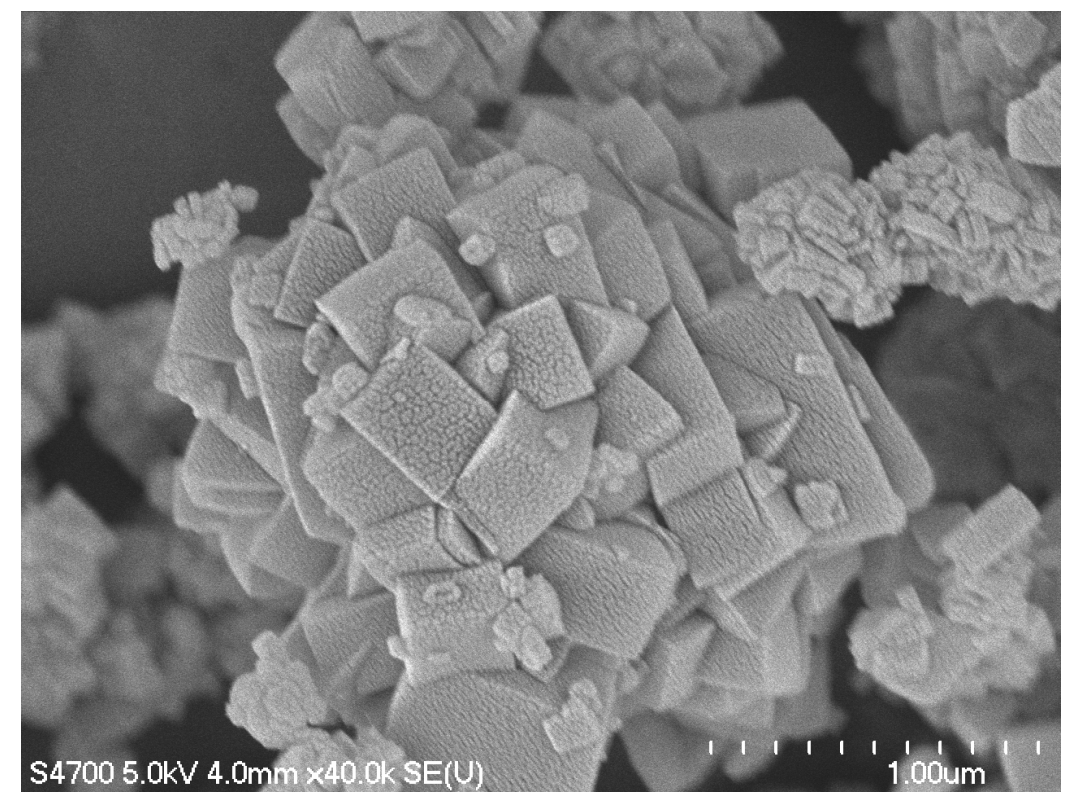

Figure 20, SEM photograph of the sample obtained from microwave hydrothermal treatment of $\mathrm{LiFePO}_{4}$ precursor at $200^{\circ} \mathrm{C}$ for $1 \mathrm{~min} . \times 40.0 \mathrm{k}$ magnification 


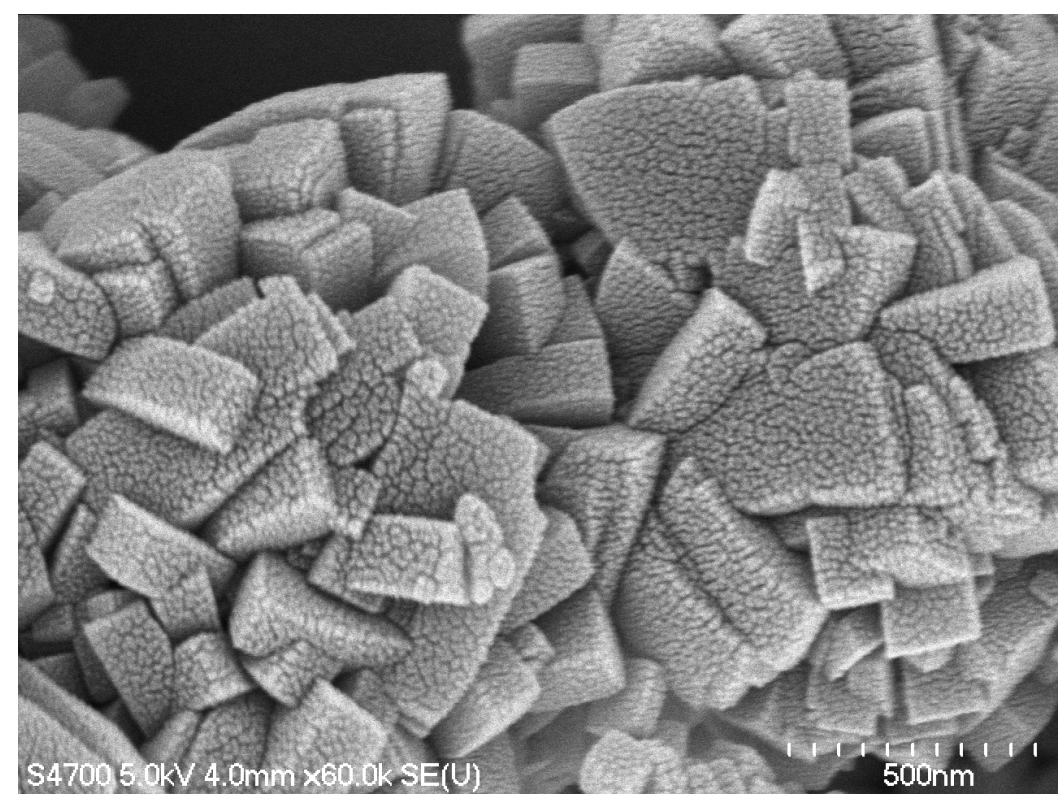

Figure 21, SEM photograph of the sample obtained from microwave hydrothermal treatment of $\mathrm{LiFePO}_{4}$ precursor at $200^{\circ} \mathrm{C}$ for $1 \mathrm{~min} . \times 60.0 \mathrm{k}$ magnification

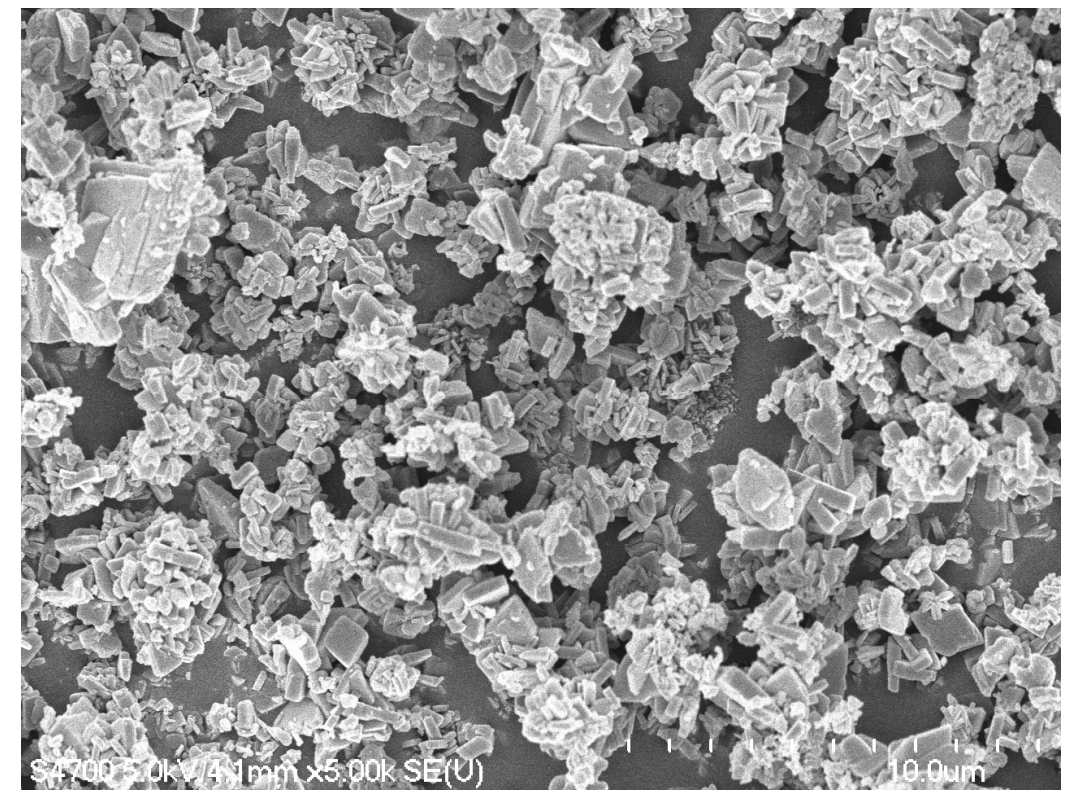

Figure 22, SEM photograph of the sample obtained from microwave hydrothermal treatment of $\mathrm{LiFePO}_{4}$ precursor at $200^{\circ} \mathrm{C}$ for $15 \mathrm{~min} . \times 5 . \mathrm{ok}$ magnification 


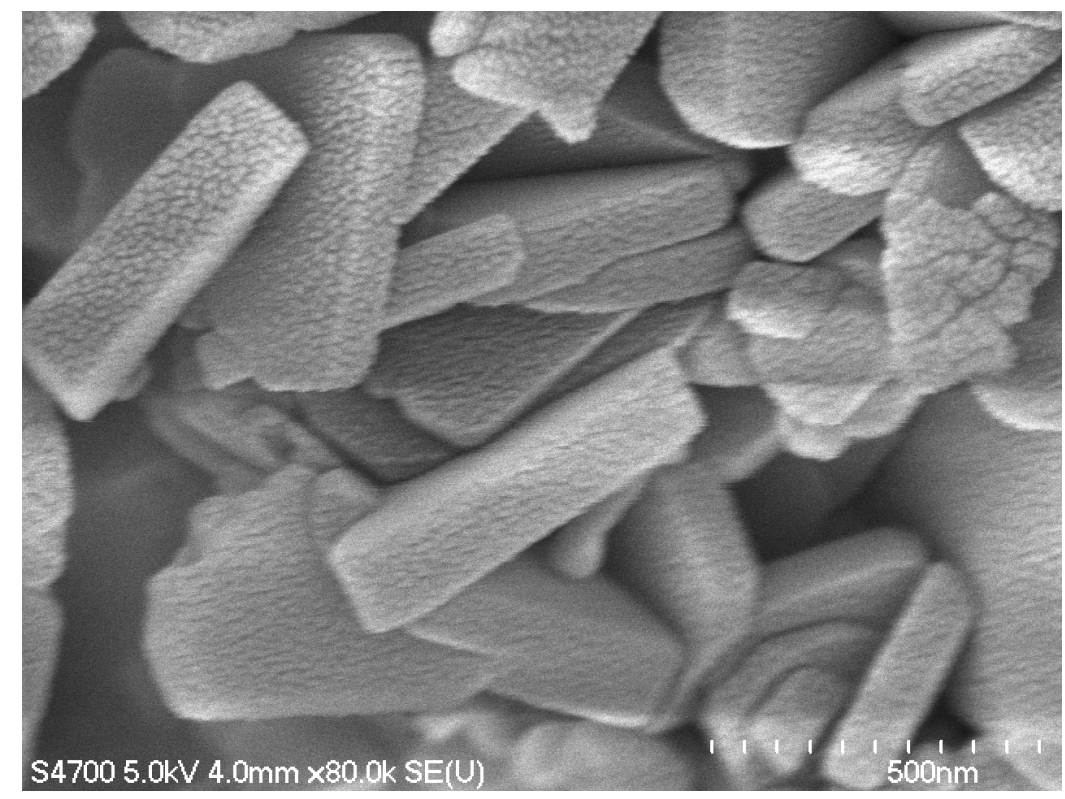

Figure 23, SEM photograph of the sample obtained from microwave hydrothermal treatment of $\mathrm{LiFePO}_{4}$ precursor at $200^{\circ} \mathrm{C}$ for $15 \mathrm{~min} . \times 80 . \mathrm{ok}$ magnification

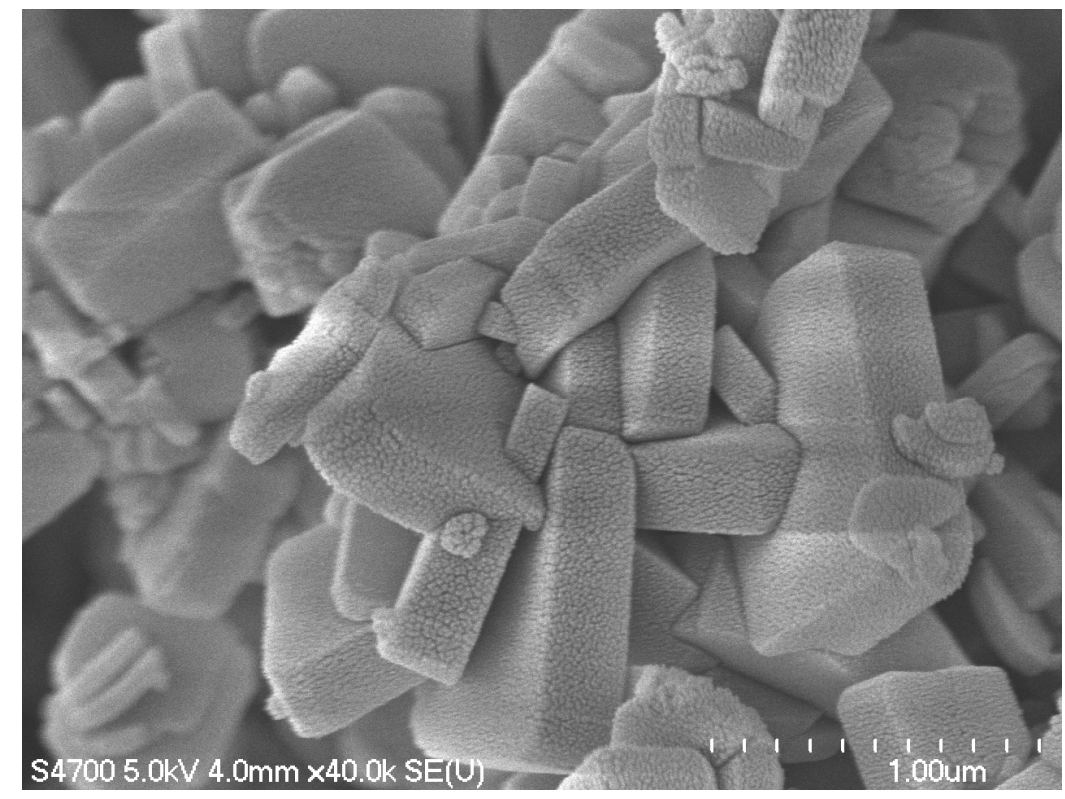

Figure 24, SEM photograph of the sample obtained from microwave hydrothermal treatment of $\mathrm{LiFePO}_{4}$ precursor at $200^{\circ} \mathrm{C}$ for $15 \mathrm{~min} . \times 80.0 \mathrm{k}$ magnification 


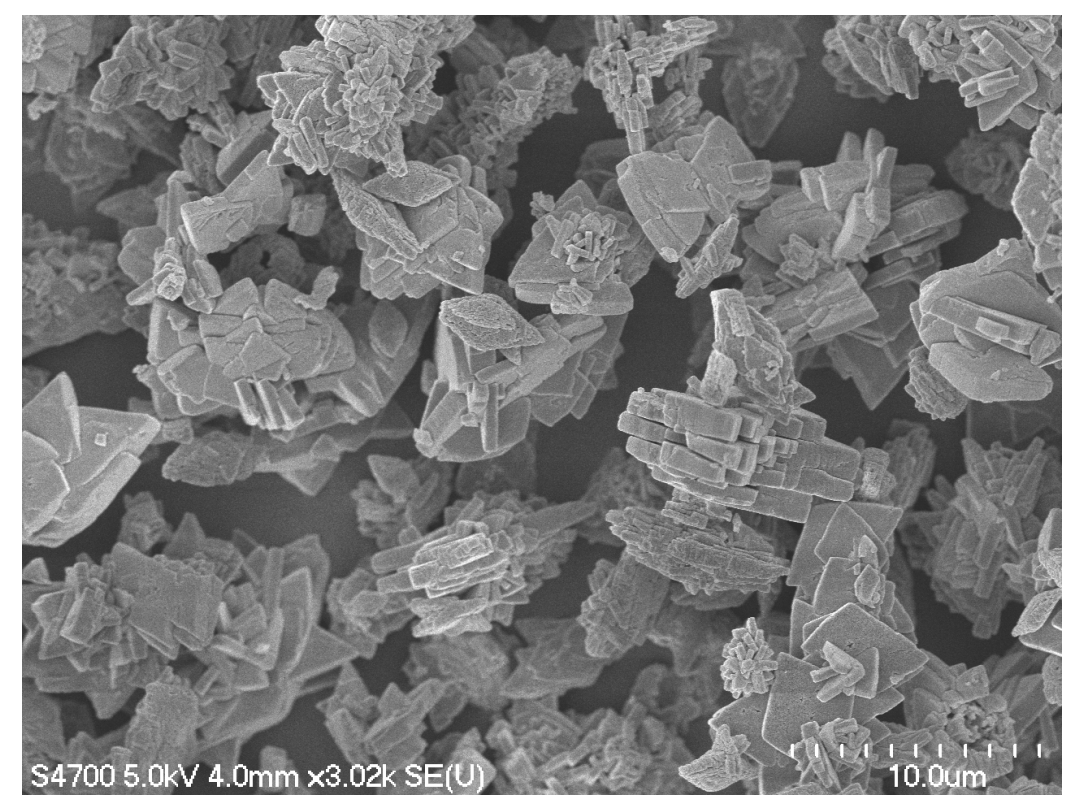

Figure 25, SEM photograph of the sample obtained from microwave hydrothermal treatment of $\mathrm{LiFePO}_{4}$ precursor at $200^{\circ} \mathrm{C}$ for $30 \mathrm{~min} . \times 3.02 \mathrm{k}$ magnification

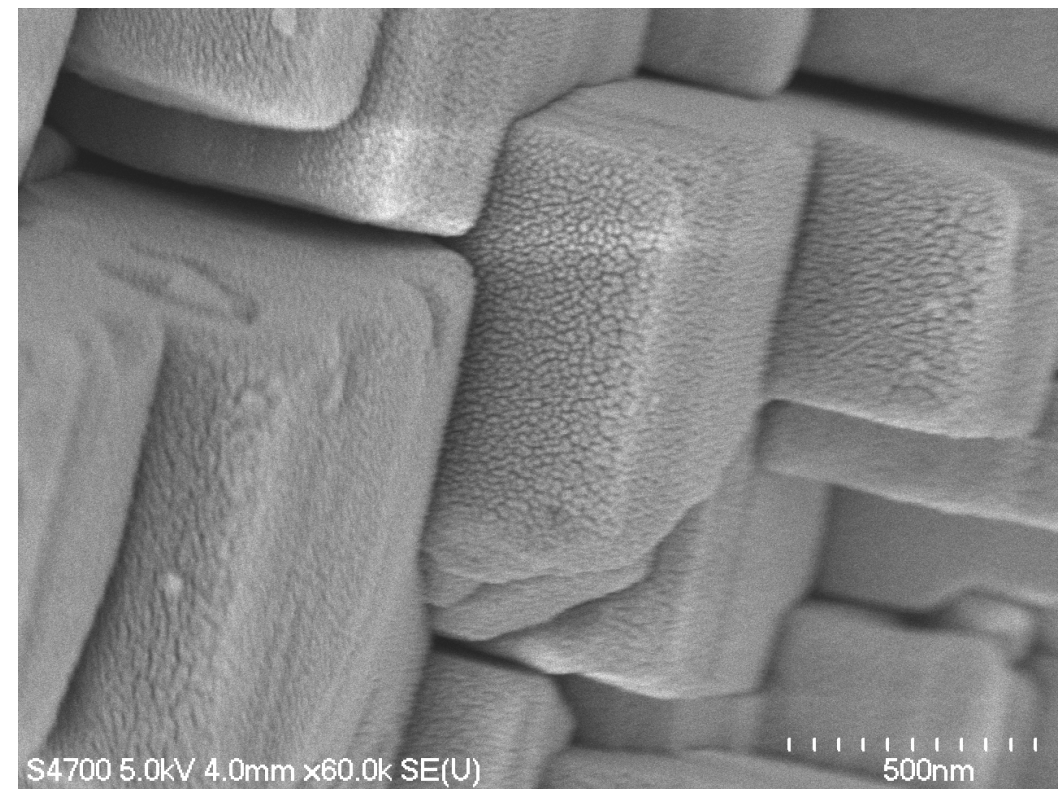

Figure 26, SEM photograph of the sample obtained from microwave hydrothermal treatment of $\mathrm{LiFePO}_{4}$ precursor at $200^{\circ} \mathrm{C}$ for $30 \mathrm{~min}$. $\times 60.0 k$ magnification 


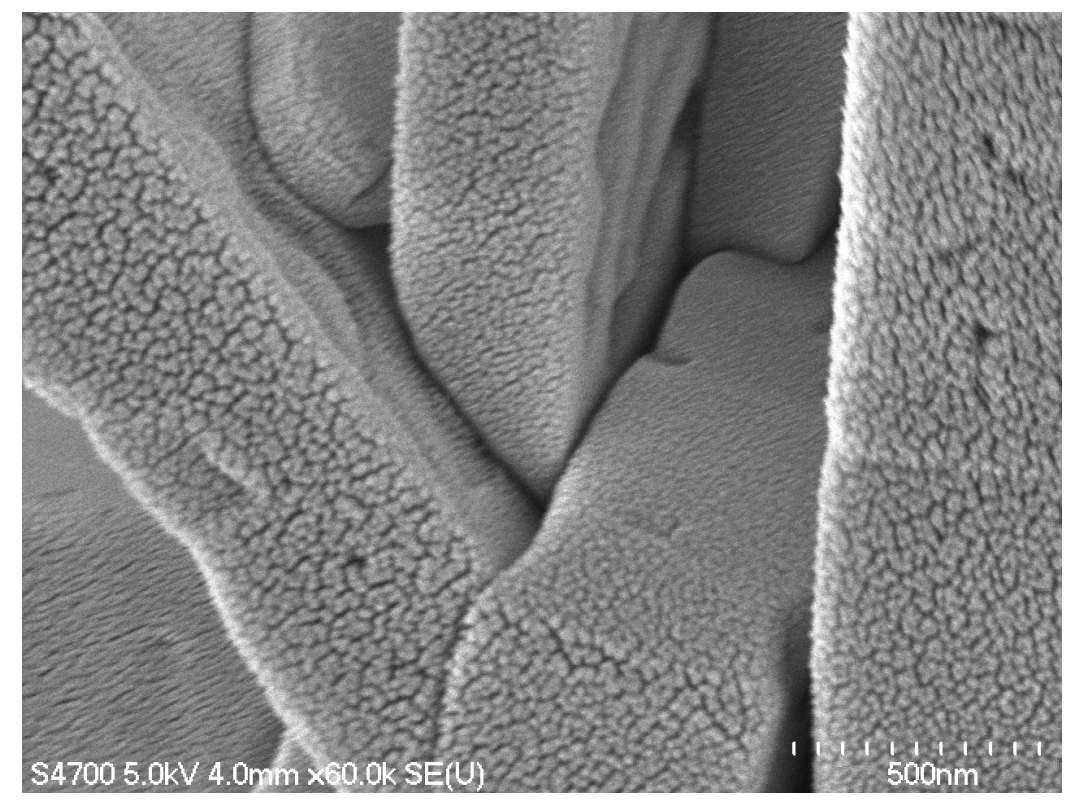

Figure 27, SEM photograph of the sample obtained from microwave hydrothermal treatment of $\mathrm{LiFePO}_{4}$ precursor at $200^{\circ} \mathrm{C}$ for $30 \mathrm{~min}$. $\times 60.0 k$ magnification

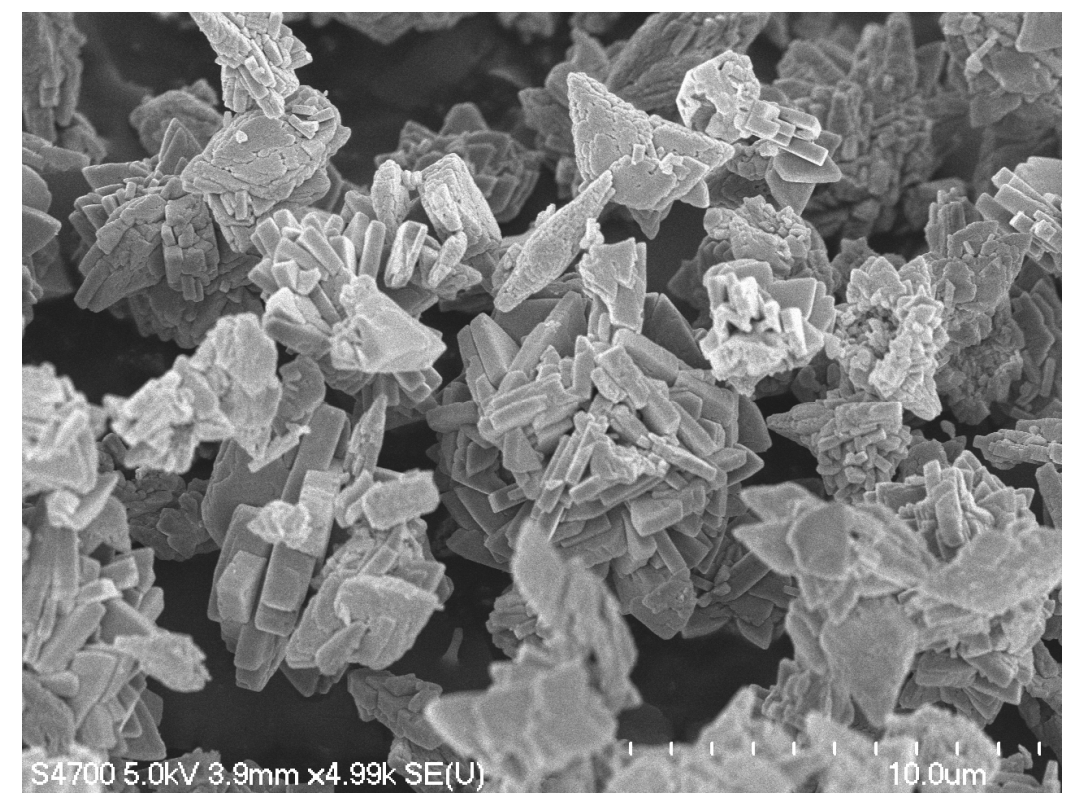

Figure 28, SEM photograph of the sample obtained from microwave hydrothermal treatment of $\mathrm{LiFePO}_{4}$ precursor at $200^{\circ} \mathrm{C}$ for $45 \mathrm{~min} . \times 60 . \mathrm{ok}$ magnification 


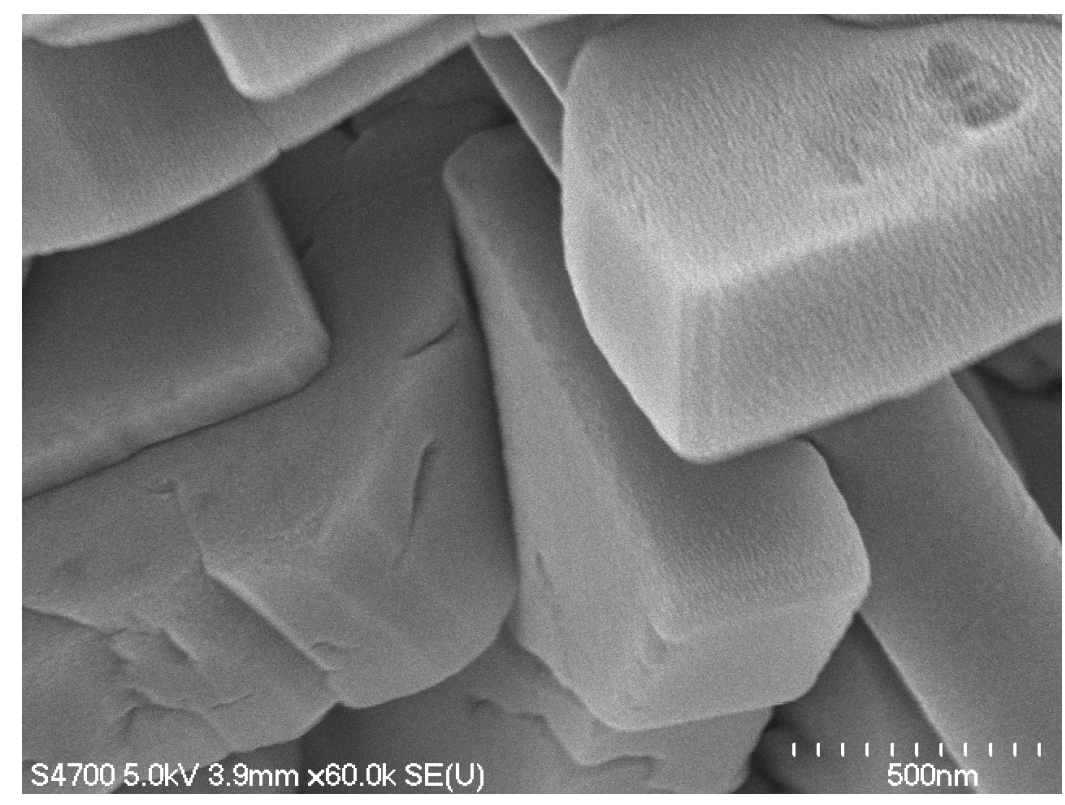

Figure 29, SEM photograph of the sample obtained from microwave hydrothermal treatment of $\mathrm{LiFePO}_{4}$ precursor at $200^{\circ} \mathrm{C}$ for $45 \mathrm{~min} . \times 60.0 \mathrm{k}$ magnification

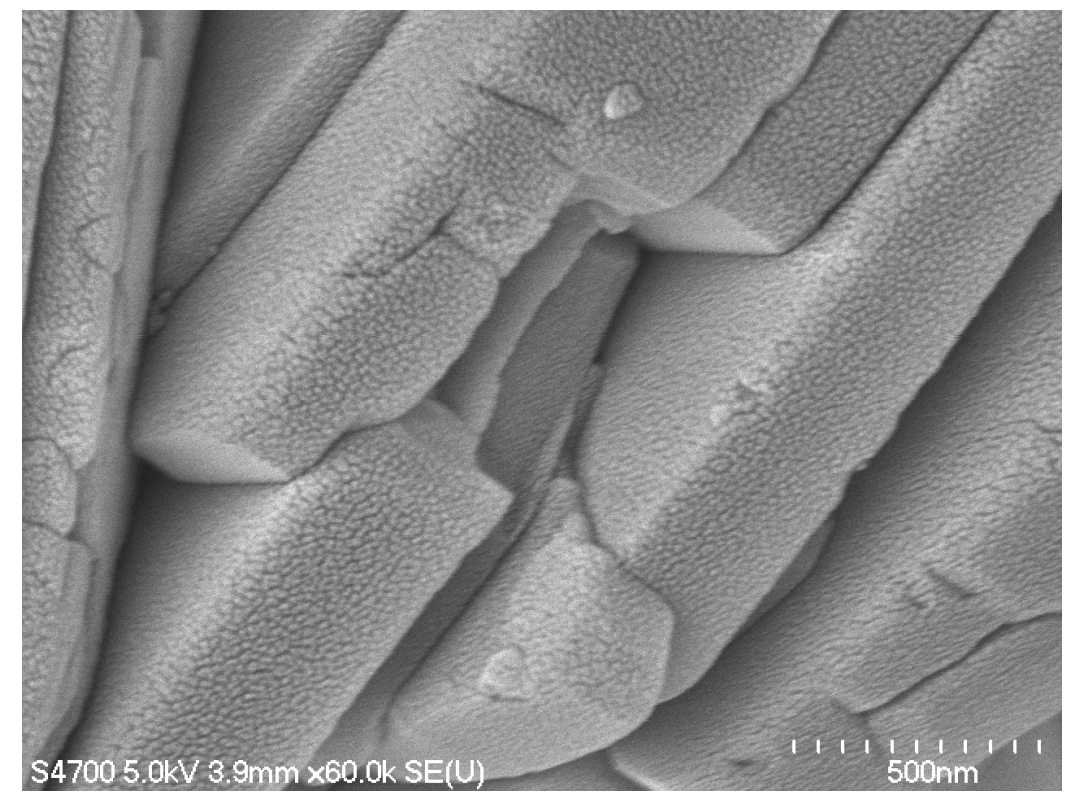

Figure 30, SEM photograph of the sample obtained from microwave hydrothermal treatment of $\mathrm{LiFePO}_{4}$ precursor at $200^{\circ} \mathrm{C}$ for $45 \mathrm{~min} . \times 60 . \mathrm{ok}$ magnification 


\section{Discussion}

\section{1 $\mathrm{LiFePO}_{4}$ precursor}

Making $\mathrm{LiFePO}_{4}$ precursor is the first step for synthesis of $\mathrm{LiFePO}_{4}$ powders via hydrothermal approach. The precursor is usually made by means of precipitation from mixed solutions of Lithium, iron and phosphor compounds. In many cases, the related compounds are $\mathrm{LiOH}, \mathrm{FeSO}_{4}$ and $\mathrm{H}_{3} \mathrm{PO}_{4}$ that are mixed together in form of aqueous solution.

Although there are a number of publications reporting hydrothermal synthesis of $\mathrm{LiFePO}_{4}$, few of them ever discussed the nature of the precursor. Generally, it is simply mentioned as "precipitates", "grey cream", or "solid stuff". However, a better understanding of the nature of the precursor is very helpful for understanding of the $\mathrm{LiFePO}_{4}$ formation mechanism.

By deductive method, we could list all of the possible precursor formation reactions:

$$
\text { 1), } \mathrm{LiOH}+\mathrm{FeSO}_{4}+\mathrm{H}_{3} \mathrm{PO}_{4}=\mathrm{LiFePO}_{4}+\mathrm{H}_{2} \mathrm{SO}_{4}+\mathrm{H}_{2} \mathrm{O}
$$

When the $\mathrm{LiOH}, \mathrm{FeSO}_{4}$ and $\mathrm{H}_{3} \mathrm{PO}_{4}$ is in 3:1:1 molar ratio, the reaction is

$$
3 \mathrm{LiOH}+\mathrm{FeSO}_{4}+\mathrm{H}_{3} \mathrm{PO}_{4}=\mathrm{LiFePO}_{4}+\mathrm{Li}_{2} \mathrm{SO}_{4}+3 \mathrm{H}_{2} \mathrm{O}
$$

If this is the case, the precursor should be only $\mathrm{LiFePO}_{4} \cdot \mathrm{Li}_{2} \mathrm{SO}_{4}$ cannot be co-precipitated into the precursor, because of its high solubility. At $25^{\circ} \mathrm{C}$, the solubility of $\mathrm{Li}_{2} \mathrm{SO}_{4}$ in water is $34 . \mathrm{g} / 100 \mathrm{ml}$ (69). It means that the saturated molar concentration of $\mathrm{Li}_{2} \mathrm{SO}_{4}$ is approximately $3.2 \mathrm{M}$. In the synthesis experiment, however, the $\mathrm{FeSO}_{4}$ concentration is only about $0.1 \mathrm{M}$ that is too low for the $\mathrm{Li}_{2} \mathrm{SO}_{4}$ to precipitate.

2), $3 \mathrm{LiOH}+3 \mathrm{FeSO}_{4}+3 \mathrm{H}_{3} \mathrm{PO}_{4}=\mathrm{Fe}_{3}\left(\mathrm{PO}_{4}\right)_{2}+\mathrm{Li}_{3} \mathrm{PO}_{4}+3 \mathrm{H}_{2} \mathrm{SO}_{4}+3 \mathrm{H}_{2} \mathrm{O}$ 
If this is the case, the precursor should be a mixture of $\mathrm{Fe}_{3}\left(\mathrm{PO}_{4}\right)_{2}$ and $\mathrm{LiP}_{3} \mathrm{O}_{4}$. The solubility of $\mathrm{Li}_{3} \mathrm{PO}_{4}$ in water is $0.039 \mathrm{wt} \%$ at $20^{\circ} \mathrm{C}(70)$ that means the saturated concentration of $\mathrm{Li}_{3} \mathrm{PO}_{4}$ is about $0.0035 \mathrm{M}$. The solubility of $\mathrm{Fe}_{3}\left(\mathrm{PO}_{4}\right)_{2}$ is not available, but it can be deduced from its solubility product of $\left[\mathrm{Fe}^{2+}\right] 3 \cdot\left[\mathrm{PO}_{4}^{3-}\right]^{2}$, which is $1.0 \times 10^{-36}(71)$. From this number, we can calculate that the saturated concentration of $\mathrm{Fe}_{3}\left(\mathrm{PO}_{4}\right)_{2}$ is about $2.47 \times 10^{-8} \mathrm{M}$. Such low solubility makes it possible for $\mathrm{Li}_{3} \mathrm{PO}_{4}$ and $\mathrm{Fe}_{3}\left(\mathrm{PO}_{4}\right)_{2}$ to precipitate.

3), $3 \mathrm{LiOH}+\mathrm{FeSO}_{4}+\mathrm{H}_{3} \mathrm{PO}_{4}=\mathrm{Fe}(\mathrm{OH})_{2}+\mathrm{Li}_{3} \mathrm{PO}_{4}+\mathrm{H}_{2} \mathrm{SO}_{4}+\mathrm{H}_{2} \mathrm{O}$

If this is the case, the precursor is a mixture of $\mathrm{Fe}(\mathrm{OH})_{2}$ and $\mathrm{Li}_{3} \mathrm{PO}_{4}$. The possibility lies on the low solubility of $\mathrm{Li}_{3} \mathrm{PO}_{4}$ and $\mathrm{Fe}(\mathrm{OH})_{2}$. The solubility product of $\mathrm{Fe}(\mathrm{OH})_{2}$ is $7.9 \times 1 \mathrm{O}^{-15}$ (72), from which the saturated concentration is calculated as $1.25 \times 10^{-5} \mathrm{M}$.

Experimental observation indicates that the as-precipitated precursor is not a single compound but a mixture. If it were a single-compound precursor, we would have seen all of the precipitated particles in a single color. However, particles of two colors were seen in the precipitates when set the precipitates in mother liquor for a few minutes. The reported "grey cream" was just seen when the precipitates and the mother liquor were stirred. The non-single colored precipitates means there were at least two compounds in the precipitated precursor.

The precipitation of $\mathrm{LiFePO}_{4}$ is excluded in the precursor by experiment observation. If it were in the precursor, we would have seen it in the XRD pattern of samples by microwave hydrothermal treatment at intermediate temperatures. However, as indicated in Figure 4, the samples treated at $100^{\circ} \mathrm{C}$ and $130^{\circ} \mathrm{C}$ only have $\mathrm{Fe}_{3}\left(\mathrm{PO}_{4}\right)_{2}$ and $\mathrm{Li}_{3} \mathrm{PO}_{4}$ in the XRD pattern. The pattern of $\mathrm{LiFePO}_{4}$ is seen 
from samples treated at above $170^{\circ} \mathrm{C}$ (Figure 4 and Figure 6). It is hard to imagine that $\mathrm{LiFePO}_{4}$ exists in the as precipitated precursor but dissolved at intermediate temperature, and comes back at higher temperatures.

The precipitation of $\mathrm{Fe}(\mathrm{OH})_{2}$ from $\mathrm{LiOH}-\mathrm{FeSO}_{4}-\mathrm{H}_{3} \mathrm{PO}_{4}$ solution under conditions of this study is excluded by analytical calculation as described in Appendix A. Briefly the incapability of $\mathrm{Fe}(\mathrm{OH})_{2}$ to precipitate is due to the lack of sufficient $\mathrm{OH}^{-}$ions in the solution. Table A2 gives the $\mathrm{H}^{+}$concentration in a series of $\mathrm{H}_{3} \mathrm{PO}_{4}$ solutions. As the $\mathrm{H}_{3} \mathrm{PO}_{4}$ concentration varies from $0.01 \mathrm{M}$ to $0.2 \mathrm{M}$, the $\mathrm{H}^{+}$ concentration changes from $5.629 \times 10^{-3} \mathrm{M}$ to $3.463 \times 10^{-2} \mathrm{M}$. To the acidic solution, addition of $\mathrm{FeSO}_{4}$ solution would not result in $\mathrm{Fe}(\mathrm{OH})_{2}$ precipitation. It can be seen more explicitly from Table $\mathrm{A6}$, which shows the $\mathrm{H}^{+}$concentration and the concentration product of $\left[\mathrm{Fe}^{2+}\right]$ and $\left[\mathrm{OH}^{-}\right]^{2}$ in equimolar concentration of $\mathrm{FeSO}_{4}^{-}$ $\mathrm{H}_{3} \mathrm{PO}_{4}$ solutions. The table indicates that the solution is also acidic. The

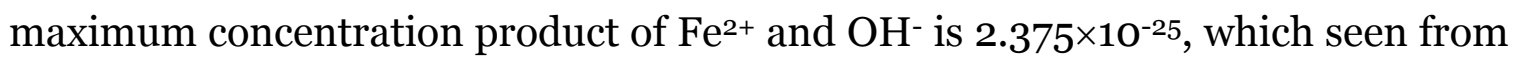
$0.2 \mathrm{M} \mathrm{FeSO}_{4}-0.2 \mathrm{M} \mathrm{H}_{3} \mathrm{PO}_{4}$ solution. It is much smaller than the solubility product of $\mathrm{Fe}(\mathrm{OH})_{2}, 7.9 \times 10^{-15}(72)$.

It was speculated that addition of $\mathrm{LiOH}$ into the $\mathrm{FeSO}_{4}-\mathrm{H}_{3} \mathrm{PO}_{4}$ might cause $\mathrm{Fe}(\mathrm{OH})_{2}$ precipitation. But the speculation is not supported by the calculation. Refer to Table A6. In a $0.15 \mathrm{M}$ FeSO4-0.15M $\mathrm{H}_{3} \mathrm{PO}_{4}$ solution, the $\mathrm{Fe}^{2+}$ concentration is $0.15 \mathrm{M}$, which requires $2.29 \times 10^{-7} \mathrm{M}$ of $\mathrm{OH}^{-}$to start precipitation of $\mathrm{Fe}(\mathrm{OH})_{2}$. However, the added $\mathrm{OH}^{-}$would be neutralized by $\mathrm{H}^{+}$in preference. Because the $\mathrm{H}^{+}$concentration in the said solution is $8.33 \times 10^{-3} \mathrm{M}$, starting the neutralization of $\mathrm{H}^{+}$by $\mathrm{OH}^{-}$only needs $1.20 \times 10^{-11} \mathrm{M}^{-} \mathrm{OH}^{-} . \mathrm{H}_{3} \mathrm{PO}_{4}$ is a weak acid. Neutralization of the $\mathrm{H}^{+}$by $\mathrm{LiOH}$ addition causes further dissociation of $\mathrm{H}_{3} \mathrm{PO}_{4}$, releasing additional $\mathrm{H}^{+}$that consumes the additional $\mathrm{OH}^{-}$. Furthermore, dissociation of $\mathrm{H}_{3} \mathrm{PO}_{4}$ releases more of $\mathrm{PO}_{4^{3-}}$ that could cause precipitation of $\mathrm{Fe}_{3}\left(\mathrm{PO}_{4}\right)_{2}$ before $\mathrm{Fe}(\mathrm{OH})_{2}$ can precipitate. 
Table A12 illustrates the precipitation preference in an $x \mathrm{M} \mathrm{LiOH-o.1M} \mathrm{FeSO}_{4}$ $0.1 \mathrm{M} \mathrm{H}_{3} \mathrm{PO}_{4}$ solution ( $\mathrm{x}=0.05$ to $0.17 \mathrm{M}$ ). It can be seen from the table that the concentration products of $\mathrm{Fe}(\mathrm{OH})_{2}$ are all much smaller than the solubility products as the add-in concentration of $\mathrm{LiOH}$ varies from $0.05 \mathrm{M}$ to $0.16 \mathrm{M}$. As the add-in concentration of $\mathrm{LOH}$ increased to $0.16 \mathrm{M}$, the total $\mathrm{Fe}^{2+}$ species in the solution falls down to below $1.12 \times 10^{-8} \mathrm{M}$. it means that further increase of the $\mathrm{LiOH}$ would not be able to cause any appreciable precipitation of $\mathrm{Fe}(\mathrm{OH})_{2}$.

$\mathrm{Fe}_{3}\left(\mathrm{PO}_{4}\right)_{2}$ should be the major species in the as-precipitated precursor. The precipitation cannot take place in $x \mathrm{M} \mathrm{FeSO}_{4}-x \mathrm{M} \mathrm{H}_{3} \mathrm{PO}_{4}$ when $x$ is smaller than 0.15. This is due to the insufficient concentration of $\mathrm{PO}_{4^{3-}}$ species dissociated from $\mathrm{H}_{3} \mathrm{PO}_{4}$. As shown in Table A6, the concentration products of $\mathrm{Fe}^{2+}$ and $\mathrm{PO}_{4}{ }^{3-}$ are all smaller than the solubility product of $\mathrm{Fe}_{3}\left(\mathrm{PO}_{4}\right)_{2}, 1.0 \times 10^{-3} 36$, when the addin concentrations of $\mathrm{FeSO}_{4}$ and $\mathrm{H}_{3} \mathrm{PO}_{4}$ are less than $0.15 \mathrm{M}$. However, as $\mathrm{LiOH}$ is added into the solution, the neutralization of $\mathrm{H}^{+}$with $\mathrm{OH}^{-}$causes more dissociation of $\mathrm{H}_{3} \mathrm{PO}_{4}$ and generates more $\mathrm{PO}_{4}{ }^{3-}$. The concentration product of $\mathrm{Fe}^{2+}$ and $\mathrm{PO}_{4}{ }^{3-}$ reaches the solubility product of $\mathrm{Fe}_{3}\left(\mathrm{PO}_{4}\right)_{2}$, as shown in Table A12. Compare Table A12 to Table A6, it can be seen that, as LiOH is dropped, the both concentrations of the iron and phosphoric species dropped monotonously. This means precipitation of $\mathrm{Fe}_{3}\left(\mathrm{PO}_{4}\right)_{2}$ from the solution.

Table A12 also shows that the concentration products of $\left[\mathrm{Li}^{+}\right]^{3}$ and $\left[\mathrm{PO}_{4}{ }^{3-}\right]$ are smaller than the solubility product of $\mathrm{Li}_{3} \mathrm{PO}_{4}, 3.2 \times 10^{-9}$, when the add-in concentrations of $\mathrm{LiOH}$ are smaller than $0.16 \mathrm{M}$. This means no $\mathrm{Li}_{3} \mathrm{PO}_{4}$ precipitation in this concentration range. However, when the add-in concentration of $\mathrm{LiOH}$ becomes greater than $0.16 \mathrm{M}$, the concentration product of $\mathrm{Li}^{+}$and $\mathrm{PO}^{3-}$ becomes greater than $3.2 \times 10^{-9}$, which satisfies the condition for precipitation of $\mathrm{Li}_{3} \mathrm{PO}_{4}$. It can be seen from the table that at $0.16 \mathrm{M}$ of add-in $\mathrm{LiOH}$, there is still about $0.033 \mathrm{M}$ of phosphoric species in the solution. We can 
deduce that substantial precipitates of $\mathrm{Li}_{3} \mathrm{PO}_{4}$ could be resulted in as further increase of the add-in concentration of $\mathrm{LiOH}$.

\subsection{Development of crystalline phases}

Refer to Section 4.2. Crystalline $\mathrm{Fe}_{3}\left(\mathrm{PO}_{4}\right)_{2} \cdot 8 \mathrm{H}_{2} \mathrm{O}$ and $\mathrm{Li}_{3} \mathrm{PO}_{4}$ are seen from samples by microwave hydrothermal treatment at $100^{\circ} \mathrm{C}$ and $130^{\circ} \mathrm{C}$ for just 1 minute. $\mathrm{Fe}_{3}\left(\mathrm{PO}_{4}\right)_{2} \cdot 8 \mathrm{H}_{2} \mathrm{O}$ disappeared when the microwave hydrothermal treatment temperature was raised to $170^{\circ} \mathrm{C}$, herein $\mathrm{LiFePO}_{4}$ appeared as the major phase. When microwave hydrothermal treatment temperature was raised to $200^{\circ} \mathrm{C}, \mathrm{Li}_{3} \mathrm{PO}_{4}$ disappeared and $\mathrm{LiFePO}_{4}$ became the only phase.

There are two mechanisms that may be considered for the development of the crystalline phases:

1), Low-temperature phase to high-temperature phase conversion

By this mechanism, $\mathrm{Fe}_{3}\left(\mathrm{PO}_{4}\right)_{2} \cdot 8 \mathrm{H}_{2} \mathrm{O}$ and $\mathrm{Li}_{3} \mathrm{PO}_{4}$ are low temperature phases that developed from amorphous to crystalline phase in temperature range from $100^{\circ} \mathrm{C}$ to $130^{\circ} \mathrm{C}$. At higher temperatures, these two crystalline phases react with each other and convert themselves into $\mathrm{LiFePO}_{4}$, the high temperature phase. The chemical reaction may proceed in this way:

$$
\mathrm{Li}_{3} \mathrm{PO}_{4}+\mathrm{Fe}_{3}\left(\mathrm{PO}_{4}\right)_{2} \cdot 8 \mathrm{H}_{2} \mathrm{O}=3 \mathrm{LiFePO}_{4}+8 \mathrm{H}_{2} \mathrm{O}
$$

More specifically, dehydration of the vivianite takes place at first

$$
\mathrm{Fe}_{3}\left(\mathrm{PO}_{4}\right)_{2} \cdot 8 \mathrm{H}_{2} \mathrm{O}=\mathrm{Fe}_{3}\left(\mathrm{PO}_{4}\right)_{2}+8 \mathrm{H}_{2} \mathrm{O}
$$

The $\mathrm{Li}^{+}$ions in mother liquor replace $\mathrm{Fe}^{2+}$ in $\mathrm{Fe}_{3}\left(\mathrm{PO}_{4}\right)_{2}$

$$
2 \mathrm{Li}^{+}+\mathrm{Fe}_{3}\left(\mathrm{PO}_{4}\right)_{2}=2 \mathrm{LiFePO}_{4}+\mathrm{Fe}^{2+}
$$


The consumption of $\mathrm{Li}^{+}$in the mother liquor causes liberation of $\mathrm{Li}^{+}$from the $\mathrm{Li}_{3} \mathrm{PO}_{4}$ precipitates

$$
\mathrm{Li}_{3} \mathrm{PO}_{4}=3 \mathrm{Li}^{+}+\mathrm{PO}_{4}^{3-}
$$

Formation of $\mathrm{LiFePO}_{4}$ directly from $\mathrm{Li}^{+}, \mathrm{Fe}^{2+}$ and $\mathrm{PO}_{4}{ }^{3-}$ in the mother liquor

$$
\mathrm{Li}^{+}+\mathrm{Fe}^{2+}+\mathrm{PO}_{4}^{3-}=\mathrm{LiFePO}_{4}
$$

By this mechanism, formation of $\mathrm{LiFePO}_{4}$ involves reconstruction of the crystalline structures. One is dissolution of $\mathrm{Li}_{3} \mathrm{PO}_{4}$ precipitates. The other is destruction of $\mathrm{Fe}_{3}\left(\mathrm{PO}_{4}\right)_{2} \cdot 8 \mathrm{H}_{2} \mathrm{O}$ that can be deduced from the $\mathrm{Fe}^{2+}$ coordination structure. Because $\mathrm{Fe}^{2+}$ ions are coordinated partially by $\mathrm{PO}_{4}{ }^{3-}$ and partially by $\mathrm{H}_{2} \mathrm{O}$ (73), dehydration of $\mathrm{Fe}_{3}\left(\mathrm{PO}_{4}\right)_{2} \cdot 8 \mathrm{H}_{2} \mathrm{O}$ would need rearrangement of the $\mathrm{Fe}^{2+}$ coordination.

Looking at the heating profile shown in Figure 3, however, it is hard to imagine that the two crystalline phases, $\mathrm{Li}_{3} \mathrm{PO}_{4}$ and $\mathrm{Fe}_{3}\left(\mathrm{PO}_{4}\right)_{2} \cdot 8 \mathrm{H}_{2} \mathrm{O}$, can form and the corresponding particles can grow into over $10 \mu \mathrm{m}$ in a matter of 1 minute (Figure 10). It seems more reasonable that they were formed non-isothermally during the cooling stage because the cooling down stage took much longer time than the heating up stage. When the cooling down stage is included, the total heat treatment time in the $80^{\circ} \mathrm{C}$ to $100^{\circ} \mathrm{C}$ range is about 12 minutes, and in the $80^{\circ} \mathrm{C}$ to $130^{\circ} \mathrm{C}$ range, is about 21 minutes.

At this viewpoint, it would be untrue that the high temperature crystalline phase, $\mathrm{LiFePO}_{4}$, was developed from conversion of $\mathrm{Fe}_{3}\left(\mathrm{PO}_{4}\right)_{2} \cdot 8 \mathrm{H}_{2} \mathrm{O}$ and $\mathrm{Li}_{3} \mathrm{PO}_{4}$ through the structure reconstruction process. Because in the heating up stage the time for the temperature from passing by $130^{\circ} \mathrm{C}$ to reaching $170^{\circ} \mathrm{C}$ was just half minutes, there would be barely no time for $\mathrm{Fe}_{3}\left(\mathrm{PO}_{4) 2} \cdot 8 \mathrm{H}_{2} \mathrm{O}\right.$ and $\mathrm{Li}_{3} \mathrm{PO}_{4}$ to form from amorphous phase. There could be no time to destruct the crystalline structure of 
$\mathrm{Fe}_{3}\left(\mathrm{PO}_{4}\right)_{2} \cdot 8 \mathrm{H}_{2} \mathrm{O}$ and $\mathrm{Li}_{3} \mathrm{PO}_{4}$ and rearrange the corresponding species into $\mathrm{LiFePO}_{4}$ lattice. The formation and the development of the crystalline phases should take place by another mechanism.

2), Competition between low-temperature and high-temperature phases

By this mechanism, both of these low temperature and high temperature phases evolved from the amorphous precipitates. The precipitates are stoichiometrically in $\mathrm{Fe}_{3}\left(\mathrm{PO}_{4}\right)_{2}$ and $\mathrm{Li}_{3} \mathrm{PO}_{4}$ formula. However, the species $\mathrm{Fe}^{2+}, \mathrm{PO}_{4}{ }^{3-}$ and $\mathrm{Li}^{+}$may be poorly coordinated that allows these species able to move around. The amorphous nature of the precipitates is shown in Figure 1, Figure 2 and Figure 3.

During hydrothermal treatment, nucleation of $\mathrm{Fe}_{3}\left(\mathrm{PO}_{4}\right)_{2}$ and $\mathrm{Li}_{3} \mathrm{PO}_{4}$ may take place in low temperature range (around $100^{\circ} \mathrm{C}$ ) but nucleation of $\mathrm{LiFePO}_{4}$ may occur at high temperatures (around $170^{\circ} \mathrm{C}$ ). In the experiments that heating up stopped at lower temperatures $\left(\mathrm{MH}_{100}{ }^{\circ} \mathrm{C} \times 1 \mathrm{~min}\right.$ and $\mathrm{MH} 130^{\circ} \mathrm{C} \times 1 \mathrm{~min} 100^{\circ} \mathrm{C}$ as shown in Figure 5), only nucleation of $\mathrm{Fe}_{3}\left(\mathrm{PO}_{4}\right)_{2}$ and $\mathrm{Li}_{3} \mathrm{PO}_{4}$ took place. The nucleation and growth of these two crystalline phases were supposed to be done primarily during the cooling down stage because the heating up time is very short (30 seconds to 1 minute). In the experiment that heating up continued to high temperature $\left(\mathrm{MH} 170^{\circ} \mathrm{C} \times 1 \mathrm{~min}\right)$, however, nucleation of $\mathrm{LiFePO}_{4}$ took over.

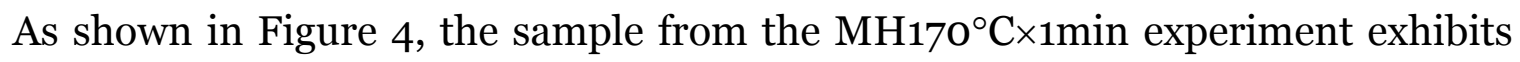
no XRD peaks of $\mathrm{Fe}_{3}\left(\mathrm{PO}_{4}\right)_{2} \cdot 8 \mathrm{H}_{2} \mathrm{O}$. It cannot be due to dissolution of the compound but due to the by-pass of its formation resulted from the rapid heating-up temperature profile. The heating-up time in the $\mathrm{MH} 17 \mathrm{O}^{\circ} \mathrm{C} \times 1 \mathrm{~min}$ experiment only experienced 80 seconds. It is too short for any crystalline phase to get appreciable nucleation. Once again, the formation of $\mathrm{LiFePO}_{4}$ phase took place primarily during the cooling down stage. 
Figure 4 also shows existence of $\mathrm{Li}_{3} \mathrm{PO}_{4}$ in the $\mathrm{MH} 17 \mathrm{O}^{\circ} \mathrm{C} \times 1 \mathrm{~min}$ sample. However, the XRD peaks of this compound are not seen from samples of $\mathrm{MH} 200^{\circ} \mathrm{C} \times 1 \mathrm{~min}$ experiment and other longer $\mathrm{MH} 200^{\circ} \mathrm{C}$ treatments (Figure 6 and Figure 8). It indicates that formation of $\mathrm{Li}_{3} \mathrm{PO}_{4}$ is still, to some extent, competitive against the

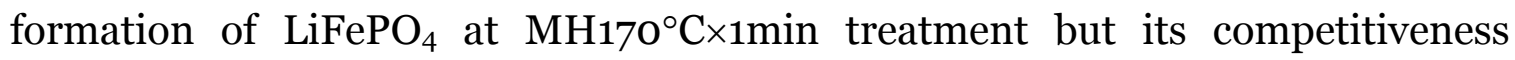
diminished at higher temperatures of microwave hydrothermal treatment. Stoichiometric calculation (Table A12) demonstrates that complete formation of $\mathrm{LiFePO}_{4}$ would consume all $\mathrm{Fe}^{2+}$ and $\mathrm{PO}_{4}^{3-}$ species and consume $1 / 3$ of $\mathrm{Li}^{+}$ species when the synthesis is started from a solution in which the $\mathrm{Li}^{+}: \mathrm{Fe}^{2+}: \mathrm{PO}_{4^{3-}}$ is 3:1:1. The existence of $\mathrm{Li}_{3} \mathrm{PO}_{4}$ in $\mathrm{MH} 170^{\circ} \mathrm{C} \times 1 \mathrm{~min}$ sample indicates incomplete formation of $\mathrm{LiFePO}_{4}$ and there is some amount of $\mathrm{Fe}^{2+}$ that remains not reacted. However, the remaining $\mathrm{Fe}^{2+}$ species is not associated with $\mathrm{Fe}_{3}\left(\mathrm{PO}_{4}\right)_{2}$ because there is no sign of $\mathrm{Fe}_{3}\left(\mathrm{PO}_{4}\right)_{2}$ is seen in the XRD spectrum. It is deduced that the iron species is released to the mother liquor from the $\mathrm{Fe}_{3}\left(\mathrm{PO}_{4}\right)_{2}$ species during formation of $\mathrm{LiFePO}_{4}$ and $\mathrm{Li}_{3} \mathrm{PO}_{4}$.

\subsection{Development of the crystalline microstructures}

The SEM graphs shown in $\$ 4.2$ illustrated that the straight-edged rectangular particles formed at very early stage. The high resolution images also revealed substructures inside these rectangular particles. As the time of microwave hydrothermal treatment increased, these substructures gradually diminished and the parent particles become smooth and solid. The text below will discuss the possible mechanisms that lie behind the experimental results.

\subsubsection{Nucleation and growth in amorphous precursor}

As discussed in \$5.1.1, the major chemical species precipitated from the $\mathrm{LiOH}$ $\mathrm{FeSO}_{4}-\mathrm{H}_{3} \mathrm{PO}_{4}$ solution were $\mathrm{Fe}_{3}\left(\mathrm{PO}_{4}\right)_{2}$ and $\mathrm{Li}_{3} \mathrm{PO}_{4}$. The as-precipitated precursors were amorphous. Nucleation and growth of the crystalline phases, $\mathrm{Fe}_{3}\left(\mathrm{PO}_{4}\right)_{2} \cdot 8 \mathrm{H}_{2} \mathrm{O}, \mathrm{Li}_{3} \mathrm{PO}_{4}$ and $\mathrm{LiFePO}_{4}$ took place from the precipitated precursor rather than from the solution. 
Zhang et al (74) proposed a multistep crystallization (MSC) mechanism that describes nucleation and growth in amorphous precipitates. According to this mechanism, solid phase forms droplets at first when it precipitates from the mother solution. The droplets comprise of nanoscale amorphous aggregates that are less stable. Because of the amorphous nature, the atomic mobility at the interfaces between the nanosized aggregates is high. The droplets can be therefore looked as a homogeneous matrix, in which nucleation and growth of crystalline phase can take place (as illustrated by Figure 31 ).

In real cases, there can be a number of nuclei that are created simultaneously within the amorphous droplets. These nuclei are subcrystalline in nature when they are created. The subcrystalline nuclei may shrink or dissolve soon after their creation and, in the meantime, other subcrystalline nuclei may form randomly again. It is reasonable to suppose that the creation as well as the dissociation of the nuclei in the dense droplets is governed by thermal fluctuations. As a certain number of subcrystalline nuclei reach critical size, Ostwald ripening would take place by which these critical nuclei grow into larger crystallites. The amorphous

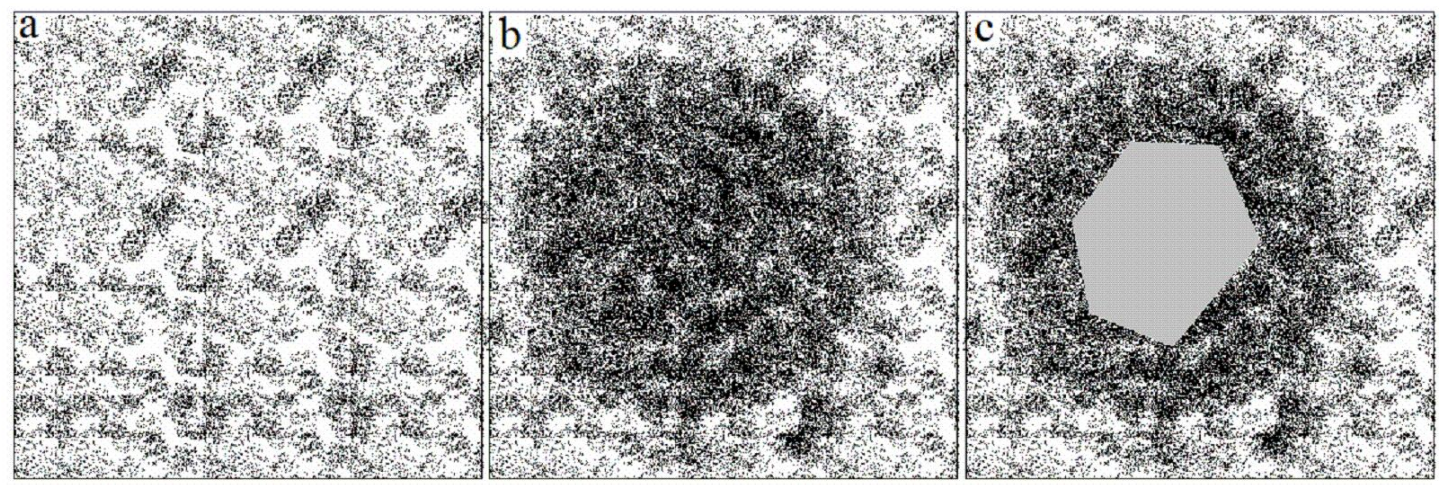

Figure 31, Multistep crystallization mechanism: (a) Initial precipitates from mother solution. (b) Amorphous dense droplets formed by the initial precipitates. (c) Crystalline nuclei created within the amorphous dense droplets 
droplets become assemblies of multiple crystalline particles, as shown in Figure 32(a).

The crystalline particles inside the assembly may coalesce into a single particle, as shown in Figure 32(b). Because of different crystallographic orientations, merging of multiple crystallites into one crystalline particle inside the droplet would need rearrangement of the crystal lattice. According to the MSC mechanism, the lattice rearrangement would involve to-and-fro transformation between the amorphous and crystalline phases.

The multistep crystallization mechanism was observed by Chen et al (75) who synthesized CdSe nano particles with the following procedure: $0.1846 \mathrm{~g}$ of cadmium stearate and $2.0588 \mathrm{~g}$ of trioctylphosphine oxide was loaded in a threeneck flask and heated to $240^{\circ} \mathrm{C}$ for $2 \mathrm{~h}$ under Ar flow in a Schlenk line. Then, hot selenium stock solution (0.0213 $\mathrm{g}$ of $\mathrm{Se}$ ) dissolved in $1.0294 \mathrm{~g}$ of tetraphenylporphyrine was quickly injected. After the injection, the temperature of the mixed solution dropped to $200^{\circ} \mathrm{C}$. This solution was quickly heated to $220^{\circ} \mathrm{C}$ and reacted at this temperature for $10 \mathrm{~min}$ and $90 \mathrm{~min}$, respectively.

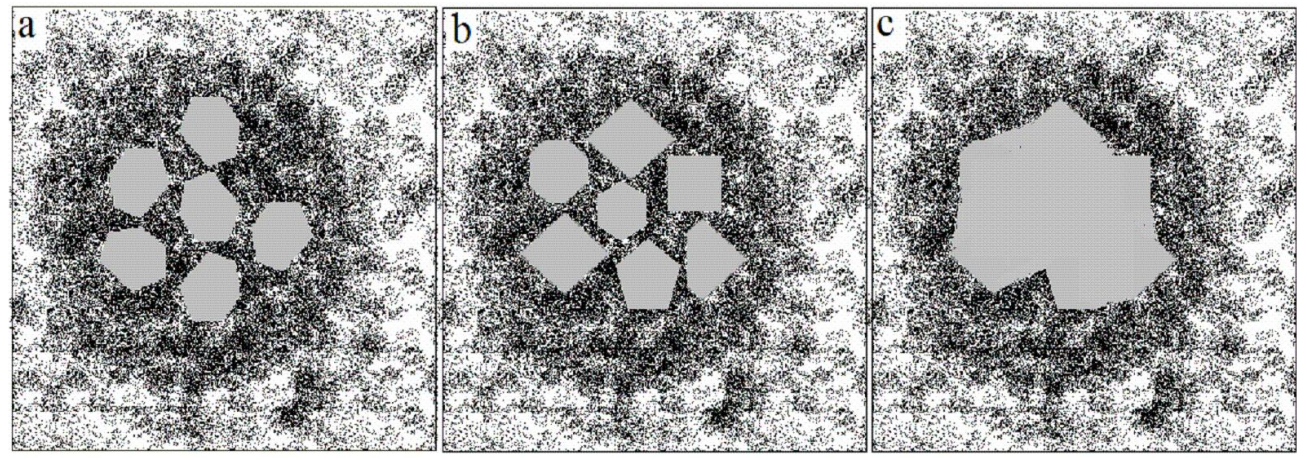

Figure 32, Crystallization by nucleation and growth of multiple subcrystalline nuclei inside an amorphous droplet. (a) Small subcrystalline nuclei are initially created in the droplets. (b) Dynamic creation and dissolution of subcrystalline nuclei. (c) Multiple subcrystalline nuclei grow into one stable mature crystalline particle. 
The 10 and 90 min samples were studied by HRTEM, which displays that both these samples had similar sizes around $2.0 \mathrm{~nm}$. For the $10 \mathrm{~min}$ sample, no lattice fringes were observed in the HRTEM images of the randomly oriented nanoparticles. Thus, the 10 min sample was suggested to be amorphous, since from the statistical point of view, there should be a chance to resolve the lattice fringe at least for some nanoparticless if the samples were well-crystallized and randomly oriented on the carbon grid. In contrast, the 90 min sample was wellcrystallized, and the lattice structure could be resolved. This observation is consistent with their XRD results, where the 90 min sample had stronger diffraction pattern than the 10 min sample. This observation suggests a two-step crystallization process: formation of amorphous nano particles and then crystallization taking place inside the amorphous particles.

Oleinik et al (76) studied the growth mechanism in sintering of AlN at elevated temperatures. The study revealed that the growth of the AlN polycrystals was governed by the occurrence of two coalescence cycles. The first is realized by nucleation in aggregates of the precursor particles (amorphous) that always form in the initial stage of powder sintering. The nucleation in amorphous aggregates determines the formation of grain growth centers (nuclei). The second cycle is growth of these nuclei, i.e. development of collecting recrystallization.

Detailed information of the second cycle was seen from their electron microscope studies. In the initial sintering stage interlayers were seen between individual AlN particles and their aggregates at the contact boundary between them changes in particle facets developed; then boundaries arise in aggregates in the form of single broad extinction contours that subsequently become less sharp and aggregates become single crystal. In parallel with this sequence of processes during sintering, boundaries form between aggregates and in the single-crystal state they emerge as grain growth centers, i.e. they determine the further occurrence of collective recrystallization within the volume of specimens as a 
whole. In summary, the second circle proceeded in this sequence: (a), formation of a continuous interlayer that joins the adjacent crystallites; (b), expansion of interlayers; and (c), extinguish of the original crystallites and emerging of larger single crystalline particles. This is a process in which the interlayers "ate up" the original crystallites by means of recrystallization.

Tamou et al (77) observed coalescence of multiple particles into a single crystal by electron beam irradiation of tungsten nanoparticles. Specifically they saw two nanoparticles came into contact and formed a neck after 120-second irradiation. The coalescence progressed through neck growth and the two partcicles became a single crystal at 240-second irradiation. The single crystalline nature is confirmed by parallel fringes inside the particles. Such a coalescence process was also observed from four nanoparticles that finally grow into one single crystal.

We may use the multistep crystallization mechanism to explain some of the results obtained form our study. As can be seen from Figure 2 and Figure 3, the amorphous precursor contains droplets (aggregates) of multiple levels. The smallest drops are in a size range of a few nanometers that can be viewed as prime particles. These prime particles then cluster into secondary aggregates of which the size ranges from 20 to 50 nanometers. The secondary aggregates further form into micron size lumps. Considering the particle sizes shown in the $\mathrm{LiFePO}_{4}$ samples (Figure 10 and later), we may assume that the micron size lumps are corresponding to the droplets described in the MSC mechanism model, in which nucleation of crystallites takes place on the prime particles.

We further use this mechanism to explain the substructures and their diminishing in the parent particles shown in Figure 20, 23, 26 and 29. While the substructures in the $200^{\circ} \mathrm{C} \times 1 \mathrm{~min}$-treated sample (Figure 20) are distinctive, those in the $200^{\circ} \mathrm{C} \times 45 \mathrm{~min}$-treated sample (Figure 29) are almost disappeared. The samples treated at $200^{\circ} \mathrm{C}$ for $15 \mathrm{~min}$ (Figure 23) and for 3omin (Figure 26) 
exhibit diminishing of the substructures. From the XRD results shown in Figure 6 and 9, we know that these substructures are crystalline particles that nucleated in the parent particles. The nucleation was not one nuclear in one parent particle, but a number of nuclei created simultaneously in a particle. The ensuing growth was by means of recrystallization. Through recrystallization, lattice rearrangement took place. An area with common lattice orientation emerged between the crystallite. This common area gradually ate up the crystallites and final took over the whole space of the parent particle.

The multistep crystallization mechanism seems able to explain the structure evolvement inside parent particles. However, it cannot explain the straight edges and flat surfaces of the parent particles. According to the mulistep crystallization mechanism, the parent particles should have spherical or irregular periphery. One may argue that continued recrystallization would eventually lead to the straight edges and the flat surfaces. If this were the case, however, we should not have seen these rectangular particles in the very early stage, especially in the $170^{\circ} \mathrm{C} \times 1 \mathrm{~min}$ - and $200^{\circ} \mathrm{C} \times 1 \mathrm{~min}$-treated samples. In order to convert a spherical or irregular particle into a rectangular particle, substantial deformation is needed. It is hard to imagine that such a kind of particle deformation can be done in such a short time because it would need a large magnitude of lattice rearrangement.

\subsubsection{Preferable periphery crystallization}

The schematic representation of preferable periphery crystallization is shown in Figure 33. As described in the previous section, an amorphous droplet can form by precipitation of species from solution and subsequently aggregation of the precipitated particles. Nucleation and growth could take place either in the interior or at the surface of the droplet. We may assume that nucleation and growth at the surface are easier than in the interior because of thermodynamic advantages. When amorphous to crystalline conversion involves chemical reactions, presence of solvent (more at surfaces) facilitates the reactions by 
means of dissolution-precipitation. The whole crystallization process of the amorphous droplet is similar to the multistep crystallization mechanism. In this case, however, because periphery growth is favored, it is possible for the particle to obtain higher crystallinity in the surface region that would result in straight edges and/or flat surfaces.

Mintova et al (78) obtained the direct evidence of preferable periphery crystallization from high-resolution electron microscopy study of mechanism of zeolite $\mathrm{Y}$ nucleation and crystal growth at elevated temperatures (faujasite structure type; FAU). The FAU crystals are nucleated in amorphous gel aggregates existing in the colloidal aqueous solution after 28 hours. Nucleation of the amorphous aggregate always began at the gel/solution interface. Their results confirmed a nucleation mechanism, where structural elements at the periphery of the gel phase act as precursors for the nucleation events. The aggregates are completely converted into crystalline zeolite $\mathrm{Y}$ within $48 \mathrm{~h}$ at $100^{\circ} \mathrm{C}$. After prolonged crystallization times, the dominant mechanism for the FAU crystals growth was mass transfer in solution.

Wu et al (79) studied the nucleation behavior of $\mathrm{YBa}_{2} \mathrm{Cu}_{3} \mathrm{O}_{6.1}$ in a buried Precursor $/ \mathrm{SrTiO}_{3}$ film. Their study showed preferential nucleation of oriented

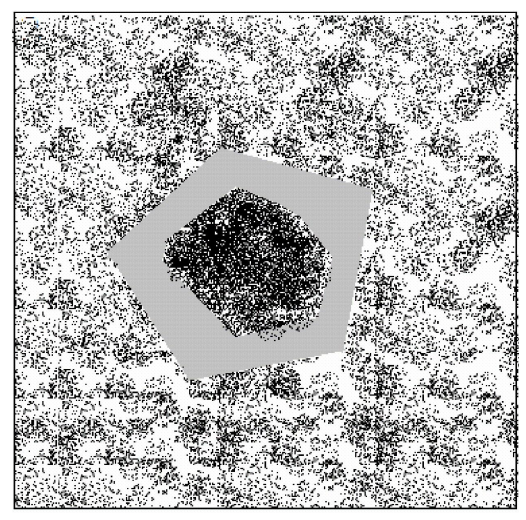

Figure 33, Crystallization takes place preferably at the periphery of an amorphous droplet 
$\mathrm{YBa}_{2} \mathrm{Cu}_{3} \mathrm{O}_{6.1}$ at the interface of precursor-substrate interface but no nucleation in any other parts was observed. This preferred nucleation at the interface was due to the lower activation energy in the interface than at other sites.

Zhang et al (80) demonstrated preferred surface/interface nucleation of rutile from anatase. Their study revealed that particle packing density was a factor that affected the nucleation behavior. In places where the packing density of the anatase samples was denser, nucleation of rutile nucleates primarily took place at the anatase particles interface. In less dense particle packing samples, nucleation of rutile not only took place at the interfaces but also at free surfaces. However as the processing temperature increased from $600^{\circ} \mathrm{C}$ to $1150^{\circ} \mathrm{C}$, bulk nucleation could replace the interface/surface nucleation as the predominant nucleation mode. These findings suggested that the preferred interface/surface nucleation was governed by the activation energy.

The preferable periphery crystallization mechanism agrees with the straight edges and the flat surfaces observed not only from the development of the $\mathrm{LiFePO}_{4}$ particles (from Figure 16 to Figure 30) but also from that of the intermediates (Figure 10 and Figure 15). Refer to the discussion in $\$ 5.1$ and §5.2. Two amorphous species, $\mathrm{Fe}_{3}\left(\mathrm{PO}_{4}\right)_{2}$ and $\mathrm{Li}_{3} \mathrm{PO}_{4}$, co-exist in the precipitated precursor, and $\mathrm{Li}_{3} \mathrm{PO}_{4}$ has larger solubility constant product. This means that dissolution of $\mathrm{Li}_{3} \mathrm{PO}_{4}$ from the amorphous precursor can be easy at the precursor/solution interface. The dissolution would have increased the concentration of $\mathrm{Li}^{+}$and $\mathrm{PO}_{4}{ }^{3-}$ in the solution, that would drive these ions precipitate back into solid phase. The dissolution and precipitation could take place at different sites, i.e. dissolution would occur at high surface energy sites but precipitation could take place at low surface energy sites. Straight edges and flat surfaces come from the site-selected dissolution and precipitation driven by the crystallographic growth habits of the crystalline products.

Similar to the multistep crystallization mechanism, preferable periphery 
crystallization only deals with the crystallization of the initially formed amorphous particles, but does not handle the subsequent growth of the crystalline particles. Refer to Figure 19 and 20, the $\mathrm{LiFePO}_{4}$ particles are crystalline and about 200-400nm in size that are in the same size range of the initially formed amorphous particles. Further crystallization would involve elimination of the crystallinity defects and/or mismatches in the particle interior, but could not lead to particle growth.

However, growth of the crystalline particles did happen in the prolonged hydrothermal treatment, as shown in Figure 22 through Figure 30. With this consideration, we may assume two consequent mechanisms: preferable periphery crystallization at first and then kinds of growth mechanisms (such as Ostwald ripening) taking effect. By examination of the particles shown in the Figure 23, 26 and 29, we can exclude Ostwald ripening for the subsequent growth. Because Ostwald ripening involves removal/addition of species in atomic scale, the growth should result in smooth regions of appreciable width in periphery of the particles. Such smooth regions were not found from these figures.

Another caution that should be taken is the prediction of porosity in the grown particles. If periphery nucleation took place preferably, it would form a rigid shell for the particle that is in amorphous-to-crystalline conversion. The rigid shell would prevent the particle from shrinking during the further conversion in the interior. Because amorphous phase is less dense than crystalline phase, further conversion would leave voids inside the particles. If this were true, we would have observed larger voids in samples by prolonged treatment, such as that shown in Figure 29. However, such voids are not observed from these figures.

\subsubsection{Oriented Attachment}

Oriented-attachment (OA) is a process by which crystallographic alignment and particle coalescence take place. Oriented attachment could lead to aligned 
crystallite aggregates that may finally develop into single crystals (81). The OA process takes places by particle collision at first. In the case that the crystalline particles are in a liquid medium, the collision can be statistical, i.e. some in same crystallographic orientations and others in different crystallographic orientations. If in the former case, direct coalescence would occur and the aggregate would transform into a new single crystal (as shown in Figure 34). If in the latter case, the OA process can occur through intermediate steps: the two colliding particles join together in misalignment orientations followed by appropriate rotation by which particles are reoriented into same crystallographic orientations (as shown in Figure 35).

Various particle shapes may form by further growth of the statistical collision induced aggregates (82). Because the crystallographic alignment can be realized anywhere at the surfaces of the involved particles, the final particle can be resulted from a number of attachment actions on the same surface. The particular shape can be an uncontrollable (shown in the left of Figure 36). However, if there are conditions under which some crystallographic planes of the particle have more energic advantages than others, the collision may change from statistical into selective, giving rise to epitaxial aggregation (shown in the right of Figure 37).

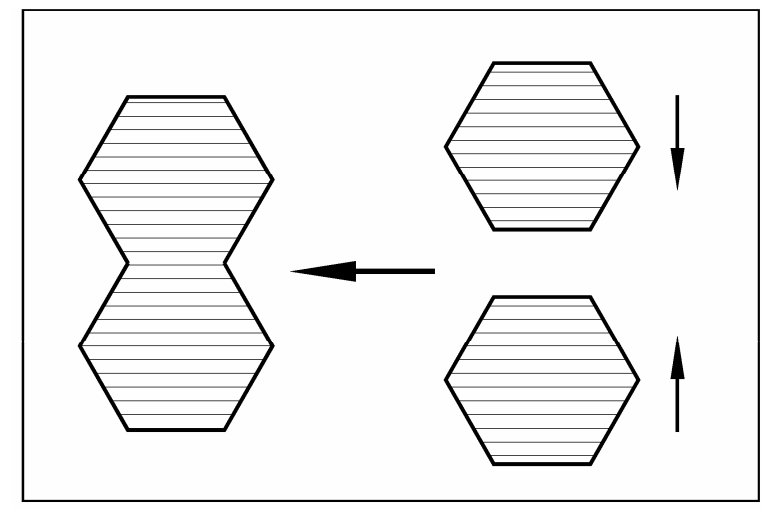

Figure 34, Oriented attachment by collision between two crystallites in same crystallographic orientation. The two colliding crystallites form a new single crystalline particle directly 


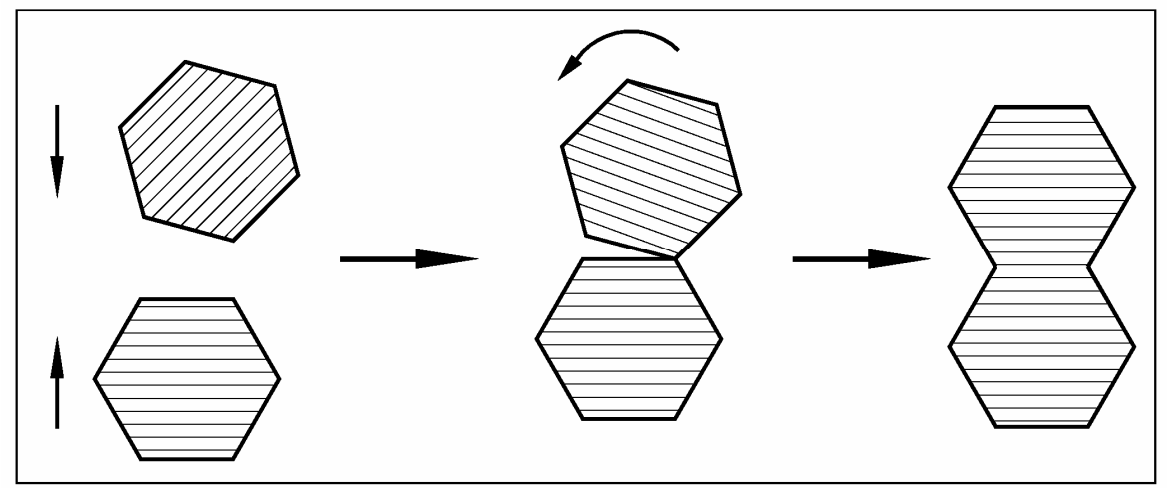

Figure 35, Oriented attachment by collision between two crystallites in mismatched crystallographic orientations. The colliding crystallites form a new single crystalline particle via appropriate rotation

Epitaxial aggregation is a process in which long chains of highly ordered crystallites can emerge from a solution of primary equiaxial nano particles, arising from "docking" of a nanocrystal with its next neighbor into full alignment (83). The occurrence of such a kind of oriented attachment is thermodynamically driven by the reduction of surface energy. Because surfaces of different crystallographic directions have different surface energy, epitaxial aggregation can expand the surfaces of lower energy while cause the surfaces of higher energy to diminish. The common feature of epitaxial aggregation is existence of point and line defects, e.g. pores and edge dislocations. These defects may be prominent in the initial growth stage but may gradually disappear by means of recrystallization as the growth proceeds.

Oriented attachment by statistical collision was observed by Ribeiro et (81) al from growth of $\mathrm{SnO}_{2}$ nanoparticles that exhibited both both elongated and sphere-like morphologies. A HRTEM image of a $\mathrm{SnO}_{2}$ nanorod showed that the crystallographic direction of the nanorod was [110], indicating that its growth was not by atomic/ionic deposition but by oriented attachment. Because, in terms of thermodynamics, the $\{110\}$ planes are most stable and hence it was unfavorable for growth along the [110] direction. There were also other directions, such as 


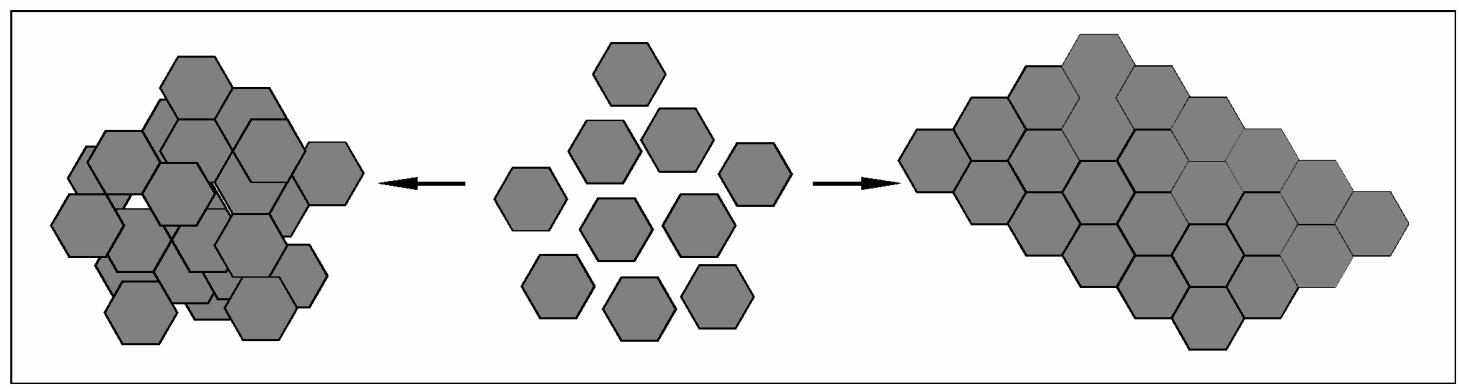

Figure 36, Final particle shapes resulted from oriented attachment. The irregular shape shown in the left is the result of attachment on random surface sites. The well-defined crystallographic shape shown in the right is the result of epitaxial aggregation.

[001], [010], and [100], along which growth of elongated particles were observed. These observations are the further evidences indicating that oriented attachment was the primary growth mechanism.

Penn et al (84) showed that oriented attachment in the manner of epitaxial aggregation can occur in colloid of $\mathrm{TiO}_{2}$ nanoparticles. Whether the epitaxial aggregation could occur or not was dependent on conditions. A bimodal population of particle types could be produced when deionized water was used for pretreatment of the primary $\mathrm{TiO}_{2}$ particles. Among the obtained particles, some were smaller and equidimensional, others were larger and had well developed facets. Growth of the facet particles was observed in prolonged hydrothermal treatment, but the bimodal population of particle types still persisted. However, addition of hydrochloric acid into the suspension eliminated the equidimensional particles and turned all of them into faceted ones, indicating that epitaxial aggregation was the only mechanism. Their results showed that lower $\mathrm{pH}$ increased the frequency of OA-induced coarsening. The most favorable $\mathrm{pH}$ value was 3.0, at which large number of primary crystallites were epitaxially attached into well-defined crystallographic crystals. 
Pen et al (85) also studied the growth behavior of heterogenite crystallites that formed from by oxidation of cobalt (II) chloride in aqueous solution. The particle size of the $\mathrm{CoOOH}$ crystallites was in 0.2-1.0 $\mu \mathrm{m}$ range and the particle shape was hexagonal. Several types of defects can be seen from HRTEM images. These defects include porosity, edge dislocations and misoriented boundaries between heterogenite building block particles. The existence of these defects in the hexagonal particles suggests that the primary growth mechanism was oriented aggregation. The attachment-driven growth direction can be assigned to a vector in $\{001\}$ axis. It means that the attachment favored crystallographic faces parallel to the [001] plane. Such crystallographic specificity evolved through oriented attachment mechanism suggests a possibility to tailor the assembly process that favors a certain specific crystallographic faces for accomplishment of targeted particle morphologies.

Xia et al (85) observed oriented attachment from their study on hydrothermal synthesis of $\mathrm{LiFePO}_{4}$. By time dependent SEM analysis, they revealed a sequence of morphological evolution. After the $\mathrm{LiFePO}_{4}$ precursor was treated under hydrothermal condition for 5 hours, a few small rectangular structures began to appear among the irregular majorities. After prolonged aging up to 10 hours, quasi-spindle shaped and semi-spindle shaped particles became into dominant in the structure. By extended treatment to 15 hours, the structure began to change into spindle-like porous morphology. Finally, the obtained product became abundant with spindle-like $\mathrm{LiFePO}_{4}$ particles after 20 hours hydrothermal treatment.

Based on the above results, they proposed a complicated growth mechanism, by which primary nanocrystallites grow concurrently with their building up into a spindle-like three dimensional hierarchical microstructure. First of all, $\mathrm{Li}_{3} \mathrm{PO}_{4}, \mathrm{FeSO}_{4}$ and l-ascorbic acid mixed together as the precursor. Hydrothermal treatment caused reaction between $\mathrm{Li}_{3} \mathrm{PO}_{4}$ and $\mathrm{FeSO}_{4}$ and nucleation of crystalline $\mathrm{LiFePO}_{4}$ took place. In the meantime, the primary $\mathrm{LiFePO}_{4}$ crystalline 
nuclei absorbed the l-ascorbic acid onto their surfaces. The primary $\mathrm{LiFePO}_{4}$ crystalline nuclei tend attached to each other driven by energy minimization in the whole system, after which is Ostwald ripening that takes place commonly in later stages of crystallization process. During the Ostwald ripening, larger $\mathrm{LiFePO}_{4}$ crystals grow but smaller crystallites diminish. The spindle-like particles formed by rearrangement of these intimately contacted $\mathrm{LiFePO}_{4}$ nanocrystals, by which a mesoporous spindle-like structure developed.

Qin et al (87) observed oriented attachment in a two-step growth mechanism from hydrothermal preparation of $\mathrm{LiFePO}_{4}$ crystals. Their experiment obtained nano sized crystals being a mixture of rods and plates. The mixed morphology in the synthesized material implies that the structural development underwent a multiple events instead of a single nucleation step. Oriented attachment mechanism is applicable for nanometer-sized crystallites. This mechanism involves spontaneous self-assembly of adjacent nuclei into a one-dimensional structure. The nuclei in the assembly shared a common crystallographic direction and joined together in planar interfaces, by which single crystals formed and grew. As the crystals grow larger, Ostwald ripening occurred that allowed the precipitates to coarsen by surface energy reduction between the precipitates and the nuclei. In this step, smaller particles dissolve due to their thermodynamically instability but larger particles, which are more stable, adsorb monomers from the dissolved particles and continue to grow.

We may use oriented attachment mechanism to explain the result from this study. The straight-edged particles shown from Figure 10 through Figure 21 suggest that the oriented attachment took place in the very beginning (within 1 minute). The building blocks are crystalline nanostructures that are confirmed by the XRD spectra shown in Figure 2, 3 and 6. The particle morphology of the $\mathrm{LiFePO}_{4}$ looks more like that of heterogenite particles prepared by oxidation of cobalt (II) chloride solution (85), which are micron sized hexagonal particles with nano sized build blocks inside. In a low magnification image, the particles appear well 
defined. In high resolution TEM image, defects such as dislocations, misoriented grain boundaries as well voids of the same dimensions as the building blocks are prevail. Note that the TEM image is a 2-dimensional picture, from which the details of the facets parallel to the projection direction represented by the edges cannot be seen. In this studied, the $\mathrm{LiFePO}_{4}$ microstructure shown in the figures are FE-SEM images which are of 3-dimensional. From these figures, such as Figure 20 and Figure 23, we can see that the voids of the same dimensions as the building blocks exist throughout all of the crystallographic facets. Despite of these larger dimension defects, the edges of the parent particles appear perfectly straight and the facets of the parent particles appear perfectly flat.

In the light of epitaxial aggregation, we may predict alignment of certain facets between crystallites inside the parent particles (84), but we cannot predict their straight edges and flat surfaces. If the build blocks are in different sizes, zigzag edges and dents-pits facets would be the case. A reasonable assumption for the straight edges and the flat surfaces is that the building blocks participating in the oriented attachment are in same size.

\subsubsection{Ostwald ripening}

Ostwald ripening is a process that consumes smaller particles by growing of larger particles due to energy difference between surfaces of the size different particles (87). Because the surface energy of a particle is proportional to its curvature, smaller particles, which have larger curvature, have higher surface energy. Chemical species (ions/atoms/molecules) on the high energy surfaces have higher intention to dissolve into the surrounding media and therefore cause higher local equilibrium concentration of the species in the media. On the contrary, larger particles have smaller curvature that is related to lower surface energy, chemical species on their surfaces have lower tendency to dissolve and therefore the local equilibrium concentration of the species around the larger particles is low. Such a concentration difference establishes concentration 


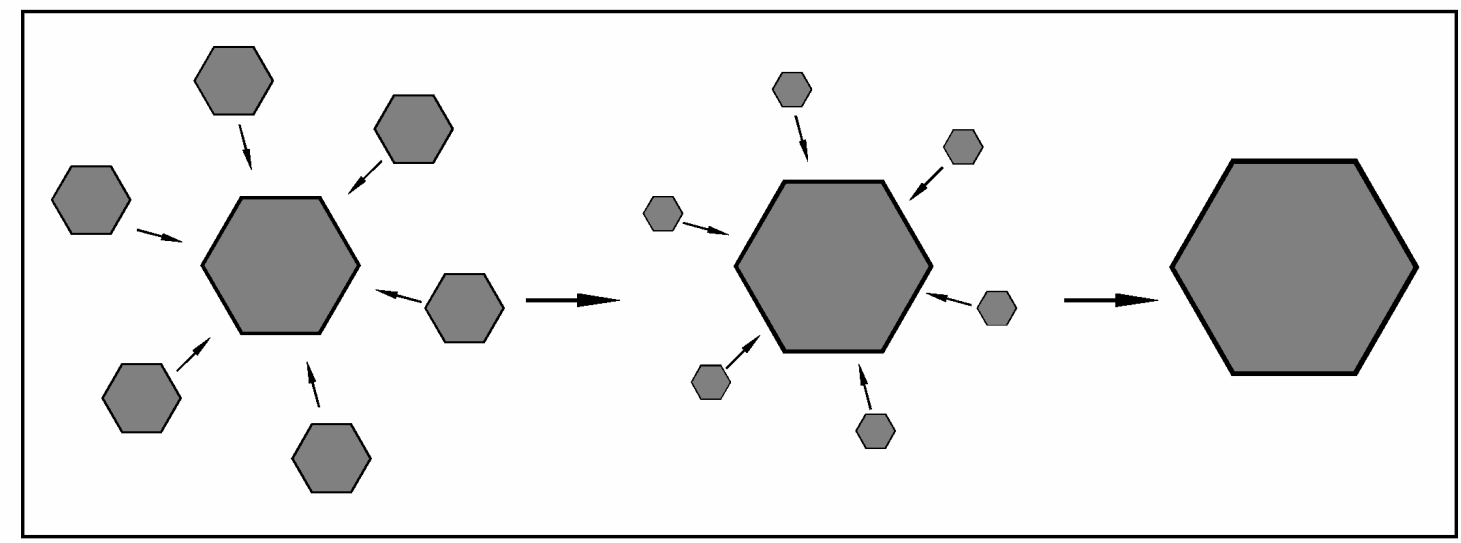

Figure 37, Growth of crystalline particles by Ostwald ripening. Atomic/ionic species dissolved from small particles precipitate onto large particles.

gradient from smaller particles to larger particles, leading to net mass flow along the gradient. This is a positive feedback process. The dissolution of smaller particles and growth of larger particles would continue until the smaller particles have completely diminished.

If different crystallographic faces have surface energies that are sufficiently different, faceted crystalline particles could result from Ostwald ripening growth mechanism. Considering the (010) plane of a nuclear that has much smaller surface energy than other planes, chemical species precipitating onto this plane would assume a slower rate and therefore a larger (010) face would form accompanying the crystal growth. As a consequence, plate-like shaped product particles would form that have smaller sizes in the $\{010\}$ direction.

Wong et al (89) reported that the growth of $\mathrm{ZnO}$ nano particles went through the Ostwald ripening mechanism. The nano particles were prepared by aging zinc acetate dehydrate with $\mathrm{NaOH}$ using propanol as the solvent. With a high resolution TEM, they observed faceted spherical particles that were surrounded by a number of non-faceted small particles that were randomly oriented. The TEM image indicated that the growth of the faceted particles went through 
expense of these small particles surrounding them. Curves of the particle radius versus aging time were plotted and linear plots were obtained. The result indicates that the growth of $\mathrm{ZnO}$ nano particles agrees with Ostwald ripening mechanism.

Xiang et al (90) obtained ultra thin platelets of $\mathrm{LiFePO}_{4}$ from which they believed that the growth of platelet $\mathrm{LiFePO}_{4}$ were also through the Ostwald ripening mechanism. In order to control the particle growth route, tetraethylene glycol (TEG) was employed in the synthesis. The TEG molecules could significantly reduce the activity of the metal ions by chelating these ions in the solution. Instruction of TEG could also reduce diffusion rate because of higher viscosity of the glycol. The effects of TEG on ion-chelating and diffusion retarding slowed the mass transfer rate and resulted in limited crystal growth. In addition, presence of TEG in sufficient amount is able to effectively chelate the $\mathrm{LiFePO}_{4}$ nuclei and keep them away from each other, that would reduce the rate of the crystallite growth. Furthermore, TEG is a kind of surfactant, use of TEG could reduce the surface energy of the $\mathrm{LiFePO}_{4}$ nuclei and growth by oriented attachment could be prohibited. All of these effects contribute to promote the Ostwald ripening mechanism.

In classical cases, Ostwald ripening processes shall not involve chemical composition change of the crystallite particles but just proceed upon existing solid phase. However, Zeng (91) described a process in which Ostwald ripening was accompanied by a process in which solid particles was chemically converted to another phase. This process was exhibited by the preparation of $\mathrm{Cu} 2 \mathrm{O}$ hollow nanospheres. The preparation was carried out by hydrothermal treatment of a copper nitrate in $\mathrm{N}, \mathrm{N}$-dimethylformamide solvent at $150-180^{\circ} \mathrm{C}$, through which nanocrystallites of $\mathrm{CuO}$ formed at first and then spherical structures developed by self-aggregation of the $\mathrm{CuO}$ nanocrystallites. Prolonged treatment caused reduction of the $\mathrm{CuO}$ aggregates gradually into $\mathrm{Cu}_{2} \mathrm{O}$ that was attributed to the presence of formic acid, a reducing agent coming from a slight hydrolysis of $\mathrm{N}, \mathrm{N}$ - 
dimethylformamide. It is noteworthy that the initially formed spherical $\mathrm{Cu}_{2} \mathrm{O}$ particles were solid but not have central voids. The voids at the centers were via Ostwald ripening started only after the $\mathrm{CuO} \rightarrow \mathrm{Cu}_{2} \mathrm{O}$ conversion. Subsequently, the monovalent $\mathrm{Cu}_{2} \mathrm{O}$ could be further reduced into metallic $\mathrm{Cu}$, by which creation of hollow interiors was facilitated. It is clearly indicated that the process of Ostwald ripening, i.e. the ripening time is a influential factor on formation of the hollow nanocrystallites in the resultant $\mathrm{Cu}_{2} \mathrm{O}$ spheres. It is possible to obtain different sized $\mathrm{Cu}_{2} \mathrm{O}$ crystallites in the shell by varying the process time.

To the growth of $\mathrm{LiFePO}_{4}$ particles in this study, the Ostwald ripening mechanism may be applicable in some extent. Figure 6 and Figure 8 show that the samples synthesized at temperatures above $170^{\circ} \mathrm{C}$ are $\mathrm{LiFePO}_{4}$. Figure 16,19 , 22, and 25 showed that the majority of the particles are straight-edged and flatsurfaced crystallites. The well defined particle shape reflects the characteristics of particles growing through a dissolution-precipitation process, i.e. the Ostwald ripening.

It is interesting to note that, with the same soaking time ( 1 minute), the sample treated at $170^{\circ} \mathrm{C}$ gave much bigger particles than the sample treated at $200^{\circ} \mathrm{C}$. This can be explained by higher nucleation rate at higher temperatures (92) and, when the amount of the available material is fixed, fast nucleation would result in small particles. Regarding the particle growth, the information given by Figure 16 and Figure 19 indicates the Ostwald ripening would have proceeded by expense of amorphous species, $\mathrm{Fe} 3\left(\mathrm{PO}_{4}\right)_{2}$ and $\mathrm{Li}_{3} \mathrm{PO}_{4}$. As discussed earlier, because both of the ramp time and the soaking time were short, it is hard to expect that the crystallization process can be completed by the end of the 1-minute soaking period. The crystallization would have continued during cooling down of the reactor to a certain temperature. Crystallization of $\mathrm{LiFePO}_{4}$ at low temperatures is evidenced by the work and Yang's (93) and Qu's (94). We believe the crystallization in cooling down stage would be easier, because appreciable 
amount of nuclei has already formed which could serve as the crystallization seeds. From this point, we can deduce that the after-soaking crystallization would be primarily the dissolution of amorphous $\mathrm{Fe}_{3}\left(\mathrm{PO}_{4}\right)_{2}$ and $\mathrm{Li}_{3} \mathrm{PO}_{4}$, and precipitation of $\mathrm{Li}^{+}, \mathrm{Fe}^{2+}$ and $\mathrm{PO}_{4}{ }^{3-}$ onto the existing $\mathrm{LiFePO}_{4}$ particles. Conversion of the amorphous $\mathrm{Fe}_{3}\left(\mathrm{PO}_{4}\right)_{2}$ and $\mathrm{Li}_{3} \mathrm{PO}_{4}$ into crystalline $\mathrm{LiFePO}_{4}$ in the Ostwald ripening process was fast, otherwise the peaks of $\mathrm{Fe}_{3}\left(\mathrm{PO}_{4}\right)_{2} \cdot 8 \mathrm{H}_{2} \mathrm{O}$ and $\mathrm{Li}_{3} \mathrm{PO}_{4}$ would have been seeing in the XRD patterns (Figure 6 and Figure 8). Ostwald ripening by expense of small $\mathrm{LiFePO}_{4}$ crystallites could be excluded from the $170^{\circ} \mathrm{C}$ - and the $200^{\circ} \mathrm{C}$-treated samples. By means of faster nucleation, there are much more small $\mathrm{LiFePO}_{4}$ crystallites in the latter than in the former. If the small crystallites had participated in the Ostwald ripening, the particle size showed in Figure 19 would have not exhibited such a big difference from that showed in Figure 16.

On the other hand, Ostwald ripening by expense of small crystallite would have take place in the samples by prolonged soaking at $200^{\circ} \mathrm{C}$. Compare the microstructures between the $200^{\circ} \mathrm{C} \times 1 \mathrm{~min}-$ and the $200^{\circ} \mathrm{C} \times 15$ min-treated samples. The latter stayed longer at the soaking temperature. The longer soaking should produce no less, if no more, $\mathrm{LiFePO}_{4}$ nuclei than shorter soaking. From the above discussion, we know that the amorphous species should be completely converted into the $\mathrm{LiFePO}_{4}$ crystalline phase. If, in the $200^{\circ} \mathrm{C} \times 15 \mathrm{~min}$-treated sample, only the amorphous species have contributed to the particle growth, the final particle size in the sample should smaller than that in the $200^{\circ} \mathrm{C} \times 1 \mathrm{~min}$ treated sample. However, the results are contrary to what it should be. As shown in Figure 19 and Figure 22, the particle size in the $200^{\circ} \mathrm{C} \times 15$ min-treated sample are greater than that in the $200^{\circ} \mathrm{C} \times 1 \mathrm{~min}$-treated sample by a couple of magnitudes. From this point, we can say that the expense of smaller $\mathrm{LiFePO}_{4}$ crystallites for growth of larger $\mathrm{LiFePO}_{4}$ particles was co-existent with the dissolution of the amorphous species, $\mathrm{Fe}_{3}\left(\mathrm{PO}_{4}\right)_{2}$ and $\mathrm{Li}_{3} \mathrm{PO}_{4}$. The amorphous species dissolved fast. Their dissolution would have been dominant in the early 
stage. The dissolution of crystallite is slow. It would be dominant after the amorphous species have bee exhausted.

The argument for growth of large particles by expense of small crystallites is further supported by comparing the particle sizes shown in Figure 22 to those in Figure 25 and Figure 28. From these figures, we can see substantial particle growth when the soaking time prolonged from 15 minutes to 30 minutes but no appreciable growth when the soaking time prolonged from 30 minutes to 45 minutes. We believe the growth in the 30-minutes soaking was dominated by expense of small crystallites of $\mathrm{LiFePO}_{4}$, based on the discussion in the last paragraph. The fact that no growth is seen when the soaking time prolonged from 30 minutes to 45 minutes is probably due to depletion of the small crystallites in the early 30-minutes soaking.

However, high resolution SEM images seem to tell us that the particle growth in this study is not simply an Ostwald ripening process. It can be seen from Figure 17, 20, 23 and 26 that these grown particles are assemblies of nano scale substructures. This is also the feature of the low temperature treated samples, as shown in Figure 11 and 14. Because Ostwald ripening is the process of addition materials to growing particles in atomic scale, the particles should be well crystallized and exhibit smooth surface. Due to the environmental heterogeneity, some defects may be induced. However, it should not be so much as shown in the figures. There must be other growth mechanism(s) accompanying the Ostwald ripening.

\subsection{The whole picture}

From the discussion in Section $\S 5.1, \S 5.2$ and $\S 5.3$, we could depict a whole picture for the development of the $\mathrm{LiFePO}_{4}$ crystalline phase and microstructure:

The first step in synthesis of $\mathrm{LiFePO}_{4}$ is the precipitation of amorphous clusters from titration of the $\mathrm{FeSO}_{4}-\mathrm{H}_{3} \mathrm{PO}_{4}$ solution with $\mathrm{LiOH}$. The precipitates are 
$\mathrm{Fe}_{3}\left(\mathrm{PO}_{4}\right)_{2}$ and $\mathrm{Li}_{3} \mathrm{PO}_{4}$ in terms of stoichiometry, as predicated by theoretical calculation. We use the term of "cluster" instead of "particle" or "droplet", because we believe the "clusters" are the units for evolvement of the primary crystallites that build up the rectangular crystalline $\mathrm{LiFePO}_{4}$ particles. These clusters were small in size (about 10 nanometers) and the size was mono modal (Figure 3).

The amorphous clusters could be crystallized into crystallites of different phases, depending on the hydrothermal treatment temperatures. At $100^{\circ} \mathrm{C}$ and $130^{\circ} \mathrm{C}$, the resulted crystallites are $\mathrm{Fe}_{3}\left(\mathrm{PO}_{4}\right)_{2} \cdot 8 \mathrm{H}_{2} \mathrm{O}$ and $\mathrm{Li}_{3} \mathrm{PO}_{4}$. At temperatures of $170^{\circ} \mathrm{C}$ and above, the resulted crystallites are $\mathrm{LiFePO}_{4}$. The crystallization (nucleation and growth of the crystallites) is isolated inside each of the individual clusters, i.e. one amorphous cluster converts into one crystallite. There are three crystallization mechanisms involved in the crystallization:

- $\mathrm{Li}_{3} \mathrm{PO}_{4}$ - direct conversion of the amorphous $\mathrm{Li}_{3} \mathrm{PO}_{4}$ cluster into the corresponding crystallites;

- $\mathrm{Fe}_{3}\left(\mathrm{PO}_{4}\right)_{2} \cdot 8 \mathrm{H}_{2} \mathrm{O}$ - incorporation of water molecules into the amorphous $\mathrm{Fe}_{3}\left(\mathrm{PO}_{4}\right)_{2}$ clusters during the amorphous-to-crystalline conversion;

- $\mathrm{LiFePO}_{4}$ - dissolution of the amorphous $\mathrm{Li}_{3} \mathrm{PO}_{4}$ cluster into $\mathrm{Li}^{+}$and $\mathrm{PO}_{4} 3^{--}$and incorporation of these ionic species into the $\mathrm{Fe}_{3}\left(\mathrm{PO}_{4}\right)_{2}$ clusters that then converted into $\mathrm{LiFePO}_{4}$ crystallites

The crystallites behave as building blocks to assemble larger particles via oriented attachment mechanism. Statistical collision is the first step, by which successful attachment occurs when crystallographic alignment between the colliding crystallites is satisfied. The initial attachment may result in irregular particles, but these particles will quickly reshape from irregular into faceted (plate-like, rectangular, etc.). The thermodynamic driving force for the reshaping is the difference of the surface energies between surfaces of different crystallographic directions. The crystallites attached via low-energy surfaces could have lower 
binding force than those attached via high-energy surfaces. The kinetic driving force for the reshaping could come from the Brown movement, but the shear stress seems be more important. Because mechanical stirring was applied throughout the hydrothermal treatment, the circumferential movement of the suspension could cause continuous rub between particles. Such a kind of rub could facilitate detachment of the loosely attached crystallites in thermodynamically unfavorable crystallographic directions. These detached crystallites could collide again the grown particles and are finally assembled into particles in the thermodynamically favorable crystallographic directions.

After all of the primary crystallites have been assembled into polycrystalline particles, further growth of the polycrystalline particles could continue with a mechanism that has the both components of oriented attachment and Ostwald ripening. Here we refer to the Ostwald ripening, because, in this stage, growth of large particles is down by expense of small particles. Here we refer to the oriented attachment, because the mass transportation from the small particles to the large particles is not in atomic scale but in crystallite scale. Unlike the conventional Ostwald ripening that dissolves small particles in atomic scale, the "Ostwald ripening" here involves dissolution of the small particles in scale of the primary crystallites. The preference of crystallite-scale dissolution over atomic scale dissolution comes from the fact that crystallite boundaries in the particle assemblies are macro sized defects through which the particles are easier to be split. The crystallites dissolved from the small particles would then deposit on the large particles in the same manner of oriented attachment as happened in the previous stage. The combined mechanism of Ostwald ripening and oriented attachment gives rise to a structural feature in agreement with the microstructure development we observed from Figure 19 through Figure 27: these figures show obvious grain growth with prolonged hydrothermal treatment, the growing particles exhibit assemblies of nanoscale building blocks all the time, and the growing particles keep in well-defined crystallographic shape from the 1-min treatment to the 30 -min treatment. 
Recrystallization of the assembled particles is the last growth mechanism. It may start in early stages but is completed in the last. The existence of this mechanism is evidenced by smoother particles surfaces shown in Figure 26 and Figure 29. The recrystallization would take place in a manner as we discussed in the Section §5.3.1. Here it is reiterated as: (a), formation of continuous interlayers between adjacent crystallites inside the particle assembly; (b), expansion of interlayers; and (c), extinguish of the original crystallites and give rise to larger single crystalline particles. 


\section{Future work}

The present study revealed several mechanisms involved in the formation of the $\mathrm{LiFePO}_{4}$ phase and in the development of its microstructure. The future work is to control and manipulate these mechanisms in order to obtain the desired material structure that correlated to the electrical properties for battery application.

Based on result of x-ray powder diffraction and the FE-SEM observation in the

present study, we concluded that oriented attachment hybrid with Ostwald ripening is the major mechanism for development of the $\mathrm{LiFePO}_{4}$ material structures. The primary units involved in the attachment and ripening are nanoscale $\mathrm{LiFePO}_{4}$ crystallites. They nucleated from the amorphous precipitates in the $\mathrm{LiOH}-\mathrm{FeSO}_{4}-\mathrm{H}_{3} \mathrm{PO}_{4}$ solution and become stable nanosized particles in a short period. They are uniform in size so that they can build up microscale $\mathrm{LiFePO}_{4}$ particles with well-defined crystallographic shapes by means of oriented attachment and Ostwald ripening.

The first issue in the future study is to examine the evolvement details of the primary blocks. In the present research, we used a microwave hydrothermal reactor with which we could only obtain samples after the reactor had cooled down to below $100^{\circ} \mathrm{C}$, at which the pressure inside the reactor can be released. Material species in the reaction system would experience substantial changes during the cool-down period, but we could not see the changes when we were unable to obtain the samples timely. The crystallization mechanism of the amorphous precursor we depicted in this research is the deducing from observations of those after-change samples. The picture may be rough and there could be more details need to be figured out. The future research should devise the reactor with an instant sampling port, by which samples can be drawn from the reactor while the reactor is under high pressure conditions. With the updated reactor, we would be able to draw a series of samples in time sequence as the 
processing progresses. FTIR and Raman spectra are to be used to investigate the chemical species in the precursors precipitated from the $\mathrm{LiOH}-\mathrm{FeSO}_{4}-\mathrm{H}_{3} \mathrm{PO}_{4}$ solution. High resolution TEM should be employed to examine how the amorphous precursors would gradually convert into crystalline particles. As these details are revealed, we would obtain detailed and more accurate information and we would be able to manipulate the mechanism for the desired size and size distribution of the primary building blocks.

The second issue in the future study is to investigate the conditions for assembling the building blocks (nanoscale $\mathrm{LiFePO}_{4}$ crystallites) into particles with desired shapes, sizes as well as assembly patterns. The present study indicated that oriented attachment occurred prior to Ostwald ripening and the former continued while the later came into being. Although such a sequence of structural evolvement seems common (81-85, 87), it could also be in reverse (86). For pursuing the ideal structure as stated in $\S 2$, we may need a dual-level assembly mechanism, i.e. assembling the nano crystallites (primary building blocks) into intermediate particles (secondary building blocks) at first and then making these secondary building blocks into final assembly. The potential for the so called dual-level assembly mechanism is indicated by the findings in the present study. Recall Figure 19, 22, 25 and 28. It seems that the plate-like particles were further assembled into larger irregular aggregates. Inside these irregular aggregates, the plate-like particles seem not loosely contacted, but have a number of fusion points that can be seen from Figure 21, 24 and 27. We have comprehensive discussions in $\S 5$ on the evolvement of the plate-like particles and the substructures in them. We did not address that how the plate-like particles were assembled into the larger aggregates. Because these large aggregates are irregular both in shape and in size, it needs further study on how to control them. The future study would address the issue on how to implement a dual-level assembly mechanism and how to manipulate the experiment conditions to 
regulate the particle growth and assembly. The effect of thermal conditions and chemical environments should be addressed in the study.

The third issue in the future study is to study the correlations between the particle morphology and the materials properties. As stated in $\S 2$, there is a lack of a clear correlation between the synthesis approaches and electrochemical properties of the synthesized materials. The initial discharge capacities and the cycling stabilities of the materials synthesized by different groups appeared scattered. The difference of these properties between samples obtained in similar synthesis approaches is in the same amplitude as that between samples got from different preparation methods. We believe that particle structure and morphology is the key element that could bridge the materials processing and the materials property. The previous section defined the second issue in the future study which is the correlation between the processing and material structure. For the third issue that would address the materials structure and the materials property, $\mathrm{LiFePO}_{4}$ powders of various sizes, shapes and structure patterns could be prepared by manipulation of the particle assembling mechanisms with controlled conditions. With these powders, the electrical properties, such as charge/discharge voltage windows, charge/discharge capacity as well as cycling stability, could be systematically studied. Correlations between materials process and the materials property via materials structure would be established that could be useful for producing high quality $\mathrm{LiFePO}_{4}$ battery materials. 


\section{Conclusions}

The findings from the present study can be summarized into the following points:

1. The precipitated precursor consisted of amorphous particles, of which the size was less than 20 nanometers. The particles were apparently grayish, but it was actually a mixture of blue and white. Analytical calculation indicates that the precursor was comprised of two chemical species, $\mathrm{Li}_{3} \mathrm{PO}_{4}$ and $\mathrm{Fe}_{3}\left(\mathrm{PO}_{4}\right)_{2}$. Titration of $\mathrm{H}_{3} \mathrm{PO}_{4}$ solution by $\mathrm{LiOH}$ confirmed that the white precipitates were $\mathrm{Li}_{3} \mathrm{PO}_{4}$, from which we deduce that the blue particles were $\mathrm{Fe}_{3}\left(\mathrm{PO}_{4}\right)_{2}$.

2. Different crystalline phases could be obtained by microwave hydrothermal treatment in different conditions. At $100^{\circ} \mathrm{C}$ and $130^{\circ} \mathrm{C}, \quad \mathrm{Li}_{3} \mathrm{PO}_{4}$ and $\mathrm{Fe}_{3}\left(\mathrm{PO}_{4}\right) \cdot 8 \mathrm{H}_{2} \mathrm{O}$ were obtained. At $170^{\circ} \mathrm{C}, \mathrm{Fe}_{3}\left(\mathrm{PO}_{4}\right) \cdot 8 \mathrm{H}_{2} \mathrm{O}$ was replaced by $\mathrm{LiFePO}_{4} \cdot \mathrm{Li}_{3} \mathrm{PO}_{4}$ still exists but its XRD peaks became much weaker than those in the low temperature samples. At $200^{\circ} \mathrm{C}$, the crystalline phase was pure $\mathrm{LiFePO}_{4}$ and no other phases were detected. $\mathrm{LiFePO}_{4}$ phase formed at the higher temperatures was not from conversion of $\mathrm{Fe}_{3}\left(\mathrm{PO}_{4}\right) \cdot 8 \mathrm{H}_{2} \mathrm{O}$ and $\mathrm{Li}_{3} \mathrm{PO}_{4}$, but directly nucleated from the amorphous phase. Nucleation of these crystalline phases from the amorphous phase took place in a competition manner. In the $200^{\circ} \mathrm{C}$ synthesis experiment, the rapid heating bypassed the nucleation of $\mathrm{Fe}_{3}\left(\mathrm{PO}_{4}\right) \cdot 8 \mathrm{H}_{2} \mathrm{O}$ and $\mathrm{Li}_{3} \mathrm{PO}_{4}$ and obtained pure $\mathrm{LiFePO}_{4}$ phases.

3. The synthesized $\mathrm{LiFePO}_{4}$ powders were of straight-edged plate-like particles. Such a well-defined crystallographic morphology came into being in very short heating period. Prolonged heat treatment maintained the plate-like morphology but resulted in larger particle sizes. Despite the straight edge and the smooth surface, FE-SEM examination revealed nanoscale substructures throughout the particle surface.

4. Rapid evolvement of such specially structured particles is attributed to a mechanism of oriented attachment. Prior to oriented attachment was conversion 
of the amorphous precursors into crystallites. The crystallization was confined within the individual amorphous particles that resulted in nanoscale crystallites of uniform size. Oriented attachment of the nanoscale crystallites occurred by means of statistical collision, followed by rearrangement of the attached crystallites into well defined crystallographic assembles (straight-edged plate-like particles). Such an epitaxial rearrangement was governed by the energy difference between different crystallographic surfaces of the $\mathrm{LiFePO}_{4}$ crystals.

5. Ostwald ripening took place for further growth of the plate-like particles. There is a difference between the term of Ostwald ripening used in this study and that from the conventional concept. The conventional concept depicts the species involved in the mass transport from small particles to large particles as that in atomic/ionic scale. The term used in this study attributes the units added onto the growing $\mathrm{LiFePO}_{4}$ crystals to be the primary crystallites. In the Ostwald ripening stage, there were no free primary crystallites available. However, they could be released from the polycrystalline $\mathrm{LiFePO}_{4}$ particles. A concentration gradient of the primary crystallites from small $\mathrm{LiFePO}_{4}$ particles to large $\mathrm{LiFePO}_{4}$ particles could be established by higher crystallites release rate at the small particles. The faster releasing was originated from the weaker bonding between the primary crystallites in the small particles.

6. Prolonged thermal treatment would bring about recrystallization inside grown polycrystalline $\mathrm{LiFePO}_{4}$ particles. Several steps were involved in the recrystallization: (i) formation of continuous interlayers between adjacent crystallites inside the particle assembly; (ii) expansion of interlayers; and (iii) extinguish of the original crystallites and give rise to larger single crystalline particles.

7. There is an indication that the polycrystalline $\mathrm{LiFePO}_{4}$ platelets could be further assembled into round-shaped particles. Such a double-level assembly can be in multi-micron sizes and have channels that facilitate the powder handling 
during battery manufacturing as well as the communication between the cathode material and the electrolytes in battery operation.

Effectively control and manipulation of the mechanisms that are found from this study would give us the capability to obtain desired material structure and therefore desired material properties for battery application. The future study should address the following three issues:

1. Examine the evolvement details of the primary blocks. Advance our knowledge in this regard would let us be able to produce the primary building blocks with desired size and size distribution.

2. Investigate the conditions for assembling the building blocks (nanoscale $\mathrm{LiFePO}_{4}$ crystallites). Knowledge acquired from this proposed investigation is essential for making $\mathrm{LiFePO}_{4}$ particles with desired shapes, sizes, and more importantly, assembly patterns. By completion of the investigation, producing of easy-to-handle $\mathrm{LiFePO}_{4}$ powders with appropriately channeled and multilevelly assembled particles could be realized.

3. Study the correlations between the particle morphology and the materials properties. The studies defined for the first two issues would make the $\mathrm{LiFePO}_{4}$ powders of various structures available. With these powders, the electrical properties would be systematically studied along with the materials structures. The study would establish a set of correlations from materials process to the materials property via materials structure. The established correlations would serve as guidance for producing high quality $\mathrm{LiFePO}_{4}$ battery materials. 


\section{References}

1, International Energy Agency. 75739 Paris Cedex 15, France. Tracking Clean Energy Progress: Energy Technology Perspectives 2012 excerpt as IEA input to the Clean Energy Ministerial; 2012. Available from: http://www.iea.org/media/ etp/etp2012_tech_overview_04_electric_vehicles.pdf.

2, U.S.Department of Energy. 1000 Independence Avenue Southwest Washington, DC 20560. Recovery Act: -Transportation Electrificatio, Funding Opportunity Number: DE-FOA- -0000028; 2009. Available from: http://www.nationalservice.gov/about/recovery/index.asp.

3, Carlos Gomes. Scotiabank. 44 King St West, Toronto, ON, Canada. Global Auto Report; 2012. Available from: http://www.scotiacapital.com/English/bns_econ /bns_auto.pdf.

4, Keith Bradsher. Hong Kong bureau chief of The New York Times. China Vies to Be World's Leader in Electric Cars; 2009. Available from: http:// www.nytimes.com/2009/04/o2/business/global/o2electric.html.

5, Anjan Hemanth Kumar. Frost \& Sullivan. 7550 W Ih 10 \# 400, San Antonio, TX. Electric motors drive future urban vehicles; 2012. Available from: http://www.automotiveworld.com/news/powertrain/94130-electric-motorsdrive-future-urban-vehicles.

6, Linden D. Handbook of Batteries and Fuel Cells. New York, NY. MCGraw-Hill Book Company; 1983.

7, Daniel C. Materials and Processing for Lithium-Ion Batteries. JOM. 2008;60(9):43-48.

8, Whittingham MS. Overview of chemical storage: Batteries, today and tomorrow. Boston, MA. 234th ACS National Meeting. 2007;19-23. 
9,Whittingham. MS. Bethesda, MD. The Synthesis and Characterization of Substituted Olivines and Layered Manganese Oxides; 2008. Available from: http://batt.lbl.gov/battfiles/BattReview2011/es050_whittingham_2011_o.pdf.

10, Xiao J, Chernova NA, Whittingham MS. Layered Mixed Transition Metal Oxide Cathodes with Reduced Cobalt Content for Lithium Ion Batteries. Chem. Mater. 2008;20:7454-7464.

11, Liu HK, Wang GX, Guo ZP, Wang JZ, Konstantinov K. Nanomaterials for lithium-ion rechargeable batteries. J. Nanosci. Nanotechnol. 2006;6:1-15.

12, Bruce PG, Scrosati B, Tarascon JM. Nanomaterials for Rechargeable Lithium Batteries. Angew. Chem. Int. Ed. 2008;47:2930-2946.

13, Ye SH, Lv JY, Gao WP, Wu F, Song DY, Synthesis and electrochemical properties of $\mathrm{LiMn}_{2} \mathrm{O}_{4}$ spinel phase with nanostructure. Electrochim. Acta. 2004;49:1623-1628.

14, Shukla AK, Kumar TP. Materials for next-generation lithium batteries. Current Science. 2008;94:315-331.

15, Padhi AK, Nanjundaswamy KS, Masquelier C, Okada S, Goodenough JB. Effect of structure on the Fe31/Fe21 redox couple in iron phosphates. J. Electrochem. Soc. 1997;144:1609-1613.

16, Ong SP, Wang L, Kang B, Ceder G. Li-Fe-P-O2 Phase Diagram from First Principles Calculations. Chem. Mater. 2008;20:1798-1807.

17, Jugovic D, Uskokovic D. A review of recent developments in the synthesis procedures of lithium iron phosphate powders. Journal of Power Sources. 2009;190:538-544.

18, Julien CM, Mauger A, Ait-Salah A, Massot M, Gendron F, Zaghib K. Nanoscopic scale studies of $\mathrm{LiFePO}_{4}$ as cathode material in lithium-ion batteries for HEV application. Ionics. 2007;13(6):395-411. 
19, Zaghib K, Ravet N, Gauthier M, Gendron F, Mauger A, Goodenough JB, Julien CM. Optimized electrochemical performance of $\mathrm{LiFePO}_{4}$ at 60 with purity controlled by SQUID magnetometry. J. Power Sources. 2006;163:560-566.

20, Yamada A, Chung C, Hinokuma K. Optimized LiFePO4 for lithium batteries. J. Electrochem. Soc. 2001;148:A224-A229.

21, Franger S, Cras FL, Bourbon C, Rouault H. Comparison between different $\mathrm{LiFePO}_{4}$ synthesis routes and their influence on its physico-chemical properties. J. Power Sources. 2003;119-121:252-257.

22, Takahashi M, Tobishima S, Takei K, Sakurai Y. Characterization of LiFePO4 as the cathode material for rechargeable lithium batteries. J. Power Sources. 2001;97-98:508-511.

23, Kosova N, Devyatkina E. Mechanochemical Preparation of Materials with Enhanced Characteristics for Lithium Batteries. Solid State Ionics. 2004;172:181184 .

24, Needham SA, Calka A, Wang GX, Mosbah A, Liu HK. A new rapid synthesis technique for electrochemically active materials used in energy storage applications. Electrochem. Commun. 2006;8:434-438.

25, Andersson AS, Kalska B, Häggström L, Thomas JO. Lithium extraction/insertion in LiFePO4: an X-ray diffraction and Mossbauer spectroscopy study. Solid State Ionics. 2000;130(1-2):41-52.

26, Konarova M, Taniguchi. Preparation of $\mathrm{LiFePO}_{4} / \mathrm{C}$ composite powders by ultrasonic spray pyrolysis followed by heat treatment and their electrochemical properties. Mater. Res. Bull. 2008;43(12):3305-3317.

27, Jugović D, Cvjetićanin N, Mitrić M, Mentus S, Uskoković D. Comparison between different $\mathrm{LiFePO}_{4}$ synthesis routes. Materials Science Forum. 2007;555:225-230. 
28, Bewlay SL, Konstantinov K, Wang GX, Dou SX, Liu HK, Conductivity improvements to spray-produced $\mathrm{LiFePO}_{4}$ by addition of a carbon source. Mater. Lett. 2004;58(11):1788-1791.

29, Teng TH, Yang MR, Wu SH, Chiang YP. Electrochemcial properties of LiFeo.9Mgo.1PO4/carbon cathode materials prepared by ultrasonic spray pyrolysis. Solid State Commun. 2007;142(7):389-392.

30, Hu CC, Chen WC, Chang $\mathrm{KH}$, How to Achieve Maximum Utilization of Hydrous Ruthenium Oxide for Supercapacitors. J. Electrochem. Soc. 2004;151 (2):A281-A290.

31, Sastry AM, Chen YH, Kim HC, Zhang X, Chung M, Shyy W. DOE Vehicle Technologies Annual Merit Review Meeting. Washington D.C. Scale-Bridging Simulations and Experiments of Electrode Materials in Li-ion Batteries; 2009. Available from: http://www1.eere.energy.gov/vehiclesandfuels/resources/vt_ merit_review_09.html

32, Yu LJ, Qin MJ, Zhu P, Yang L. Numerical simulation and optimization of nickel-hydrogen batteries. Journal of Power Sources. 2008;179(2):848-853.

33, Goodenough JB, Kim Y. DOE Vehicle Technologies Annual Merit Review Meeting, Washington D.C. Search for New Anode Materials; 2009. Available from: http://www1.eere.energy.gov/vehiclesandfuels/resources/vt_merit_review _ o9.html.

34, Park GJ, Kalpana D, Thapa AK, Nakamura H, Lee YS, M. Yoshio M. A Novel Hybrid Supercapacitor Using a Graphite Cathode and a Niobium(V) Oxide Anode. Bull. Korean Chem. Soc. 2009;30(4):817-820.

35, Jung YS, Lee S, Ahn D, Dillon AC, Lee SH. Electrochemical Reactivity of Ballmilled $\mathrm{MoO}_{3}$-y Powders as Anode for Lithium Secondary Batteries. J. Power Sources. 2009;188:286-291. 
36, Armstrong G, Armstrong AR, Bruce PG, Reale P, Scrosati B. TiO2(B) Nanowires as an Improved Anode Material for Lithium-Ion Batteries Containing $\mathrm{LiFePO}_{4}$ or LiNio.5Mn1.5 $\mathrm{O}_{4}$ Cathodes and a Polymer Electrolyte. Adv. Mater. 2006;18;2597-2600.

37, Bruce PG, Scrosati B, Tarascon JM. Nanomaterials for Rechargeable Lithium Batteries. Angew. Chem. Int. Ed. 2008;47:2930-2946.

38, Fusalba F, Gouérec P, Villers D, Bélanger D. Electrochemical Characterization of Polyaniline in Nonaqueous Electrolyte and Its Evaluation as Electrode Material for Electrochemical Supercapacitors. Journal of the Electrochemical Society, 2001;148:A1-A6.

39, Higuchi M, Katayamaa K, Azumaa Y, Yukawab M, Suharab M. Synthesis of $\mathrm{LiFePO}_{4}$ cathode material by microwave processing. Journal of Power Sources. 2003;119-121:258-261.

40, Higuchi M, Tsuruoka T, Asaka T, Mihara T, Suhara M, Katayama K, Azuma Y. Preparation of $\mathrm{LiFePO}_{4}$ as cathode material for a lithium ion battery by microwave processing. Key Engineering Materials. 2004;269:147-150.

41, Li Q, Song Y, Zhou M, Sun Y, Qiao Q. Synthesis of the doped lithium iron phosphate by the microwave heating method. Liaoning Shiyou Huagong Daxue Xuebao. 2006;26(4):32-37.

42, Wang L, Jia D, Huang Y. Microwave synthesis method of lithium iron phosphate anode material for lithium secondary batteries. Faming Zhuanli Shenqing. 2008; CN 101121508 A 20080213.

43, Beninati S, Damen L, Mastragostino M. Microwave-assisted synthesis of $\mathrm{LiFePO}_{4}$ for high power applications. Journal of Power Sources. 2008;180(2):875-879. 
44, Li W, Ying J, Wan C, Jiang C, Gao J, Tang C. Preparation and characterization of $\mathrm{LiFePO}_{4}$ from $\mathrm{NH}_{4} \mathrm{FePO}_{4} \cdot \mathrm{H}_{2} \mathrm{O}$ under different microwave heating conditions. Journal of Solid State Electrochemistry. 2007;11(6):799-803.

45, Zou H, Zhang G, Shen PK. Intermittent microwave heating synthesized high performance spherical $\mathrm{LiFePO} 4 / \mathrm{C}$ for Li-ion batteries. Materials Research Bulletin. 2010;45(2):149-152.

46, Song MS, Kang YM, Kim JH, Kim HS, Kim DY, Kwon HS, Lee JY. Simple and fast synthesis of LiFePO4-C composite for lithium rechargeable batteries by ballmilling and microwave heating. Journal of Power Sources. 2007;166:260-265.

47, Herle PS, Ellis B, Coombs N, Nazar LF. Nano-network electronic conduction in iron and nickel olivine phosphates. Nat. Mater. 2004;3:147-152.

48, Song MS, Kim DY, Kang YM, Kim YI, Lee JY, Kwon HS. Amphoteric effects of $\mathrm{Fe} 2 \mathrm{P}$ on electrochemical performance of lithium iron phosphate-carbon composite synthesized by ball-milling and microwave heating. Journal of Power Sources. 2008;180(1):546-552.

49, Park KS, Son JT, Chung HT, Kim SJ, Lee CH, Kim HG. Synthesis of LiFePO4 by co-precipitation and microwave heating. Electrochemistry Communications. 2003;5:839-842.

50, Li P, He W, Zhao H, Wang S. Biomimetic synthesis and characterization of the positive electrode material LiFePO4. Journal of Alloys and Compounds. 2009;471(1-2):536-538.

51, Zhou W, He W, Li Z, Zhao H, Yan S. Biosynthesis and electrochemical characteristics of $\mathrm{LiFePO}_{4} / \mathrm{C}$ by microwave processing. Journal of Solid State Electrochemistry. 2009;13(12):1819-1823. 
52, Sato C, Hoshi E, Uematsu K, Ishigaki T, Toda K, Sato M. Hydrothermal reaction by microwave heating for synthesis of $\mathrm{LiFePO}_{4}$ as cathode material. Transactions of the Materials Research Society of Japan. 2010;35(2):397-400.

53, Yang G, Ji H, Liu H, Huo K, Fu J, Chu P. Fast preparation of $\mathrm{LiFePO}_{4}$ nanoparticles for lithium batteries by microwave-assisted hydrothermal method. Journal of Nanoscience and Nanotechnology. 2010;10(2):980-986.

54, Murugan A, Muraliganth T, Manthiram A. One-Pot Microwave-Hydrothermal Synthesis and Characterization of Carbon-Coated LiMPO4 (M = Mn, Fe, and Co) Cathodes. Journal of the Electrochemical Society. 2009;156 (2):A79-A83

55, Murugan A, Muraliganth T, Manthiram A. Comparison of Microwave Assisted Solvothermal and Hydrothermal Syntheses of $\mathrm{LiFePO}_{4} / \mathrm{C}$ Nanocomposite Cathodes for Lithium Ion Batteries. J. Phys. Chem. C. 2008;112:14665-14671.

56, BBilecka I, Hintennach A, Djerdj I, Novak P, Niederberger M. Efficient microwave-assisted synthesis of $\mathrm{LiFePO}_{4}$ mesocrystals with high cycling stability. Journal of Materials Chemistry. 2009;19:5125-5128.

57, Murugan A, Murraliganth T, Manthiram A, Microwave-irradiated solvothermal synthesis of $\mathrm{LiFePO}_{4}$ nanorods and their nanocomposites for lithium ion batteries. ECS Transactions. 2009;16:49-56.

58, Chen J, Wang S, Whittingham MS. Hydrothermal synthesis of cathode materials. Journal of Power Sources. 2007;174:442-448.

59, Dokko K, Koizumi S, Sharaishi K, Kanamura K. Electrochemical properties of LiFePO4prepared via hydrothermal route. Journal of Power Sources. 2007;165:656-659. 
60, Liu $\mathrm{H}$, Zhang $\mathrm{P}$, Li GC, Wu Q, Wu YP. $\mathrm{LiFePO}_{4} / \mathrm{C}$ composites from carbothermal reduction method. J Solid State Electrochem. 2008;12:1011-1015.

61, Wang YG, Wang YR, Hosono E, Wang K, Zhou H. The Design of a LiFePO4/Carbon Nanocomposite With a Core-Shell Structure and Its Synthesis by an In Situ Polymerization Restriction Method. Angew. Chem. Int. Ed. 2008;47:7461-7465.

62, Kim DH, Kim J. Synthesis of LiFePO4nanoparticles and their electrochemical properties. Journal of Physics and Chemistry of Solids. 2007;68:734-737.

63, Lai JCK, Jandhyam S, Lai SMB, Dukhande VV, Bhushan A, Christopher K. Daniels CK, Leung SW. Idaho State University, Pocatello, ID; 2008. Cytotoxicity of Metallic Oxide Nanoparticles: New Insights into Methodological Problems and Advances in Elucidation of Underlying Mechanisms. Available from: http://www.iiis.org/CDs2008/CD2008SCI/SCI2008/PapersPdf/S187QI.pdf

64, Bradley S. swissinfo.ch; 2011. Health concerns raised over nanoparticles. Available from: http://www.swissinfo.ch/eng/science_technology/Health_ concerns_raised_over_nanoparticles.html?cid=29293290.

65, Gangulibabu N, Kalaiselvi D, Bhuvaneswari CHD. On the synergistic effect of carbonate anion directed shape controlled morphology and super P carbon in preparing $\mathrm{LiFePO} 4 / \mathrm{C}$ cathode with improved lithium intercalation behavior. Int. J. Electrochem. Sci. 2010;5:1597-1604.

66, Teng F, Santhanagopalan S, Lemmens R, Geng X, Patel P, Meng DD. In situ growth of $\mathrm{LiFePO}_{4}$ nanorod arrays under hydrothermal condition. Sol State Sci 2010;12(5):952-955.

67, Zhou N, Liu Y, Li J, Uchaker E, Liu S, Huang K, Cao G. Synthesis and characterization of high power $\mathrm{LiFePO}_{4} / \mathrm{C}$ nano-plate thin films. Journal of Power Sources. 2012;213:100-105. 
68, Ellis B, Kan WH, Makahnouk WRM, Nazar LF. Synthesis of nanocrystals and morphology control of hydrothermally prepared LiFePO4. J. Mater. Chem. 2007;17:3248-3254.

69, Wikipedia. Lithium sulfate;2012. Available from: http://en.wikipedia.org/ wiki/Lithium_sulfate.

70, FMC Corporation. Charlotte, NC 28208. Lithium Orthophosphate MSDS;

2010. Available from: http://www.fmclithium.com/Portals/FMCLithium/

content/docs/msds/QS-SDS-094\%20ro.pdf.

71, Lee MH, Kim JY, Song HK. A hollow sphere secondary structure of

LiFePO4nanoparticles. Chem. Commun. 2010;46:6795-6797.

72, Department of Chemistry-University of Alabama in Huntsville. Huntsville, AL 35899. Table of Solubility Product Constants (Ksp at 250 C); 2009. Available from: http://chemistry.uah.edu/courseware/ch123/resources/ch123solubility_ constants.html.

73, Mattievich E, Danon J. Hydrothermal synthesis and mössbauer studies of ferrous phosphates of homologous series $\mathrm{Fe}^{2+}\left(\mathrm{PO}_{4}\right) 2(\mathrm{H} 2 \mathrm{O}) n$. J. Inorg. Nucl. Chem. 1977;39:569-580.

74, Zhang TH, Liu XY. How Does a Transient Amorphous Precursor Template Crystallization. J. AM. CHEM. SOC. 2007;129:13520-13526.

75, Chen X, Samia ACS, Lou Y, and Burda C. Investigation of the Crystallization Process in $2 \mathrm{~nm}$ CdSe Quantum Dots. J. AM. CHEM. SOC. 2005;127:4372-4375.

76, Oleinik GS, Danilenko NV. Sove features of coalescence processes and mechanisms in systems of nonmetallic crystalline particles. Powder Metallurgy and Metal Ceramics. 2002;41(3-4):195-198. 
77, Tamou Y, Tanaka SI. Formation and coalescence of tungsten nanoparticles under electron beam irradiation. NanoStructured Materials. 1999;12(1-4):123126.

78, Mintova S, Olson NH, Bein T. Electron Microscopy Reveals the Nucleation Mechanism of Zeolite Y from Precursor Colloid. Angew. Chem. Int. Ed. 1999;38 (21):3201-3204.

79, Wu L, Solovyov VF, Wiesmann HJ, Zhu Y, Suenaga M. Mechanisms for hetero-epitaxial nucleation of $\mathrm{YBa}_{2} \mathrm{Cu}_{3} \mathrm{OR} 6.1$ at the buried precursor/SrTiO3 interface in the postdeposition reaction process. Appl. Phys. Lett. 2002;80:419412.

8o, Zhang H, Banfield JF. Phase transformation of nanocrystalline anatase-torutile via combined interface and surface nucleation. Journal of Materials Research. 2000;15:437-448.

81, Ribeiro C, Lee EJH, Giraldi TR, Longo E, Varela JA, Leite ER. Study of Synthesis Variables in the Nanocrystal Growth Behavior of Tin Oxide Processedby Controlled Hydrolysis. J. Phys. Chem. B. 2004;108:15612-15617.

82, Lee EJH, Ribeiro C, Longo E, Leite ER. Oriented Attachment: An Effective Mechanism in the Formation of Anisotropic Nanocrystals. J. Phys. Chem. B. 2005;109:20842-20846.

83, Alivisatos P. Naturally Aligned Nanocrystals. Science. 2000;289:736-737.

84, Penn RL, Banfield JF. Morphology development and crystal growth in nanocrystalline aggregates under hydrothermal conditions: Insights from titania. Geochimica et Cosmochimica Acta. 1999;63(10):1549-1557.

85, Penn RL, Oskam G, Strathmann TJ, Searson PC, Stone AT, Veblen DR. Epitaxial Assembly in Aged Colloids. J. Phys. Chem. B. 2001;105:2177-2182. 
86, Xia Y, Zhang W, Huang H, Gan Y, Tian J, Tao X. Self-assembled mesoporous $\mathrm{LiFePO}_{4}$ with hierarchical spindle-like architectures for high-performance lithium-ion batteries. Journal of Power Sources. 2011;196:5651-5658.

87, Qin X, Wang J, Xie J, Li F, Wen L, Wang X. Hydrothermally synthesized $\mathrm{LiFePO}_{4}$ crystals with enhanced electrochemical properties: simultaneous suppression of crystal growth along [010] and antisite defect formation. Phys. Chem. Chem. Phys. 2012;14:2669-2677.

88, Penn RL, Oskam G, Strathmann TJ, Searson PC, Stone AT, Veblen DR; Epitaxial Assembly in Aged Colloids. J. Phys. Chem. B. 2001;105:2177-2182.

89, Wong EM, Bonevich JE, Searson PC. Growth Kinetics of Nanocrystalline ZnO Particles from Colloidal Suspensions. J. Phys. Chem. B. 1998;102:7770-7775.

90, Xiang H, Zhang D, Jin Y, Chen C, Wu J, Wang H. Hydrothermal synthesis of ultra-thin LiFePO4 platelets for Li-ion Batteries. J Mater Sci. 2011;46:4906-4912.

91, Zeng HC. Ostwald Ripening: A Synthetic Approach for Hollow Nanomaterials. Current Nanoscience. 2007;3:177-181.

92, Kingery WD, Brown HK, Uhlmann DR. Introduction to Ceramics. 2nd ed. New York (NY): John Willey and Sons, Inc.; 1975. 425-428P.

93, Yang S, Zavalij PY, Whittingham MS. Hydrothermal synthesis of lithium iron phosphate cathodes. Electrochemistry Communications. 2001;3:505-508

94, Ou X, Pan L, Gu H, Wu Y, Lu J. Temperature-dependent crystallinity and morphology of $\mathrm{LiFePO}_{4}$ prepared by hydrothermal synthesis. J. Mater. Chem. 2012;22:9064-9068

95, Wikipedia, the free encyclopedia. Phosphoric acid. Available from: http://en.wikipedia.org/wiki/Phosphoric_acid. 
96, Kobylin P, Kaskiala T, Salminen J. Modeling of $\mathrm{H}_{2} \mathrm{SO}_{4}-\mathrm{FeSO}_{4}-\mathrm{H}_{2} \mathrm{O}$ and $\mathrm{H}_{2} \mathrm{SO}_{4}-\mathrm{Fe} 2\left(\mathrm{SO}_{4}\right)_{3}-\mathrm{H}_{2} \mathrm{O}$ Systems for Metallurgical Applications. Ind. Eng. Chem. Res. 2007;46:2601-2608.

97, Zumdahl SS, Zumdahl SA. Chemical Principles. 7th ed. Houghton Mifflin; 2007. $260 \mathrm{p}$.

98, Nriagu JO. Stability of vivianite and ion-pair formation in the system $\mathrm{Fe}_{3}\left(\mathrm{PO}_{4}\right)_{2}-\mathrm{H}_{3} \mathrm{PO}_{4} \mathrm{H}_{3} \mathrm{PO}_{4}-\mathrm{H}_{2} \mathrm{O}$. Geochimica et Cosmochimica Acta. 1972;36(4): 459-470.

99, Department of Chemistry-University of Alabama in Huntsville. Huntsville, AL. Table of solubility product constant (Ksp at $25^{\circ} \mathrm{C}$ ). Available from: http:// chemistry.uah.edu/courseware/ch123/resources/ch123solubilityconstants.html

100, Hobbs PV. Basic physical chemistry for atmospheric sciences. 2nd. Cambridge(UK):The Press Syndicate of the University of Cambridge;2000. 167p. 
Appendix: Theoretical Analysis of $\mathrm{LiFePO}_{4}$ precursors

Definition of mathematical variables

$\boldsymbol{K}$. Cumulative dissociation constant of chemical species in aqueous solution. It may have numerical subscripts, such as $K_{1}, K_{2}, K_{3}$, etc. The numerical subscripts represent the number of dissociation steps that are cumulated.

Ka. Dissociation constant of chemical species in aqueous solution. For multi-step dissociation, the subscript $a$ is followed by a number, which represents the dissociation step.

$\boldsymbol{K}_{\boldsymbol{s} p}$. Solubility constant product of chemical species. A chemical formula may follow the subscript $s p$ to specify the represented species.

$\boldsymbol{K}_{\boldsymbol{w}}$. Dissociation constant of water.

m. Moles of $\mathrm{H}_{3} \mathrm{PO}_{4}$ added into $1000 \mathrm{ml}$ aqueous solution.

$\boldsymbol{m}_{2}$. Moles of $\mathrm{FeSO}_{4}$ added into $1000 \mathrm{ml}$ aqueous solution.

$\boldsymbol{m}_{3}$. Moles of LiOH added into $1000 \mathrm{ml}$ aqueous solution.

m. Moles of $\mathrm{LiPO}_{3}$ precipitated from $1000 \mathrm{ml}$ of $\mathrm{LiOH}-\mathrm{H}_{3} \mathrm{PO}_{4}$ aqueous solution.

$\boldsymbol{m}_{5}$. Moles of $\mathrm{Fe}_{3}\left(\mathrm{PO}_{4}\right)_{2}$ precipitated from $1000 \mathrm{ml} \mathrm{LiOH}-\mathrm{FeSO}_{4}-\mathrm{H}_{3} \mathrm{PO}_{4}$ solution.

p. Moles of $\mathrm{Li}^{+}$in $1000 \mathrm{ml}$ aqueous solution at equilibrium, i.e. $\left[\mathrm{Li}^{+}\right]$. The unit is denoted by M.

q. Moles of $\mathrm{OH}^{-}$in $1000 \mathrm{ml}$ aqueous solution at equilibrium, i.e. [OH-]. The unit is denoted by $\mathrm{M}$.

r. Moles of $\mathrm{Fe}^{2+}$ in $1000 \mathrm{ml}$ aqueous solution at equilibrium, i.e. $\left[\mathrm{Fe}^{2+}\right]$. The unit is denoted by $\mathrm{M}$. 
s. Moles of $\mathrm{FeOH}^{+}$in $1000 \mathrm{ml}$ aqueous solution at equilibrium, i.e. $\left[\mathrm{FeOH}^{+}\right]$. The unit is denoted by M.

$\boldsymbol{t}$. Moles of $\mathrm{SO}_{4}{ }^{2-}$ in $1000 \mathrm{ml}$ aqueous solution at equilibrium, i.e. [ $\left.\mathrm{SO}_{4}{ }^{2-}\right]$. The unit is denoted by M.

u. Moles of $\mathrm{HSO}_{4}^{-}$in $1000 \mathrm{ml}$ aqueous solution at equilibrium, i.e. $\left[\mathrm{SO}_{4}^{-}\right]$. The unit is denoted by M.

$\boldsymbol{v}$. Moles of $\mathrm{H}^{+}$in $1000 \mathrm{ml}$ aqueous solution at equilibrium, i.e. $[\mathrm{H}+]$. The unit is denoted by M.

$\boldsymbol{w}$. Moles of $\mathrm{H}_{3} \mathrm{PO}_{4}$ in $1000 \mathrm{ml}$ aqueous solution at equilibrium, i.e. $\left[\mathrm{H}_{3} \mathrm{PO}_{4}\right]$. The unit is denoted by $\mathrm{M}$.

$\boldsymbol{x}$. Moles of $\mathrm{H}_{2} \mathrm{PO}_{4}^{-}$in $1000 \mathrm{ml}$ aqueous solution at equilibrium, i.e. $\left[\mathrm{H}_{2} \mathrm{PO}_{4}^{-}\right]$. The unit is denoted by $\mathrm{M}$.

$\boldsymbol{y}$. Moles of $\mathrm{HPO}_{4}{ }^{2-}$ in $1000 \mathrm{ml}$ aqueous solution at equilibrium, i.e. $\left[\mathrm{HPO}_{4}{ }^{2-}\right.$. The unit is denoted by M.

z. Moles of $\mathrm{PO}_{4}{ }^{-}$in $1000 \mathrm{ml}$ aqueous solution at equilibrium, i.e. $\left[\mathrm{PO}_{4}^{3-}\right]$. The unit is denoted by $\mathrm{M}$.

\section{Chemical species in $\mathrm{H}_{3} \mathrm{PO}_{4}$ solution}

When $\mathrm{H}_{3} \mathrm{PO}_{4}$ is dissolved in water, three dissociation reactions would take place (95).

$$
\begin{gathered}
\mathrm{H}_{3} \mathrm{PO}_{4} \leftrightarrow \mathrm{H}^{+}+\mathrm{H}_{2} \mathrm{PO}_{4^{-}} \\
K_{a 1}=\frac{\left[H^{+}\right] \cdot\left[H_{2} P O_{4}^{-}\right]}{\left[H_{3} P O_{4}\right]} \\
\mathrm{H}_{2} \mathrm{PO}_{4^{-}} \leftrightarrow \mathrm{H}^{+}+\mathrm{HPO}_{4}{ }^{2-}
\end{gathered}
$$




$$
\begin{aligned}
& K_{a 2}=\frac{\left[\mathrm{H}^{+}\right] \cdot\left[\mathrm{HPO}_{4}^{2-}\right]}{\left[\mathrm{H}_{2} \mathrm{PO}_{4}^{-}\right]} \\
& \mathrm{HPO}_{4}{ }^{2-} \leftrightarrow \mathrm{H}^{+}+\mathrm{PO}_{4} 3^{-} \\
& K_{a 3}=\frac{\left[H^{+}\right] \cdot\left[\mathrm{PO}_{4}^{3-}\right]}{\left[\mathrm{HPO}_{4}^{2-}\right]}
\end{aligned}
$$

In order to facilitate the calculation of the equilibrium concentration of $\left[\mathrm{H}^{+}\right]$, the above dissociation equations can be reorganized into cumulative dissociations, as are listed in the following

$$
\begin{aligned}
& \mathrm{H}_{3} \mathrm{PO}_{4} \leftrightarrow 2 \mathrm{H}^{+}+\mathrm{HPO}_{4}{ }^{2-} \\
& K_{2}=\frac{\left[H^{+}\right]^{2} \cdot\left[\mathrm{HPO}_{4}^{2-}\right]}{\left[H_{3} P O_{4}\right]}=\frac{\left[H^{+}\right] \cdot\left[H_{2} P O_{4}^{-}\right]}{\left[H_{3} P O_{4}\right]} \cdot \frac{\left[H^{+}\right] \cdot\left[H P O_{4}^{2-}\right]}{\left[H_{2} P O_{4}^{-}\right]}=K_{a 1} K_{a 2} \\
& \mathrm{H}_{3} \mathrm{PO}_{4} \leftrightarrow 3 \mathrm{H}^{+}+\mathrm{PO}_{4}{ }^{3-} \\
& K_{3}=\frac{\left[H^{+}\right]^{3} \cdot\left[P O_{4}^{3-}\right]}{\left[H_{3} P O_{4}\right]}=\frac{\left[H^{+}\right] \cdot\left[H_{2} P O_{4}^{-}\right]}{\left[H_{3} P O_{4}\right]} \cdot \frac{\left[H^{+}\right] \cdot\left[H P O_{4}^{2-}\right]}{\left[H_{2} P O_{4}^{-}\right]} \cdot \frac{\left[H^{+}\right] \cdot\left[P O_{4}^{3-}\right]}{\left[H P O_{4}^{2-}\right]}=K_{a 1} K_{a 2} K_{a 3}
\end{aligned}
$$

The values of the dissociation constants, $K_{a 1}, K_{a 2}$ and $K_{a 3}$, and the cumulative dissociation constants are listed in Table A1(95)

Rewrite the equilibrium expressions of (A1.1), (A1.2a), (A1.3a) with the corresponding concentration variables.

$$
\begin{aligned}
& K_{1}=\frac{v \cdot x}{w} \\
& K_{2}=\frac{v^{2} \cdot y}{w} \\
& K_{3}=\frac{v^{3} \cdot z}{w}
\end{aligned}
$$


Table A1 Values of the dissociation constants of $\mathrm{H}_{3} \mathrm{PO}_{4}$ in aqueous solution

\begin{tabular}{cccc}
\hline Dissociation constant & Ka1 & $K a 2$ & $K a 3$ \\
\hline value & $7.25 \times 10^{-3}$ & $6.31 \times 10^{-8}$ & $3.98 \times 10^{-13}$ \\
\hline Cumulative Dissociation constant & $K 1$ & $K 2$ & $K 3$ \\
\hline value & $7.25 \times 10^{-3}$ & $4.75 \times 10^{-10}$ & $1.82 \times 10^{-22}$ \\
\hline
\end{tabular}

By electrical neutrality,

$$
v=x+2 y+3 z+\frac{K_{w}}{v}
$$

By mass conservation

$$
x+y+z+w=m_{1}
$$

Refer to Expressions (A1.4), (A1.5) and (A1.6) and use $v$ and $w$ to represent $x, y$ and $z$, respectively,

$$
\begin{aligned}
& x=\frac{K_{1} w}{v} \\
& x=\frac{K_{2} \cdot w}{v^{2}} \\
& z=\frac{K_{3} \cdot w}{v^{3}}
\end{aligned}
$$

Rewrite Equation (A1.7) and (A1.8) only with $v$ and $w$ as the unknown variables

$$
\begin{aligned}
& v=\frac{K_{w}}{v}+\frac{K_{1} \cdot w}{v}+\frac{2 \cdot K_{2} \cdot w}{v^{2}}+\frac{3 K_{3} \cdot w}{v^{3}} \\
& \frac{K_{1} w}{v}+\frac{K_{2} w}{v^{2}}+\frac{K_{3} w}{v^{3}}+w=m_{1}
\end{aligned}
$$

Rewrite Equation (A1.12) and (A1.13) with the known $K$ s and let $m_{1}=0.2$ 
Table A2 Concentrations of chemical species in $\mathrm{H}_{3} \mathrm{PO}_{4}$ aqueous solutions with various add-in amount of $\mathrm{H}_{3} \mathrm{PO}_{4}$

\begin{tabular}{ccccccc}
\hline \multirow{2}{*}{$\begin{array}{c}\text { Chemical } \\
\text { species }\end{array}$} & Variable & \multicolumn{5}{c}{ Concentration at different $m_{2}(\mathrm{M})$} \\
\cline { 3 - 6 } & & 0.01 & 0.05 & 0.1 & 0.15 & 0.2 \\
\hline $\mathrm{H}_{3} \mathrm{PO}_{4}$ & $w$ & $4.37 \times 10^{-3}$ & $3.42 \times 10^{-2}$ & $7.65 \times 10^{-2}$ & $1.20 \times 10^{-1}$ & $1.65 \times 10^{-1}$ \\
\hline $\mathrm{H}_{2} \mathrm{PO}_{4}{ }^{-}$ & $x$ & $5.63 \times 10^{-3}$ & $1.57 \times 10^{-2}$ & $2.35 \times 10^{-2}$ & $2.96 \times 10^{-2}$ & $3.46 \times 10^{-2}$ \\
\hline $\mathrm{HPO}_{4}{ }^{2-}$ & $y$ & $6.31 \times 10^{-8}$ & $6.31 \times 10^{-8}$ & $6.31 \times 10^{-8}$ & $6.31 \times 10^{-8}$ & $6.31 \times 10^{-8}$ \\
\hline $\mathrm{PO}_{4}{ }^{3-}$ & $z$ & $4.46 \times 10^{-18}$ & $1.59 \times 10^{-18}$ & $1.07 \times 10^{-18}$ & $8.50 \times 10^{-18}$ & $7.25 \times 10^{-19}$ \\
\hline $\mathrm{H}^{+}$ & $v$ & $5.63 \times 10^{-3}$ & $1.58 \times 10^{-2}$ & $2.35 \times 10^{-2}$ & $2.96 \times 10^{-2}$ & $3.46 \times 10^{-2}$ \\
\hline
\end{tabular}

$$
\begin{aligned}
& \frac{w \times 7.25 \times 10^{-3}}{v}+\frac{2 w \times 4.57 \times 10^{-10}}{v^{2}}+\frac{3 w \times 1.82 \times 10^{-22}}{v^{3}}-v+\frac{K_{w}}{v}=0 \\
& \frac{w \times 7.25 \times 10^{-3}}{v}+\frac{w \times 4.57 \times 10^{-10}}{v^{2}}+\frac{w \times 1.82 \times 10^{-22}}{v^{3}}+w=0.2
\end{aligned}
$$

Solve Equation (A1.14) and (A1.15) by trial and error method,

$$
\begin{aligned}
& v=3.46 \times 10^{-2} \mathrm{~mole} / 1000 \mathrm{ml} \\
& w=0.165 \mathrm{~mole} / 1000 \mathrm{ml}
\end{aligned}
$$

Take the $v$ and $w$ into Equation (A1.9), (A1.10) and (A1.11), we can obtain the $x, y$, $z$ values. Use the same approach, the concentrations of chemical species in $\mathrm{H}_{3} \mathrm{PO}_{4}$ solutions of various add-in amounts of $\mathrm{H}_{3} \mathrm{PO}_{4}$ are calculated, as listed in Table A2.

\section{Chemical species in $\mathrm{FeSO}_{4}$ aqueous solution}

In this study, various concentrations of $\mathrm{FeSO}_{4}$ solutions were prepared by adding appropriate moles of $\mathrm{FeSO}_{4} \cdot 7 \mathrm{H}_{2} \mathrm{O}$ into 1000 mole distilled water. Because $\mathrm{FeSO}_{4}$ is a strong acid-weak base salt, the following dissociation and association reactions could take place as the $\mathrm{FeSO}_{4 \cdot 7} \mathrm{H}_{2} \mathrm{O}$ salt is added into the water:

$$
\mathrm{FeSO}_{4} \Rightarrow \mathrm{Fe}^{2+}+\mathrm{SO}_{4}^{2-}
$$




$$
\begin{aligned}
& \mathrm{Fe}^{2+}+\mathrm{H}_{2} \mathrm{O} \Leftrightarrow \mathrm{FeOH}^{+}+\mathrm{H}^{+} \\
& \mathrm{K}_{a 4}=\frac{\left[\mathrm{H}^{+}\right] \cdot\left[\mathrm{FeOH}{ }^{+}\right]}{\left[\mathrm{Fe}^{2+}\right]} \\
& \mathrm{SO}_{4}^{2-}+\mathrm{H}^{+} \Leftrightarrow \mathrm{HSO}_{4}^{2-} \\
& K_{a 5}=\frac{\left[\mathrm{HSO}_{4}^{2-}\right]}{\left[\mathrm{SO}_{4}^{2-}\right] \cdot\left[\mathrm{H}^{+}\right]}
\end{aligned}
$$

Rewrite the equilibrium expressions of (A2.1), (A2.2), (A2.3) with the corresponding concentration variables. Let $K_{4}=K_{a 4}$ and $K_{5}=K_{a 5}$.

$$
\begin{aligned}
& K_{4}=\frac{v \cdot s}{r} \\
& K_{5}=\frac{u}{t \cdot v}
\end{aligned}
$$

By mass conservation,

$$
\begin{aligned}
& r+s=m_{2} \\
& t+u=m_{2}
\end{aligned}
$$

By electrical neutrality

$$
v+2 r+s=2 t+u+\frac{K_{w}}{v}
$$

Take Equation (A2.4), (A2.5) into (A2.6), we obtain

$$
v+r=t+\frac{K_{w}}{v}
$$

Take Equation (A2.2a) into Equation (A2.4) and eliminate $x$,

$$
r=\frac{m_{2}}{1+\frac{K_{1}}{v}}
$$

Take Equation (A2.3a) into Equation (A2.5) and eliminate z 


$$
t \cdot\left(1+K_{2} v\right)=m_{2}
$$

Use Equation (A2.7) to eliminate $y$ in Equation (A2.9),

$$
\left(v+r-\frac{K_{w}}{v}\right) \cdot\left(1+K_{2} v\right)=m_{2}
$$

Use Equation (A2.8) to eliminate w in Equation (A2.10),

$$
\begin{gathered}
\left(v+\frac{m_{2}}{1+\frac{K_{1}}{v}}-\frac{K_{w}}{v}\right) \cdot\left(1+K_{2} v\right)=m_{2} \\
K_{2} v^{4}+\left(1+K_{1} K_{2}+m_{2} K_{2}\right) v^{3}+\left(K_{1}-K_{2} K_{w}-K_{1} K_{2} K_{w}\right) v^{2}-\left(m_{2} K_{1}+K_{w}\right) v=K_{1} K_{w}
\end{gathered}
$$

The values of $K_{1}$ can be calculated from

$$
\begin{gathered}
\Delta G^{\mathrm{o}}=-R T \ln K \\
K=\exp \left(-\frac{\Delta G^{0}}{R T}\right)
\end{gathered}
$$

Since the solution is prepared at ambient temperature, the free energy change in Reaction (A2.1) is

$$
\Delta G_{298}^{0}=\Delta G_{298, \mathrm{FeOH}}^{0}+\Delta G_{298, H^{+}}^{0}-\left(\Delta G_{298, F e^{2+}}^{0}+\Delta G_{298, H_{2} \mathrm{O}}^{0}\right)
$$

The free energy values of the involved species could be obtained from the work of Kobylin et al (96). Those are listed in Table A3

$$
\Delta G_{298}^{0}=51495.6(\mathrm{~J} / \text { mole })
$$

Take this value into Expression (A2.14), we obtain

With the values listed in Table A3, the free energy change in Reaction (A2.1) was calculated via Expression (A2.15). 
Table A3 Gibbs free energy of species in $\mathrm{FeSO}_{4}$ aqueous solution

\begin{tabular}{ccccc}
\hline Species & $\mathrm{Fe}^{2+}$ & $\mathrm{FeOH}^{+}$ & $\mathrm{H}_{2} \mathrm{O}$ & $\mathrm{H}^{+}$ \\
\hline$\Delta \mathrm{GO}^{\mathrm{o}_{298}}(\mathrm{~J} / \mathrm{mole})$ & -60685.9 & -316075.3 & -306885.0 & $\mathrm{O}$ \\
\hline & & & & \\
$K_{4}=\exp \left(\frac{-51295.6}{8.314 \times 298}\right)=9.41 \times 10^{-10}$ & & (A2.17)
\end{tabular}

According to Zumdahl et al (97) the equilibrium constant of the reverse reaction (A2.2) is

$$
K_{\mathrm{a} 5}=1.2 \times 10^{-2}
$$

Therefore

$$
K_{5}=1 / K_{\mathrm{a} 5}=83 \cdot 33
$$

Take the $K_{1}$ and $K_{2}$ value into Equation (A.12), and let $m_{2}=0.2$, we have

$$
8.856 \times 10^{24} \cdot v^{4}+1.877 \times 10^{24} \cdot v^{3}+9.991 \times 10^{13} \cdot v^{2}+2.000 \times 10^{13} \cdot v-1=0
$$

Equation (A2.20) can be solved by Trial and Error method. Use the same approach, the concentrations of chemical species in $\mathrm{FeSO}_{4}$ solutions of various $m_{2}$ were calculated, as listed in Table A4.

Table A4 Concentrations of chemical species in $\mathrm{FeSO}_{4}$ aqueous solutions

\begin{tabular}{ccccccc}
\hline \multirow{2}{*}{$\begin{array}{c}\text { Chemical } \\
\text { species }\end{array}$} & \multirow{2}{*}{ variable } & \multicolumn{5}{c}{ Concentration at different $m_{2}(\mathrm{M})$} \\
\cline { 3 - 7 } & & 0.01 & 0.05 & 0.10 & 0.15 & 0.2 \\
\hline $\mathrm{Fe}^{2+}$ & $r$ & 0.01 & 0.05 & 0.10 & 0.15 & 0.20 \\
\hline $\mathrm{FeOH}^{+}$ & $s$ & $4.15 \times 10^{-6}$ & $1.56 \times 10^{-5}$ & $2.92 \times 10^{-5}$ & $4.36 \times 10^{-5}$ & $5.76 \times 10^{-5}$ \\
\hline $\mathrm{SO}_{4}{ }^{2-}$ & $t$ & 0.01 & 0.05 & 0.10 & 0.15 & 0.20 \\
\hline $\mathrm{HSO}_{4}^{-}$ & $u$ & $1.89 \times 10^{-6}$ & $1.26 \times 10^{-5}$ & $2.65 \times 10^{-5}$ & $4.04 \times 10^{-5}$ & $5.44 \times 10^{-5}$ \\
\hline $\mathrm{H}^{+}$ & $v$ & $2.27 \times 10^{-6}$ & $3.02 \times 10^{-6}$ & $3.18 \times 10^{-6}$ & $3.23 \times 10^{-6}$ & $3.27 \times 10^{-6}$ \\
\hline
\end{tabular}


3. Chemical species in $\mathrm{FeSO}_{4}-\mathrm{H}_{3} \mathrm{PO}_{4}$ solution

When the $\mathrm{FeSO}_{4}$ solution and the $\mathrm{H}_{3} \mathrm{PO}_{4}$ solution are mixed together, both of the concentrations of the chemical species from the each solution are diluted. Suppose the $\mathrm{FeSO}_{4}-\mathrm{H}_{3} \mathrm{PO}_{4}$ solution is prepared from equal volumes of $\mathrm{FeSO}_{4}$ solution and $\mathrm{H}_{3} \mathrm{PO}_{4}$ solution, the chemical species would be diluted to concentrations as calculated by Equation (A3.1)

$$
[\text { species }]_{\mathrm{Fes}_{4}-\mathrm{H}_{3} \mathrm{PO}_{4}}=\frac{[\text { species }]_{\mathrm{Fes}_{4}}+[\text { species }]_{\mathrm{H}_{3} \mathrm{PO}_{4}}}{2}
$$

For example, Table A5 listed the initial dilution when the mixing is prepared from equal volumes of $0.2 \mathrm{M} \mathrm{FeSO}_{4}$ solution and $0.2 \mathrm{M} \mathrm{H}_{3} \mathrm{PO}_{4}$ solution.

Compare the data in Table A5 with the date in Table A2, we can see that the diluted concentration of $\left[\mathrm{H}_{3} \mathrm{PO}_{4}\right]$ is greater than the equilibrium concentration of $\left[\mathrm{H}_{3} \mathrm{PO}_{4}\right]$ in the $0.1 \mathrm{M} \mathrm{H}_{3} \mathrm{PO}_{4}$ solution, whereas the diluted concentrations of

Table A5 Initial dilution of chemical species when the $0.2 \mathrm{M} \mathrm{FeSO} 4$ solution is mixed with $0.2 \mathrm{M} \mathrm{H}_{3} \mathrm{PO}_{4}$ solution

\begin{tabular}{ccccc}
\hline \multirow{2}{*}{ Chem. species } & \multirow{2}{*}{ variable } & \multicolumn{2}{c}{ Before mixing } & \multirow{2}{*}{ Dilution by mixing } \\
\cline { 3 - 4 } & & $\mathrm{In} \mathrm{FeSO}_{4}$ & $\mathrm{In}_{3} \mathrm{PO}_{4}$ & \\
\hline $\mathrm{H}_{3} \mathrm{PO}_{4}$ & $w$ & 0 & $1.65 \times 10^{-1}$ & $8.27 \times 10^{-2}$ \\
\hline $\mathrm{H}_{2} \mathrm{PO}_{4}^{-}$ & $y$ & 0 & $3.46 \times 10^{-2}$ & $1.73 \times 10^{-2}$ \\
\hline $\mathrm{HPO}_{4}{ }^{2-}$ & $z$ & 0 & $6.31 \times 10^{-8}$ & $3.16 \times 10^{-8}$ \\
\hline $\mathrm{PO}_{4}{ }^{3-}$ & $r$ & 0.20 & $7.25 \times 10^{-18}$ & $3.63 \times 10^{-19}$ \\
\hline $\mathrm{Fe}^{2+}$ & $s$ & $5 \cdot 76 \times 10^{-5}$ & 0 & $1.00 \times 10^{-2}$ \\
\hline $\mathrm{FeOH}^{+}$ & $t$ & 0.20 & 0 & $2.88 \times 10^{-5}$ \\
\hline $\mathrm{SO}_{4}{ }^{2-}$ & $u$ & $5.44 \times 10^{-5}$ & 0 & $1.00 \times 10^{-1}$ \\
\hline $\mathrm{HSO}_{4}{ }^{2-}$ & $v$ & $3.26 \times 10^{-6}$ & $3.46 \times 10^{-2}$ & $1.73 \times 10^{-2}$ \\
\hline $\mathrm{H}^{+}$ & & & 0 &
\end{tabular}


$\left[\mathrm{H}_{2} \mathrm{PO}_{4}^{-}\right],\left[\mathrm{HPO}_{4}{ }^{2-}\right],\left[\mathrm{PO}_{4^{3-}}\right]$ and $\left[\mathrm{H}^{+}\right]$become smaller than those in the $0.1 \mathrm{M}$ $\mathrm{H}_{3} \mathrm{PO}_{4}$ solution. This means that the dissociation of the phosphate species as described in the Equation (A1.1), (A1.2) and (A1.3) will resume and reach a new equilibrium.

Compare the data in Table A5 with the data in Table A4, we can see that the diluted $\left[\mathrm{H}^{+}\right]$is much greater than that in the $\mathrm{FeSO}_{4}$ solutions of all $\mathrm{FeSO}_{4}$ concentrations. The $\mathrm{H}^{+}$of higher concentration will react with the $\mathrm{FeOH}^{+}$and $\mathrm{SO}_{4}{ }^{2-}$.

$$
\begin{aligned}
& \mathrm{FeOH}^{+}+\mathrm{H}^{+} \Leftrightarrow \mathrm{H}_{2} \mathrm{O}+\mathrm{Fe}^{2+} \\
& \mathrm{K}_{4}=\frac{\left[\mathrm{Fe}^{2+}\right]}{\left[\mathrm{FeOH}^{+}\right] \cdot\left[\mathrm{H}^{+}\right]} \\
& \mathrm{SO}_{4}^{2-}+\mathrm{H}^{+} \Leftrightarrow \mathrm{HSO}_{4}^{-} \\
& \mathrm{K}_{5}=\frac{\left[\mathrm{HSO}_{4}^{-}\right]}{\left[\mathrm{SO}_{4}^{2-}\right] \cdot\left[\mathrm{H}^{+}\right]}
\end{aligned}
$$

The consumption of the protons by $\mathrm{FeOH}^{+}$and $\mathrm{SO}_{4}{ }^{2-}$ would cause further dissociation of $\mathrm{H}_{3} \mathrm{PO}_{4}$ into $\mathrm{H}_{2} \mathrm{PO}_{4}^{-}, \mathrm{HPO}_{4}{ }^{2-}$ and $\mathrm{PO}_{4}{ }^{3-}$ :

$$
\begin{aligned}
& \mathrm{H}_{3} \mathrm{PO}_{4} \Leftrightarrow \mathrm{H}^{+}+\mathrm{H}_{2} \mathrm{PO}_{4}^{-} \\
& \mathrm{K}_{1}=\frac{\left[\mathrm{H}^{+}\right] \cdot\left[\mathrm{H}_{2} \mathrm{PO}_{4}^{3-}\right]}{\left[\mathrm{H}_{3} \mathrm{PO}_{4}\right]} \\
& \mathrm{H}_{3} \mathrm{PO}_{4} \Leftrightarrow 2 \mathrm{H}^{+}+H P O_{4}^{2-} \\
& K_{2}=\frac{\left[H^{+}\right]^{2} \cdot\left[\mathrm{HPO}_{4}^{2-}\right]}{\left[\mathrm{H}_{3} P O_{4}\right]} \\
& \mathrm{H}_{3} \mathrm{PO}_{4} \Leftrightarrow 3 \mathrm{H}^{+}+\mathrm{PO}_{4}^{3-} \\
& \mathrm{K}_{3}=\frac{\left[H^{+}\right]^{3} \cdot\left[\mathrm{PO}_{4}^{3-}\right]}{\left[\mathrm{H}_{3} P O_{4}\right]}
\end{aligned}
$$


Rewrite the equilibrium expressions of (A3.2), (A3.3), (A3.4), (A3.5) and (A3.6) with the assigned variables as described in $\mathrm{A} 1$ and $\mathrm{A} 2$

$$
\begin{aligned}
& K_{4}=\frac{r}{s \cdot v} \\
& K_{5}=\frac{u}{t \cdot v} \\
& K_{1}=\frac{v \cdot x}{w} \\
& K_{2}=\frac{v^{2} \cdot y}{w} \\
& K_{3}=\frac{v^{3} \cdot z}{w}
\end{aligned}
$$

By mass conservation of the phosphate species

$$
x+y+z+w=m_{1}
$$

By mass conservation of the iron species

$$
r+s=m_{2}
$$

By mass conservation of the sulfate species,

$$
t+u=m_{2}
$$

By electrical neutrality,

$$
v+s+2 r=x+2 y+3 z+2 t+u+\frac{K_{w}}{v}
$$

By consideration of (A3.13) and (A3.14), Equation (A3.15) can be simplified as

$$
v+r=x+2 y+3 z+t+\frac{K_{w}}{v}
$$

Let $v$ and $w$ represent the other variables 


$$
\begin{gathered}
x=\frac{K_{1} w}{v} \\
y=\frac{K_{2} \cdot w}{v^{2}} \\
z=\frac{K_{3} \cdot w}{v^{3}}
\end{gathered}
$$

Rewrite Equation (A3.12) only with $v$ and $w$ as the unknown variables

$$
\frac{K_{1} w}{v}+\frac{K_{2} w}{v^{2}}+\frac{K_{3} w}{v^{3}}+w=m_{1}
$$

From Equation (A3.7) and (A3.13), we obtain

$$
\begin{aligned}
& r=m_{2}-s=m_{2}-\frac{r}{K_{4} v} \\
& r=\frac{m_{2}}{1+\frac{1}{K_{4} v}}
\end{aligned}
$$

From Equation (A3.8) and (A3.14), we obtain

$$
\begin{aligned}
& t=m_{2}-u=m_{2}-K_{5} t v \\
& t=\frac{m_{2}}{1+K_{5} v}
\end{aligned}
$$

Take consideration of Expression (A3.21) and (A3.22), Equation (A3.16) becomes,

$$
x+z y+3 z+\frac{K_{w}}{v}-v-\frac{m_{2}}{1+\frac{1}{K_{4} v}}+\frac{m_{2}}{1+K_{5} v}=0
$$

Rewrite Equation (A3.23) with $v$ and $w$ as the only unknown variables

$$
\frac{K_{1} w}{v}+\frac{2 K_{2} w}{v^{2}}+\frac{3 K_{3} w}{v^{3}}+\frac{K_{w}}{v}-v-\frac{m_{2}}{1+\frac{1}{K_{4} v}}+\frac{m_{2}}{1+K_{5} v}=0
$$


Use the values of $K_{1}, K_{2}$ and $K_{3}$ listed in Table A.1 and the value of $K_{4}$ and $K_{5}$ given by Equation (A2.17) and (A2.19), Equation (A3.20) and (A3.24) can be rewritten as

$$
\begin{gathered}
w \cdot\left(\frac{7.25 \times 10^{-3}}{v}+\frac{4.57 \times 10^{-10}}{v^{2}}+\frac{1.82 \times 10^{-22}}{v^{3}}+1\right)=m_{1} \\
w \cdot\left(\frac{7.25 \times 10^{-3}}{v}+\frac{2 \times 4.57 \times 10^{-10}}{v^{2}}+\frac{3 \times 1.82 \times 10^{-22}}{v^{3}}\right) \\
+\frac{10^{-14}}{v}-v-\frac{m_{2}}{1+\frac{1}{1.06 \times 10^{9} v}}+\frac{m_{2}}{1+v \times 83.33}=0
\end{gathered}
$$

With given values of $m_{1}$ and $m_{2}\left(m_{1}=m_{2}\right)$, the $v$ and $w$ in Equation (A3.25) and (A3.26) were obtained by trial and error method. The other variables were calculated with Equations (A3.7) to (A3.14), correspondingly. Table A6 listed these results.

In the $\mathrm{FeSO}_{4}-\mathrm{H}_{3} \mathrm{PO}_{4}$ solution, the coexistence of $\mathrm{Fe}^{2+}$ and $\mathrm{PO}_{4}{ }^{3-}$ ions may produce precipitation of $\mathrm{Fe}_{3}\left(\mathrm{PO}_{4}\right)_{2}$

$$
3 \mathrm{Fe}^{2+}+2 \mathrm{PO}_{4}^{3-}=\mathrm{Fe}_{3}\left(\mathrm{PO}_{4}\right)_{2} \downarrow
$$

The solubility product constant of $\mathrm{Fe}_{3}\left(\mathrm{PO}_{4}\right)_{2}$ is reported by Nriagu (98)

$$
K_{s p, F e_{3}\left(P O_{4}\right)_{3}}=\left[\mathrm{Fe}^{2+}\right]^{3} \cdot\left[\mathrm{PO}_{4}^{3-}\right]^{2}=1.0 \times 10^{-36}
$$

The existence of $\mathrm{Fe}^{2+}$ may also produce precipitation of $\mathrm{Fe}(\mathrm{OH})_{2}$, which are governed by the solubility product constant of $\mathrm{Fe}^{2+}$ and $\mathrm{OH}^{-}$(99)

$$
\begin{aligned}
& \mathrm{Fe}^{2+}+2 \mathrm{OH}^{-}=\mathrm{Fe}(\mathrm{OH})_{2} \downarrow \\
& K_{s p, F e(\mathrm{OH})_{2}}=\left[\mathrm{Fe}^{2+}\right] \cdot[\mathrm{OH}]^{2}=\left[\mathrm{Fe}^{2+}\right] \cdot\left(\frac{K_{w}}{\left[\mathrm{H}^{+}\right]}\right)^{2}=7.9 \times 10^{-15}
\end{aligned}
$$


Table A6 Concentration of chemical species in $\mathrm{FeSO}_{4}-\mathrm{H}_{3} \mathrm{PO}_{4}$ solutions

\begin{tabular}{lcccccc}
\hline \multirow{2}{*}{ Chem. species variable } & \multicolumn{5}{c}{ Concentration at different $m_{1}$ and $m_{2}\left(\mathrm{M}, m_{1}=m_{2}\right)$} \\
\cline { 3 - 7 } & & 0.01 & 0.05 & 0.1 & 0.15 & 0.2 \\
\hline $\mathrm{H}_{3} \mathrm{PO}_{4}$ & $w$ & $3.54 \times 10^{-3}$ & $2.57 \times 10^{-2}$ & $5.23 \times 10^{-2}$ & $8.02 \times 10^{-2}$ & $1.08 \times 10^{-2}$ \\
\hline $\mathrm{H}_{2} \mathrm{PO}_{4}{ }^{-}$ & $x$ & $6.46 \times 10^{-3}$ & $2.54 \times 10^{-2}$ & $4.77 \times 10^{-2}$ & $4.77 \times 10^{-2}$ & $9.18 \times 10^{-2}$ \\
\hline $\mathrm{HPO}_{4}{ }^{2-}$ & $y$ & $1.03 \times 10^{-7}$ & $2.29 \times 10^{-7}$ & $3.79 \times 10^{-7}$ & $5.28 \times 10^{-7}$ & $6.77 \times 10^{-7}$ \\
\hline $\mathrm{PO}_{4}{ }^{3-}$ & $z$ & $1.03 \times 10^{-17}$ & $1.30 \times 10^{-17}$ & $1.90 \times 10^{-17}$ & $2.52 \times 10^{-17}$ & $3.15 \times 10^{-17}$ \\
\hline $\mathrm{Fe}^{2+}$ & $r$ & 0.01 & 0.05 & 0.10 & 0.15 & 0.20 \\
\hline $\mathrm{FeOH}^{+}$ & $s$ & $2.37 \times 10^{-9}$ & $6.72 \times 10^{-9}$ & $1.19 \times 10^{-8}$ & $1.69 \times 10^{-8}$ & $2.20 \times 10^{-8}$ \\
\hline $\mathrm{SO}_{4}{ }^{2-}$ & $t$ & $7.51 \times 10^{-3}$ & $3.52 \times 10^{-2}$ & $6.02 \times 10^{-2}$ & $8.85 \times 10^{-2}$ & 0.20 \\
\hline $\mathrm{HSO}_{4}{ }^{2-}$ & $u$ & $2.49 \times 10^{-3}$ & $2.84 \times 10^{-3}$ & $3.98 \times 10^{-2}$ & $6.15 \times 10^{-2}$ & $8.30 \times 10^{-2}$ \\
\hline $\mathrm{H}^{+}$ & $v$ & $3.79 \times 10^{-3}$ & $7.00 \times 10^{-3}$ & $7.93 \times 10^{-3}$ & $8.33 \times 10^{-3}$ & $8.33 \times 10^{-3}$ \\
\hline$\left[\mathrm{Fe}^{2+}\right]^{3 \cdot\left[\mathrm{PO}_{4}{ }^{3-}\right]^{2}}$ & $r Z^{2}$ & $1.51 \times 10^{-40}$ & $2.12 \times 10^{-38}$ & $3.62 \times 10^{-37}$ & $2.15 \times 10^{-36}$ & $7.94 \times 10^{-36}$ \\
\hline$\left[\mathrm{Fe}^{2+}\right] \cdot\left[\mathrm{OH}^{-}\right]^{2}$ & $r\left(\mathrm{k}_{\mathrm{w}} / \mathrm{v}\right)^{2}$ & $6.33 \times 10^{-26}$ & $1.02 \times 10^{-25}$ & $1.59 \times 10^{-25}$ & $2.16 \times 10^{-25}$ & $2.74 \times 10^{-25}$ \\
\hline & & & & & &
\end{tabular}

Table A6 also listed the equilibrium concentration products of the corresponding species. The data shows that there is no $\mathrm{Fe}(\mathrm{OH})_{2}$ precipitation from the solution throughout the calculated range of $\mathrm{FeSO}_{4}$ and $\mathrm{H}_{3} \mathrm{PO}_{4}$ add-in concentration (0.01 to $0.2 \mathrm{M})$. Precipitation could occur only when the $\mathrm{Fe}_{3}(\mathrm{PO})_{4}$ of $\mathrm{FeSO}_{4}$ add-in concentration is somewhere greater than $0.10 \mathrm{M}$.

4. Chemical species in $\mathrm{LiOH}-\mathrm{Li}_{3} \mathrm{PO}_{4}$ solution

For convenience, we rewrite the cumulative dissociation equations of $\mathrm{H}_{3} \mathrm{PO}_{4}$ derived in the previous sections.

$$
\begin{aligned}
& \mathrm{H}_{3} \mathrm{PO}_{4} \Leftrightarrow H^{+}+\mathrm{H}_{2} \mathrm{PO}_{4}^{-} \\
& K_{1}=\frac{\left[H^{+}\right] \cdot\left[\mathrm{H}_{2} P O_{4}^{-}\right]}{\left[\mathrm{H}_{3} P O_{4}\right]}
\end{aligned}
$$




$$
\begin{aligned}
& \mathrm{H}_{3} \mathrm{PO}_{4} \Leftrightarrow 2 \mathrm{H}^{+}+H P O_{4}^{2-} \\
& K_{2}=\frac{\left[H^{+}\right]^{2} \cdot\left[H P O_{4}^{2-}\right]}{\left[H_{3} P O_{4}\right]} \\
& H_{3} P O_{4} \Leftrightarrow 3 H^{+}+P O_{4}^{3-} \\
& K_{3}=\frac{\left[H^{+}\right]^{3} \cdot\left[P O_{4}^{3-}\right]}{\left[H_{3} P O_{4}\right]}
\end{aligned}
$$

When $\mathrm{LiOH}$ is added into the $\mathrm{H}_{3} \mathrm{PO}_{4}$ solution, the add-in $\mathrm{OH}^{-}$would react with $\mathrm{H}^{+}$.

$$
\begin{aligned}
& \mathrm{OH}^{-}+H^{+} \Leftrightarrow \mathrm{H}_{2} \mathrm{O} \\
& K_{w}=\left[\mathrm{OH}^{-}\right] \cdot\left[H^{+}\right]=1.0 \times 10^{-14}
\end{aligned}
$$

The neutralization of $\mathrm{H}^{+}$would cause the above dissociation equations to move to the right side and produce more $\mathrm{PO}_{4}{ }^{3-}$. The equilibrium concentration product of $\left[\mathrm{Li}^{+}\right]$and $\left[\mathrm{PO}_{4}{ }^{3-}\right]$ may exceed their solubility product (100) and precipitation of $\mathrm{Li}_{3} \mathrm{PO}_{4}$ may occur.

$$
\begin{aligned}
& 3 \mathrm{Li}^{+}+P \mathrm{O}_{4}^{3-} \Leftrightarrow \mathrm{Li}_{3} P \mathrm{O}_{4} \downarrow \\
& K_{s p, L i_{3} \mathrm{PO}_{4}}=\left[\mathrm{Li}^{+}\right]^{3} \cdot\left[P \mathrm{PO}_{4}^{3-}\right]=3.2 \times 10^{-9}
\end{aligned}
$$

Rewrite the above equations with the defined variables

$$
\begin{aligned}
& K_{1}=\frac{v \cdot x}{w} \\
& K_{2}=\frac{v^{2} \cdot y}{w} \\
& K_{3}=\frac{v^{3} \cdot z}{w} \\
& K_{w}=q \cdot v \\
& K_{s p}=p^{3} \cdot z
\end{aligned}
$$

By mass conservation of the phosphate species,

$$
x+y+z+w+m_{4}=m_{1}
$$


By mass conservation of lithium species,

$$
p+3 m_{4}=m_{3}
$$

By electrical neutrality,

$$
x+2 y+3 z+q=p+v
$$

Combine Equation (A4.6) with (A4.7) and eliminate $m_{4}$

$$
x+y+z+w+\frac{m_{3}-p}{3}=m_{1}
$$

In order to predict the chemical species evolved in the solution as $\mathrm{LiOH}$ is added in, we consider three situations.

4.1 $\mathrm{m}_{3}$ is small and the $\mathrm{Li}_{3} \mathrm{PO}_{4}$ does not precipitate, here

$$
\begin{aligned}
& p=m_{3} \\
& x+y+z+w=m_{1} \\
& x+2 y+3 z+q-v=m_{3}
\end{aligned}
$$

Use $w$ and $v$ to represent the other variables

$$
\begin{gathered}
w \cdot\left(1+\frac{K_{1}}{v}+\frac{K_{2}}{v^{2}}+\frac{K_{3}}{v^{3}}\right)=m_{1} \\
w \cdot\left(\frac{K_{1}}{v}+\frac{2 \cdot K_{2}}{v^{2}}+\frac{3 \cdot K_{3}}{v^{3}}\right)+\frac{K_{w}}{v}-v=m_{3}
\end{gathered}
$$

From Equation (A4.5a) and (A4.10), we know that if $m_{1}=0.1 \mathrm{M}$,

$$
m_{3}=p<\sqrt[3]{\frac{3.2 \times 10^{-9}}{0.1}}=0.00317 M
$$

Let $m_{3}=0.003 \mathrm{M}$ and take the values of $K_{1}, K_{2}, K_{3}$ and $m_{1}$ into Equation (A4.13) and (A4.14), we have

$$
w \cdot\left(1+\frac{7.25 \times 10^{-3}}{v}+\frac{4.57 \times 10^{-10}}{v^{2}}+\frac{1.82 \times 10^{-22}}{v^{3}}\right)=0.1
$$


Table A7 Concentration of chemical species in $\mathrm{LiOH}-\mathrm{H}_{3} \mathrm{PO}_{4}$ solution without $\mathrm{Li}_{3} \mathrm{PO}_{4}$ precipitation $\left(m_{1}=0.1 \mathrm{M}, m_{3}=0.003 \mathrm{M}\right)$

\begin{tabular}{ccc}
\hline Chemical species & variable & Concentration \\
\hline $\mathrm{H}_{3} \mathrm{PO}_{4}$ & $w$ & $7.51 \times 10^{-2}$ \\
\hline $\mathrm{H}_{2} \mathrm{PO}_{4}^{-}$ & $x$ & $2.49 \times 10^{-2}$ \\
\hline $\mathrm{HPO}_{4}{ }^{--}$ & $y$ & $7.17 \times 10^{-8}$ \\
\hline $\mathrm{PO}_{4}^{3^{-}}$ & $z$ & $1.30 \times 10^{-18}$ \\
\hline $\mathrm{H}^{+}$ & $v$ & $2.19 \times 10^{-2}$ \\
\hline $\mathrm{Li}^{+}$ & $p$ & 0.003 \\
\hline $\mathrm{OH}^{-}$ & $q$ & $4.57 \times 10^{-13}$ \\
\hline
\end{tabular}

$$
w \cdot\left(\frac{7.25 \times 10^{-3}}{v}+\frac{9.15 \times 10^{-10}}{v^{2}}+\frac{5.46 \times 10^{-22}}{v^{3}}\right)+\frac{1.0 \times 10^{-14}}{v}-v=0.003
$$

$v$ and $w$ can be obtained by solving these two equations with trial and error method. The values of other variables can be obtained from Equations (A4.1a) to (A4.5a) with the known $v$ and $w$ values, correspondingly. The results are listed in Table A7

$4.2 m_{3}$ is sufficiently large to induce $\mathrm{Li}_{3} \mathrm{PO}_{4}$ precipitation

When $m_{3}=3 m_{1}=0.3 \mathrm{M}$, Equation (A4.9) and (A4.12) can be rewritten as

$$
\begin{aligned}
& x+y+z+w-\frac{p}{3}=0 \\
& x+2 y+3 z+q-v=0.3
\end{aligned}
$$

Use Equation (A4.5a),

$$
\begin{aligned}
& p=\left(\frac{K_{s p, L i_{3} P O_{4}}}{z}\right)^{\frac{1}{3}} \\
& x+y+z+w-\frac{1}{3} \cdot\left(\frac{K_{s p, L i_{3} P O_{4}}}{z}\right)^{\frac{1}{3}}=0
\end{aligned}
$$


Compare Equation (A4.21) to Equation (A4.13) and (A4.16) and use the $K_{s p, \mathrm{Li}_{3} \mathrm{PO}_{4}}$ value given from Equation (A4.5a), Equation (A4.21) becomes

$$
w \cdot\left(1+\frac{7.25 \times 10^{-3}}{v}+\frac{4.57 \times 10^{-10}}{v^{2}}+\frac{1.82 \times 10^{-22}}{v^{3}}\right)-8.67 \times 10^{3} \cdot \frac{v}{w^{\frac{1}{3}}}=0
$$

Compare Equation (A4.19) to Equation (A4.14) and (A4.17) and use the $K_{\mathrm{w}}$ value given from Equation (A4.4a), Equation (A4.19) becomes

$$
w \cdot\left(\frac{7.25 \times 10^{-3}}{v}+\frac{2 \times 4.57 \times 10^{-10}}{v^{2}}+\frac{3 \times 1.82 \times 10^{-22}}{v^{3}}\right)+\frac{10^{-14}}{v}-v=0.3
$$

$v$ and $w$ can be obtained by solving these two equations with trial and error method. The values of other variables can be obtained from Equations (A4.1a) to (A4.5a) with the known $v$ and $w$ values, correspondingly. The results are listed in Table A8.

The precipitated amount of $\mathrm{Li}_{3} \mathrm{PO}_{4}, m_{4}$, can be calculated either from Equation (A4.6) or from Equation (A4.7). From Equation (A4.6),

$$
m_{4}=m_{1}-(x+y+z+w) \approx m_{1}-(y+z)=0.097 M
$$

Table A8 Concentration of chemical species in $\mathrm{LiOH}-\mathrm{H}_{3} \mathrm{PO}_{4}$ solution after $\mathrm{Li}_{3} \mathrm{PO}_{4}$ precipitation $\left(m_{1}=0.1 \mathrm{M}, m_{3}=0.3 \mathrm{M}\right)$

\begin{tabular}{ccc}
\hline Chemical species & variable & Concentration \\
\hline $\mathrm{H}_{3} \mathrm{PO}_{4}$ & $w$ & $6.97 \times 10^{-22}$ \\
\hline $\mathrm{H}_{2} \mathrm{PO}_{4}{ }^{-}$ & $x$ & $1.47 \times 10^{-10}$ \\
\hline $\mathrm{HPO}_{4}{ }^{--}$ & $y$ & $2.68 \times 10^{-4}$ \\
\hline $\mathrm{PO}_{4}^{3^{-}}$ & $z$ & $3.10 \times 10^{-3}$ \\
\hline $\mathrm{H}^{+}$ & $v$ & $3.45 \times 10^{-14}$ \\
\hline $\mathrm{OH}^{-}$ & $q$ & $2.91 \times 10^{-1}$ \\
\hline $\mathrm{Li}^{+}$ & $P$ & $1.01 \times 10^{-2}$ \\
\hline
\end{tabular}


From Equation (A4-7),

$$
m_{4}=\frac{m_{2}-p}{3}=\frac{0.3-1.011}{3}=0.097 \mathrm{M}
$$

$4.3 m_{3}$ is at a critical point at which increase of $m_{3}$ will induce precipitation but decrease of $m_{3}$ will cause complete dissolution of precipitation

In this situation, we know that there is no precipitation, i.e. $m_{4}=0 . m_{3}$ is unknown, but it is related to $p, z$ and $w$

$$
m_{3}=p=\left(\frac{k_{s p, L i_{3} P O_{4}}}{z}\right)^{\frac{1}{3}}=\left(\frac{k_{s p, L i_{3} P O_{4}}}{k_{3} w}\right)^{\frac{1}{3}} v
$$

Rewrite Equation (A4.6) and (A4.8) in regard with this condition,

$$
\begin{aligned}
& x+y+z+w=m_{1} \\
& x+2 y+3 z+q-v-\left(\frac{K_{s p, L L_{3} P O_{4}}}{k_{3} w}\right)^{\frac{1}{3}} v=0
\end{aligned}
$$

Equation (A4.27) is same as Equation (A4.11). It can be transformed into

$$
\begin{gathered}
w \cdot\left(1+\frac{7.25 \times 10^{-3}}{v}+\frac{4.57 \times 10^{-10}}{v^{2}}+\frac{1.82 \times 10^{-22}}{v^{3}}\right)=0.1 \\
w \cdot\left(\frac{7.25 \times 10^{-3}}{v}+\frac{2 \times 4.57 \times 10^{-10}}{v^{2}}+\frac{3 \times 1.82 \times 10^{-22}}{v^{3}}\right)+\frac{10^{-14}}{v}-v-2.6 \times 10^{4} \cdot \frac{v}{w^{\frac{1}{3}}}-=0
\end{gathered}
$$

Take the values of $k_{\mathrm{sp}, \mathrm{Li}_{3} \mathrm{PO}_{4} \text { and }} k_{3}$ into Equation (A4.28) and compare the equation with Equation (A4.27). Equation (A4.28) can be transformed into

$v$ and $w$ can be obtained by solving these two equations with trial and error method. The values of other variables can be obtained from Equations (A4.1a) to (A4.5a) with the known $v$ and $w$ values, correspondingly. The results are listed in Table A9 
Table A9 Concentration of chemical species in $\mathrm{LiOH}-\mathrm{H}_{3} \mathrm{PO}_{4}$ at critical amount of add-in $\mathrm{LiOH}\left(m_{1}=0.1 \mathrm{M}\right)$

\begin{tabular}{ccc}
\hline Chemical species & variable & Concentration \\
\hline $\mathrm{H}_{3} \mathrm{PO}_{4}$ & $w$ & $3.53 \times 10^{-8}$ \\
\hline $\mathrm{H}_{2} \mathrm{PO}_{4}^{-}$ & $x$ & $3.59 \times 10^{-2}$ \\
\hline $\mathrm{HPO}_{4}^{2-}$ & $y$ & $6.41 \times 10^{-2}$ \\
\hline $\mathrm{PO}_{4}^{3^{-}}$ & $z$ & $7.24 \times 10^{-7}$ \\
\hline $\mathrm{H}^{+}$ & $v$ & $3.53 \times 10^{-8}$ \\
\hline $\mathrm{OH}^{-}$ & $q$ & $2.84 \times 10^{-7}$ \\
\hline $\mathrm{Li}^{+}$ & $p$ & 0.164 \\
\hline $\mathrm{Add}-\mathrm{in} \mathrm{LiOH}$ & $m_{3}$ & 0.164 \\
\hline
\end{tabular}

From the previous discussion, we know that when the LiOH add-in amount is less $\tan 0.164 \mathrm{M}$, there would be no $\mathrm{Li}_{3} \mathrm{PO}_{4}$ precipitation. The calculation of chemical species concentration can use the following equations transformed from Equation (A4.16) and (A4.17).

$$
\begin{aligned}
& w \cdot\left(1+\frac{7.25 \times 10^{-3}}{v}+\frac{4.57 \times 10^{-10}}{v^{2}}+\frac{1.82 \times 10^{-22}}{v^{3}}\right)=0.1 \\
& w \cdot\left(\frac{7.25 \times 10^{-3}}{v}+\frac{9.15 \times 10^{-10}}{v^{2}}+\frac{5.46 \times 10^{-22}}{v^{3}}\right)+\frac{1.0 \times 10^{-14}}{v}-v=m_{3}
\end{aligned}
$$

Whereas when the $\mathrm{LiOH}$ add-in amount is greater than $0.164 \mathrm{M}$, precipitation of $\mathrm{Li}_{3} \mathrm{PO}_{4}$ would take place. The calculation equations need to be rearranged from Equation (A4.8) and (A4.9):

$$
\begin{aligned}
& x+y+z+w=m_{1}-\frac{m_{3}}{3}+\frac{p}{3} \\
& 3 x+3 y+3 z+3 w=3 m_{1}-m_{3}+p
\end{aligned}
$$

Subtract Equation (A4.32) from Equation (A4.33) and rearrange the result, we obtain

$$
2 x+y+3 w=3 m_{1}-m_{3}+q-v
$$


Refer to Equation (A4.18), (A4.21) and (A4.22), Equation (A.32) becomes

$$
w \cdot\left(1+\frac{7.25 \times 10^{-3}}{v}+\frac{4.57 \times 10^{-10}}{v^{2}}+\frac{1.82 \times 10^{-22}}{v^{3}}\right)-8.67 \times 10^{3} \cdot \frac{v}{w^{\frac{1}{3}}}=0.1-\frac{m_{3}}{3}
$$

Refer to Equation (A4.8), (A4.19) and (A4.23), Equation (A4.34) can become

$$
w \cdot\left(\frac{2 \times 7.25 \times 10^{-3}}{v}+\frac{4.57 \times 10^{-10}}{v^{2}}+3\right)=0.3-m_{3}+\frac{10^{-14}}{v}-v
$$

$v$ and $w$ can be obtained by solving Equation (A4.35) and (A4.36) with trial and error method. The values of other variables can be obtained from Equations (A4.1a) to (A4.5a) with the known $v$ and $w$ values, correspondingly. The results are listed in Table A10.

5: Precipitation from $\mathrm{LiOH}$-titrated $\mathrm{H}_{3} \mathrm{PO}_{4}-\mathrm{FeSO}_{4}$ solution

Table A8 indicates that, in order to avoid $\mathrm{Li}_{3} \mathrm{PO}_{4}$ precipitation, the maximum concentration of $\mathrm{LiOH}$ should be not greater than $0.164 \mathrm{M}$ if the $\mathrm{H}_{3} \mathrm{PO}_{4}$ add-in concentration is $0.1 \mathrm{M}$. However, there are a number of references mentioning that the concentration ratio of $\mathrm{Li}^{+}$to $\mathrm{Fe}^{2+}$ to $\mathrm{PO}_{4}{ }^{3+}$ should be 3:1:1 in order to form a stoichiometric $\mathrm{LiFePO}_{4}$ compound. For this consideration, this work adopted an approach for preparation of the $\mathrm{LiFePO}_{4}$ precursors, in which a nonprecipitation $0.1 \mathrm{M} \mathrm{H}_{3} \mathrm{PO}_{4}-\mathrm{O} .1 \mathrm{M} \mathrm{FeSO}_{4}$ solution is prepared at first and then $\mathrm{LiOH}$ is gradually added in.

The addition of LiOH into the $0.1 \mathrm{M} \mathrm{H}_{3} \mathrm{PO}_{4}-\mathrm{O} .1 \mathrm{M} \mathrm{FeSO}_{4}$ solution may cause precipitation of either $\mathrm{Fe}(\mathrm{OH})_{2}$ or $\mathrm{Fe}_{3} \mathrm{PO}_{4}$. It may also cause precipitation of $\mathrm{Li}_{3} \mathrm{PO}_{4}$. What precipitation would take place depends on their concentration products. 
Table A1o Concentration of chemical species in $\mathrm{LiOH}-\mathrm{H}_{3} \mathrm{PO}_{4}$ solution below and above critical amount of add-in LiOH $\left(m_{1}=0.1 \mathrm{M}\right)$.

\begin{tabular}{lcccccc}
\hline \multirow{2}{*}{$\begin{array}{c}\text { Chemical } \\
\text { species }\end{array}$} & variable & \multicolumn{5}{c}{ Concentration at different $m_{3}(\mathrm{M})$} \\
\cline { 2 - 6 } & & 0.1 & 0.164 & 0.2 & 0.25 & 0.3 \\
\hline $\mathrm{H}_{3} \mathrm{PO}_{4}$ & $w$ & $2.83 \times 10^{-4}$ & $3.53 \times 10^{-8}$ & $5.69 \times 10^{-8}$ & $1.68 \times 10^{-9}$ & $6.97 \times 10^{-22}$ \\
\hline $\mathrm{H}_{2} \mathrm{PO}_{4}^{-}$ & $x$ & $9.94 \times 10^{-2}$ & $3.588 \times 10^{-2}$ & $1.97 \times 10^{-2}$ & $2.92 \times 10^{-3}$ & $1.47 \times 10^{-10}$ \\
\hline $\mathrm{HPO}_{4}{ }^{2-}$ & $y$ & $3.31 \times 10^{-4}$ & $6.41 \times 10^{-2}$ & $6.03 \times 10^{-2}$ & $4.42 \times 10^{-2}$ & $2.68 \times 10^{-4}$ \\
\hline $\mathrm{PO}_{4}{ }^{3-}$ & $z$ & $5.86 \times 10^{-12}$ & $7.24 \times 10^{-7}$ & $1.16 \times 10^{-6}$ & $4.21 \times 10^{-6}$ & $3.10 \times 10^{-3}$ \\
\hline $\mathrm{H}^{+}$ & $v$ & $2.06 \times 10^{-5}$ & $3.53 \times 10^{-8}$ & $2.08 \times 10^{-8}$ & $4.18 \times 10^{-9}$ & $3.45 \times 10^{-14}$ \\
\hline $\mathrm{OH}^{-}$ & $q$ & $4.85 \times 10^{-10}$ & $2.84 \times 10^{-7}$ & $4.82 \times 10^{-7}$ & $2.40 \times 10^{-6}$ & $2.91 \times 10^{-1}$ \\
\hline $\mathrm{Li}^{+}$ & $p$ & 0.10 & 0.164 & 0.140 & 0.09 & 0.10 \\
\hline \multicolumn{2}{c}{$\left[\mathrm{Li}^{+}\right] 3 \cdot\left[\mathrm{PO}_{4}^{-3}\right]$} & $5.82 \times 10^{-15}$ & $3.20 \times 10^{-9}$ & $3.20 \times 10^{-9}$ & $3.20 \times 10^{-9}$ & $3.20 \times 10^{-9}$ \\
\hline
\end{tabular}

At first, let us consider the possibility for $\mathrm{Fe}(\mathrm{OH})_{2}$ precipitation

$$
\begin{aligned}
& \mathrm{Fe}^{2+}+2 \mathrm{OH}^{-}=\mathrm{Fe}(\mathrm{OH})_{2} \downarrow \\
& \mathrm{K}_{s p, F e(\mathrm{OH})_{2}}=\left[\mathrm{Fe}^{2+}\right] \cdot[\mathrm{OH}]^{2}=\left[\mathrm{Fe}^{2+}\right] \cdot\left(\frac{K_{w}}{\left[\mathrm{H}^{+}\right]}\right)^{2}=7.9 \times 10^{-15}
\end{aligned}
$$

Since the concentration of $\mathrm{Fe}^{2+}$ in the $\mathrm{H}_{3} \mathrm{PO}_{4}-\mathrm{FeSO}_{4}$ solution is $0.1 \mathrm{M}$, the required $\left[\mathrm{H}^{+}\right]$for $\mathrm{Fe}(\mathrm{OH})_{2}$ concentration is

$$
\left[H^{+}\right] \leq\left(\frac{\left[\mathrm{Fe}^{2+}\right]}{K_{s p, F e(O H)_{2}}}\right)^{\frac{1}{2}} \cdot K_{w}=\left(\frac{0.1}{7.9 \times 10^{-15}}\right)^{\frac{1}{2}} \cdot 10^{-14}=3.56 \times 10^{-8}(\mathrm{M})
$$

In the range of $\left[\mathrm{H}^{+}\right]>3.558 \times 10^{-8} \mathrm{M}, \mathrm{Fe}(\mathrm{OH})_{2}$ does not precipitate. However, $\mathrm{Fe}_{3}\left(\mathrm{PO}_{4}\right)_{2}$ and $\mathrm{Li}_{3} \mathrm{PO}_{4}$ may precipitate. Assume at a certain $\left[\mathrm{H}^{+}\right]$in this range, $\mathrm{Fe}_{3}\left(\mathrm{PO}_{4}\right)_{2}$ begins to take place but $\mathrm{Li}_{3} \mathrm{PO}_{4}$ does not, the phosphate species in the solution can be calculated by combination of Equations (A3.17), (A3.18), (A3.19), (A3.26) and (A3.29). Keeping in mind that the precipitation of $\mathrm{Fe}_{3}\left(\mathrm{PO}_{4}\right)_{2}$ is just to 
Table A11 Concentration of species in LiOH-FeSO $-\mathrm{H}_{3} \mathrm{PO}_{4}$ solution at the point when $\mathrm{Fe}_{3}\left(\mathrm{PO}_{4}\right)_{2}$ precipitation begins $\left(m_{1}=m_{2}=0.1 \mathrm{M}\right)$

\begin{tabular}{ccc}
\hline \multicolumn{1}{c}{ Species } & Variables & Concentration (mole/10ooml) \\
\hline $\mathrm{H}_{3} \mathrm{PO}_{4}$ & $w$ & $4.72 \times 10^{-2}$ \\
\hline $\mathrm{H}_{2} \mathrm{PO}_{4}{ }^{-}$ & $x$ & $5.28 \times 10^{-2}$ \\
\hline $\mathrm{HPO}_{4}{ }^{2-}$ & $y$ & $5 \cdot 15^{\circ} \times 10^{-7}$ \\
\hline $\mathrm{PO}_{4}{ }^{3-}$ & $z$ & $3.16 \times 10^{-17}$ \\
\hline $\mathrm{H}^{+}$ & $v$ & $6.48 \times 10^{-3}$ \\
\hline $\mathrm{Fe}^{2+}$ & $r$ & 0.10 \\
\hline$\left[\mathrm{Fe}^{2+}\right]^{3 \cdot\left[\mathrm{PO}_{4}{ }^{3-}\right]^{2}}$ & $r^{3} \cdot \mathrm{Z}^{2}$ & $1.00 \times 10^{-36}$ \\
\hline
\end{tabular}

begin, there concentration of $\mathrm{Fe}^{2+}$ in the solution is still the add-in concentration, o.1M. The calculation result is listed in Table A11.

The results indicated that when $\mathrm{H}^{+}$concentration is greater than $6.48 \times 10^{-3} \mathrm{M}$, the concentration product of $\mathrm{Fe}^{2+}$ and $\mathrm{PO}_{4}^{3-}$ will be close to the solubility product constant of $\mathrm{Fe}_{3}\left(\mathrm{PO}_{4}\right)_{2}, 1.0 \times 10^{-36}$. the $\mathrm{Fe}_{3}\left(\mathrm{PO}_{4}\right)_{2}$ precipitation would occur when the $\mathrm{H}^{+}$concentration is going down below $6.48 \times 10^{-3} \mathrm{M}$.

Compare the $\mathrm{H}^{+}$concentration in Table A11 to that in Table A6, we can see that the drop of $\mathrm{H}^{+}$concentration is

$$
7.93 \times 10^{-3}-6.48 \times 10^{-3}=1.45 \times 10^{-3}(M)
$$

This drop is caused by the titration of $\mathrm{LiOH}$, i.e., there are $1.45 \times 10^{-3} \mathrm{M}$ of $\mathrm{OH}^{-}$ consumed. From here we know that the introduced $\mathrm{Li}^{+}$is this value. The concentration product of $\left[\mathrm{Li}^{+}\right] 3 \cdot\left[\mathrm{PO}_{4}{ }^{3-}\right]$ is thus

$$
\left[L^{+}\right]^{3} \cdot\left[P O_{4}^{3-}\right]=\left(1.46 \times 10^{-3}\right)^{3} \cdot 3.16 \times 10^{-17}=9.78 \times 10^{-26}
$$


This number is much smaller than the $\mathrm{Li}_{3} \mathrm{PO}_{4}$ solubility product constant given in Equation (A4.5a), $3.2 \times 10^{-9}$. There is no $\mathrm{Li}_{3} \mathrm{PO}_{4}$ precipitation in the range of $\left[\mathrm{H}^{+}\right]$ $>6.45 \times 10^{-3} \mathrm{M}$.

Now we proceed to investigate the precipitation when the $\mathrm{H}^{+}$concentration is going down below $6.45 \times 10^{-3} \mathrm{M}$. From the above discussion, we know that $\mathrm{Fe}_{3}\left(\mathrm{PO}_{4}\right)_{2}$ will precipitate first and $\mathrm{Li}_{3} \mathrm{PO}_{4}$ may precipitate afterward. In order to predict the $\mathrm{Li}_{3} \mathrm{PO}_{4}$ precipitation, we assume a critical point in the $\mathrm{H}^{+}$ concentration range from $6.48 \times 10^{-3} \mathrm{M}$ to $3.56 \times 10^{-8} \mathrm{M}$, at which the precipitation of $\mathrm{Li}_{3} \mathrm{PO}_{4}$ is just to start.

When only $\mathrm{Fe}_{3}\left(\mathrm{PO}_{4}\right)_{2}$ precipitates but $\mathrm{L}_{3} \mathrm{PO}_{4}$ does not, the reactions involved with the $\mathrm{LiOH}$ titration can be written as the following

Hydroxyl generation

$$
\begin{gathered}
\mathrm{LiOH}=\mathrm{Li}^{+}+\mathrm{OH}^{-} \\
{\left[\mathrm{Li}^{+}\right]=\left[\mathrm{OH}^{-}\right]=p=q=m_{3}} \\
\mathrm{SO}_{4}^{2-}+\mathrm{H}_{2} \mathrm{O}=\mathrm{HSO}_{4}^{-}+\mathrm{OH}^{-} \\
\frac{\left[\mathrm{SO}_{4}^{2-}\right]}{\left[\mathrm{HSO}_{4}^{-}\right] \cdot\left[\mathrm{OH}^{-}\right]}=\frac{\left[\mathrm{SO}_{4}^{2-}\right] \cdot\left[\mathrm{H}^{+}\right]}{\left[\mathrm{HSO}_{4}^{-}\right] \cdot \mathrm{K}_{w}}=\frac{1}{K_{5} \cdot \mathrm{K}_{w}}=\frac{1.2 \times 10^{-2}}{1.0 \times 10^{-14}}=1.2 \times 10^{12}
\end{gathered}
$$

Hydroxyl annihilation

$$
\begin{gathered}
\mathrm{Fe}^{2+}+\mathrm{OH}^{-}=\mathrm{FeOH}^{+} \\
\frac{\left[\mathrm{FeOH}{ }^{+}\right]}{\left[\mathrm{Fe}^{2+}\right] \cdot\left[\mathrm{OH}^{-}\right]}=\frac{\left[\mathrm{FeOH} H^{+}\right] \cdot\left[\mathrm{H}^{+}\right]}{\left[\mathrm{Fe}^{2+}\right] \cdot K_{w}}=\frac{K_{4}}{K_{w}}=\frac{9.41 \times 10^{-10}}{1.0 \times 10^{-14}}=9.41 \times 10^{4}
\end{gathered}
$$




$$
\begin{aligned}
& \mathrm{H}_{3} \mathrm{PO}_{4}+\mathrm{OH}^{-}=\mathrm{H}_{2} \mathrm{PO}_{4}^{-}+\mathrm{H}_{2} \mathrm{O} \\
& K_{1}=\frac{\left[\mathrm{H}_{2} \mathrm{PO}_{4}^{3-}\right]}{\left[\mathrm{H}_{3} \mathrm{PO}_{4}\right] \cdot\left[\mathrm{OH}^{-}\right]}=\frac{\left[\mathrm{H}_{2} \mathrm{PO}_{4}^{3-}\right] \cdot\left[\mathrm{H}^{+}\right]}{\left[\mathrm{H}_{3} \mathrm{PO}_{4}\right] \cdot K_{w}}=\frac{K_{1}}{K_{w}}=\frac{7.25 \times 10^{-3}}{10^{-14}}=7.25 \times 10^{11} \\
& \mathrm{H}_{3} \mathrm{PO}_{4}+2 \mathrm{OH}^{-}=\mathrm{H}_{2} \mathrm{PO}_{4}^{-}+2 \mathrm{H}_{2} \mathrm{O} \\
& \frac{\left[\mathrm{HPO}_{4}^{2-}\right]}{\left[\mathrm{H}_{3} \mathrm{PO}_{4}\right] \cdot\left[\mathrm{OH}^{-}\right]^{2}}=\frac{\left[\mathrm{HPO}_{4}^{2-}\right] \cdot\left[\mathrm{H}^{+}\right]^{2}}{\left[\mathrm{H}_{3} \mathrm{PO}_{4}\right] \cdot \mathrm{K}_{w}^{2}}=\frac{K_{2}}{K_{w}^{2}}=\frac{4.57 \times 10^{-10}}{\left(10^{-14}\right)^{2}}=4.57 \times 10^{18} \\
& \mathrm{H}_{3} \mathrm{PO}_{4}+3 \mathrm{OH}^{-}=\mathrm{PO}_{4}^{3-}+3 \mathrm{H}_{2} \mathrm{O} \\
& K_{5}=\frac{\left[\mathrm{PO}_{4}^{3-}\right]}{\left[\mathrm{H}_{3} P \mathrm{O}_{4}\right] \cdot\left[\mathrm{OH}^{-}\right]^{3}}=\frac{\left[\mathrm{PO}_{4}^{3-}\right] \cdot\left[\mathrm{H}^{+}\right]^{3}}{\left[\mathrm{H}_{3} P \mathrm{O}_{4}\right] \cdot K_{w}^{3}}=\frac{K_{3}}{K_{w}^{3}}=\frac{1.82 \times 10^{-22}}{\left(10^{-14}\right)^{3}}=1.82 \times 10^{20}
\end{aligned}
$$

$\mathrm{PO}_{4}{ }^{3-}$ consumption

$$
\begin{aligned}
& 3 \mathrm{Fe}^{2+}+2 \mathrm{PO}_{4}^{3-}=\mathrm{Fe}_{3}\left(\mathrm{PO}_{4}\right)_{2} \downarrow \\
& K_{s p, \mathrm{Fe}_{3}\left(\mathrm{PO}_{4}\right)_{2}}=\left[\mathrm{Fe}^{2+}\right]^{3} \cdot\left[\mathrm{PO}_{4}^{3-}\right]^{2}=r^{3} \cdot z^{2}=1.0 \times 10^{-36}
\end{aligned}
$$

By mass conservation of the phosphate species,

$$
x+y+z+w+2 m_{4}=m_{1}
$$

By mass conservation of the iron species

$$
r+s+3 m_{4}=m_{2}
$$

By mass conservation of the sulfate species

$$
t+u=m_{2}
$$

By mass conservation of $\mathrm{OH}^{-}$

$$
x+2 y+3\left(z+2 m_{4}\right)+s=m_{3}+u
$$

By electrical neutrality 


$$
x+2 y+3 z+2 t+u+\frac{K_{w}}{v}=v+2 r+s+p
$$

Combine Equation (A5.13) and (A5.16), we get

$$
2 x+y+3 w+u-s=3 m_{1}-m_{3}
$$

From Equation (A5.11) and (A5.14), we obtain

$$
s=\frac{m_{2}-3 m_{4}}{1+\frac{v}{K_{2} K_{w}}}=\frac{0.1-3 m_{4}}{1+\frac{v}{9.41 \times 10^{-10}}}
$$

The value of $s$ depends on $v$ and $m_{4}$. As the LiOH titration proceeds, $v$ becomes smaller and smaller but $m_{4}$ becomes bigger and bigger. The concerted values change of $v$ and $m_{4}$ may render the $s$ negligible in Equation (A5.8). Although we are uncertain if it is true, however, in order to facilitate the calculation, we assume it is true. We can very the assumption after the calculation.

From Equation (A5.6) and (A5-14), we obtain

$$
u=\frac{m_{2}}{1+\frac{K_{1} K_{w}}{v}}
$$

Take Equation (A5.19) into Equation (A5.15) and eliminate s. Equation (A5.18) becomes

$$
2 x+y+3 w+\frac{m_{2}}{1+\frac{K_{1} K_{w}}{v}}=3 m_{1}-m_{3}
$$

Combine Equation (A5.13), (A5.14), (A5.15) and (A5.17), we get

$$
x-y-3 z+3 w-2 t+2 v+2 r+2 p-\frac{2 K_{w}}{v}=3 m_{1}
$$

From Equation (A5.7) and (A5.14), we get 


$$
t=\frac{m_{2}}{1+\frac{v}{K_{w} K_{1}}}
$$

From Equation (A5.10) and (A5.11), we get

$$
r=\left(\frac{K_{s p 1}}{K_{5}^{2}}\right)^{\frac{1}{3}} \cdot \frac{v^{2}}{w^{\frac{2}{3}}}
$$

Take Equation (A5.19), (A5.22) and (A5.23) into Equation (A5.16) and (A5.17). Use $v$ and $w$ to represent other variables. Also use $p$ to represent $m_{3}$. Equation (A5.16) and (A5.17) become

$$
\begin{gathered}
w \cdot\left(3+\frac{2 K_{w} K_{3}}{v}+\frac{K_{w} K_{4}}{v^{2}}\right)+\frac{m_{2}}{1+\frac{K_{w} K_{1}}{v}}=3 m_{1}-m_{3} \\
w \cdot\left(3+\frac{K_{w} K_{3}}{v}-\frac{K_{w} K_{4}}{v^{2}}-\frac{3 K_{w} K_{5}}{v^{3}}\right)-\frac{2 m_{2}}{1+\frac{v}{K_{w} K_{1}}}+2 \cdot\left(\frac{K_{s p 1}}{K_{5}^{2}}\right)^{\frac{1}{3}} \cdot \frac{v^{2}}{w^{\frac{2}{3}}}+2 v-\frac{2 K_{w}}{v}=3 m_{1}-2 m_{3}
\end{gathered}
$$

Use the known value of $K_{2}, K_{3}, K_{4}, K_{5}, K_{\mathrm{sp} 1}, K_{\mathrm{sp} 2}, m_{1}, m_{2}$ and several given values of $m_{3}$, these two equations can be solved jointly by trial and error method. The obtained values of the related variables are listed in Table A12

Table A12 shows that when the $\mathrm{LiOH}$ add-in concentration is $0.16 \mathrm{M},\left[\mathrm{Li}^{+}\right] 3 \cdot\left[\mathrm{PO}_{4}{ }^{3-}\right]$ is smaller than the solubility product constant of $\mathrm{Li}_{3} \mathrm{PO}_{4}, 3.2 \times 10^{-9}$. However, when the $\mathrm{LiOH}$ add-in concentration is $0.17 \mathrm{M}$, the concentration product, $\left[\mathrm{Li}^{+}\right] 3 \cdot\left[\mathrm{PO}_{4}^{3-}\right]$, becomes greater than $3.2 \times 10^{-9}$. It indicates that $\mathrm{Li}_{3} \mathrm{PO}_{4}$ precipitation starts at a $\mathrm{LiOH}$ add-in concentration between $0.160 \mathrm{M}$ and $0.17 \mathrm{M}$.

The data on the table also indicates that no $\mathrm{Fe}(\mathrm{OH})_{2}$ precipitation has taken place during the precipitation of $\mathrm{Fe}_{3}\left(\mathrm{PO}_{4}\right)_{3}$ because the concentration product of $\left[\mathrm{Fe}^{2+}\right] \cdot\left[\mathrm{OH}^{-}\right]^{2}$ in the whole range of the $\mathrm{LiOH}$ add-in concentration are much smaller than the $\mathrm{Fe}(\mathrm{OH})_{2}$ solubility product, $7.9 \times 10^{-15}$. 
Table A12 Concentration of chemical species in LiOH-FeSO ${ }_{4}-\mathrm{H}_{3} \mathrm{PO}_{4}$ solution with selected amount of add-in $\mathrm{LiOH}\left(m_{1}=m_{2}=0.1 \mathrm{M}\right)$

\begin{tabular}{ccccccc}
\hline \multirow{2}{*}{$\begin{array}{c}\text { Chemical } \\
\text { species }\end{array}$} & \multirow{2}{*}{ variable } & \multicolumn{5}{c}{ Concentration at different $m_{3}(\mathrm{M})$} \\
\cline { 2 - 6 } & & 0.05 & 0.10 & 0.15 & 0.16 & 0.17 \\
\hline $\mathrm{H}^{+}$ & $v$ & $3.24 \times 10^{-3}$ & $1.50 \times 10^{-3}$ & $6.31 \times 10^{-8}$ & $1.58 \times 10^{-8}$ & $1.30 \times 10^{-8}$ \\
\hline $\mathrm{H}_{3} \mathrm{PO}_{4}$ & $w$ & $2.01 \times 10^{-2}$ & $7.88 \times 10^{-3}$ & $1.45 \times 10^{-7}$ & $1.46 \times 10^{-8}$ & $1.10 \times 10^{-8}$ \\
\hline $\mathrm{H}_{2} \mathrm{PO}_{4}{ }^{-}$ & $x$ & $4.49 \times 10^{-2}$ & $3.82 \times 10^{-2}$ & $1.67 \times 10^{-2}$ & $6.68 \times 10^{-3}$ & $5.676 \times 10^{-3}$ \\
\hline $\mathrm{HPO}_{4}{ }^{2-}$ & $y$ & $8.75 \times 10^{-7}$ & $1.61 \times 10^{-6}$ & $1.67 \times 10^{-2}$ & $2.67 \times 10^{-2}$ & $2.77 \times 10^{-2}$ \\
\hline $\mathrm{PO}_{4}{ }^{3-}$ & $z$ & $1.08 \times 10^{-16}$ & $4.28 \times 10^{-16}$ & $1.05 \times 10^{-7}$ & $6.71 \times 10^{-7}$ & $8.50 \times 10^{-7}$ \\
\hline $\mathrm{Fe}^{2+}$ & $r$ & $4.42 \times 10^{-2}$ & $1.76 \times 10^{-2}$ & $4.49 \times 10^{-8}$ & $1.31 \times 10^{-8}$ & $1.11 \times 10^{-8}$ \\
\hline $\mathrm{FeOH}^{+}$ & $s$ & $1.29 \times 10^{-8}$ & $1.11 \times 10^{-8}$ & $6.70 \times 10^{-10}$ & $7.77 \times 10^{-10}$ & $8.91 \times 10^{-10}$ \\
\hline $\mathrm{SO}_{4}{ }^{2-}$ & $t$ & $7.79 \times 10^{-2}$ & $8.89 \times 10^{-2}$ & 0.10 & 0.10 & 0.10 \\
\hline $\mathrm{HSO}_{4}{ }^{2-}$ & $u$ & $2.13 \times 10^{-2}$ & $1.11 \times 10^{-2}$ & - & - & - \\
\hline $\mathrm{Li}^{+}$ & $p=m_{3}$ & 0.05 & 0.10 & 0.150 & 0.16 & 0.161 \\
\hline $\mathrm{OH}^{-}$ & $q=K_{w} / \mathrm{v}$ & $3.01 \times 10^{-12}$ & $6.68 \times 10^{-12}$ & $1.58 \times 10^{-7}$ & $6.33 \times 10^{-7}$ & $7.77 \times 10^{-7}$ \\
\hline$\left[\mathrm{Fe}^{2+}\right]^{3 \cdot}\left[\mathrm{PO}_{4}{ }^{3-}{ }^{2}\right.$ & $1.0 \times 10^{-36}$ & $1.0 \times 10^{-36}$ & $1.0 \times 10^{-36}$ & $1.0 \times 10^{-36}$ & $1.0 \times 10^{-36}$ \\
\hline$\left[\mathrm{Li}^{+}\right]^{3} \cdot\left[\mathrm{PO}_{4}{ }^{3-}\right]$ & $1.35 \times 10^{-20}$ & $4.28 \times 10^{-19}$ & $3.55 \times 10^{-10}$ & $2.75 \times 10^{-9}$ & $3.55^{2} \times 10^{-9}$ \\
\hline$\left[\mathrm{Fe}^{2+}\right] \cdot\left[\mathrm{OH}^{2}\right.$ & $4.22 \times 10^{-25}$ & $7.86 \times 10^{-25}$ & $1.13 \times 10^{-21}$ & $5.22 \times 10^{-21}$ & $6.65 \times 10^{-21}$ \\
\hline & & & & &
\end{tabular}

The data further indicates neither $\mathrm{Fe}(\mathrm{OH})_{2}$ and nor $\mathrm{Fe}_{3}\left(\mathrm{PO}_{4}\right)_{2}$ precipitation through further $\mathrm{LiOH}$ titration. Since the iron species have been almost exhausted as the $\mathrm{LiOH}$ add-in concentration reached $0.15 \mathrm{M}$, adding more $\mathrm{LiOH}$ will only cause $\mathrm{Li}_{3} \mathrm{PO}_{4}$ precipitation. 